\section{OAK RIDGE NATIONAL LABORATORY}

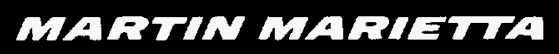

FEB $2 ?$ ?

$08 \mathrm{TI}$

\title{
Preliminary Fracture Analysis of the Core Pressure Boundary Tube for the Advanced Neutron Source Research Reactor
}

\author{
Kurt C. Schulz \\ G. T. Yahr
}

August 1995

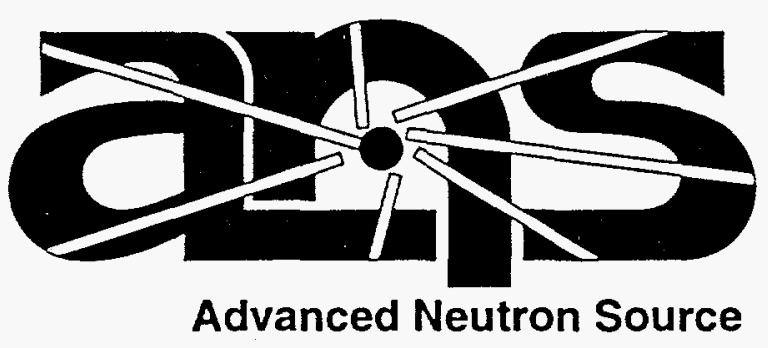


This report has been reproduced directly from the best available copy.

Available to DOE and DOE contractors from the Office of Scientific and Technical Information, P.O. Box 62, Oak Ridge, TN 37831; prices available from (615) 576-8401, FTS 626-8401.

Available to the public from the National Technical Information Service, U.S. Department of Commerce, 5285 Port Royal Rd., Springfield, VA 22161.

This report was prepared as an account of work sponsored by an agency of the United States Government. Neither the United States Government nor any agency thereof, nor any of their employees. makes any warranty, express or implied, or assumes any legal liability or responsibility for the accuracy, completeness, or usefuiness of any information, apparatus, product, or process disclosed, or represents that its use would not infringe privately owned rights. Reference herein to any specific commercial product, process, or service by trade name, trademark, manufacturer, or otherwise, does not necessarily constitute or imply its endorsement, recommendation, or favoring by the United States Government or any agency thereof. The views and opinions of authors expressed herein do not necessarily state or reflect those of the United States Government or any agency thereof. 
ORNL/M-4619

PRELIMINARY FRACTURE ANALYSIS OF THE CORE PRESSURE BOUNDARY TUBE FOR THE ADVANCED NEUTRON SOURCE RESEARCH REACTOR

Kurt C. Schulz*

G. T. Yahr ${ }^{\dagger}$

\footnotetext{
Assistant Professor, University of Turabo, College of Engineering, Box 3030, Gurabo, Puerto Rico 00778.

'Engineering Technology Division, Oak Ridge National Laboratory, P.O. Box 2009, Oak Ridge, Tennessee 37831 .
}

Date Published-August 1995

Prepared by

OAK RIDGE NATIONAL LABORATORY

- OAK RIDGE, TENNESSEE 37831 managed by

LOCKHEED MARTIN ENERGY SYSTEMS, INC.

for the

U.S. DEPARTMENT OF ENERGY

under contract DE-AC05-84OR21400 


\section{CONTENTS}

LIST OF FIGURES $\ldots \ldots \ldots \ldots \ldots \ldots \ldots \ldots \ldots \ldots \ldots \ldots$

LIST OF TABLES $\ldots \ldots \ldots \ldots \ldots \ldots \ldots \ldots \ldots \ldots \ldots \ldots \ldots \ldots \ldots \ldots$

ACRONYMS $\ldots \ldots \ldots \ldots \ldots \ldots \ldots \ldots \ldots \ldots \ldots \ldots \ldots \ldots \ldots \ldots \ldots \ldots$

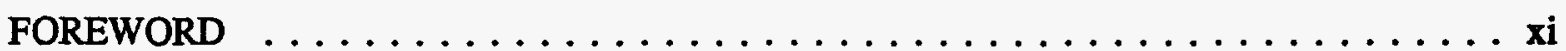

ABSTRACT $\ldots \ldots \ldots \ldots \ldots \ldots \ldots \ldots \ldots \ldots \ldots \ldots \ldots \ldots \ldots \ldots \ldots \ldots \ldots \ldots$

INTRODUCTION $\ldots \ldots \ldots \ldots \ldots \ldots \ldots \ldots \ldots \ldots \ldots \ldots \ldots \ldots \ldots$

METHODOLOGY FOR EVALUATING POTENTIAL NONDUCTILE

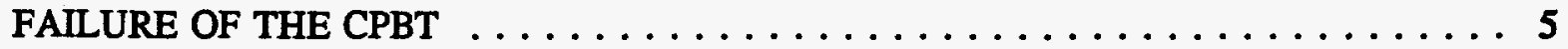

LINEAR ELASTIC FRACTURE MECHANICS APPROACH $\ldots \ldots \ldots \ldots \ldots \ldots$

CPBT Stress State . . . . . . . . . . . . . . . . . . . . . . . . . . . 14

Stress Intensity Factor Due to Thermal Stresses . . . . . . . . . . . . . . 15

Parametric Analysis of Crack Size vs Stress Intensity Factor: $f(a / c) \ldots \ldots \ldots$

Parametric Analysis of Crack Size vs Stress Intensity Factor: $f(t) \ldots \ldots$

FRACTURE TOUGHNESS $\ldots \ldots \ldots \ldots \ldots \ldots \ldots \ldots \ldots \ldots \ldots \ldots$

INTEGRITY REQUIREMENTS AND NONDESTRUCTIVE EVALUATION . . . . . . 25

EFFECT OF FATIGUE ON CRACK GROWTH IN THE CPBT $\ldots \ldots \ldots$

ELASTIC-PLASTIC APPROACHES TO FRACTURE ANALYSIS . . . . . . . . . . 47

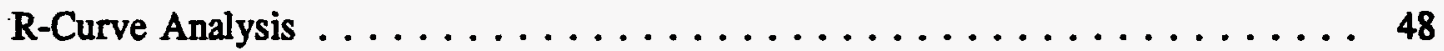

Crack-Tip Opening Displacement $\ldots \ldots \ldots \ldots \ldots \ldots \ldots \ldots \ldots \ldots \ldots \ldots$

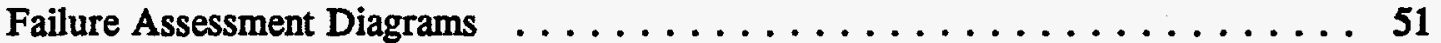

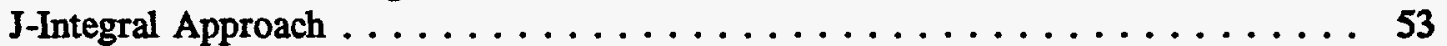

Determination of the Critical Value of $\mathrm{J}, \mathrm{J}_{0} \ldots \ldots \ldots \ldots \ldots \ldots$

EPRI Ductile Fracture Handbook Solution . . . . . . . . . . . . . . 55

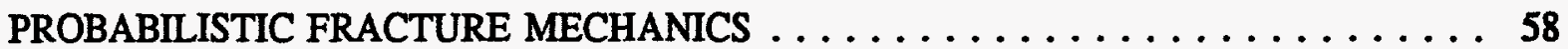

PFM Analytical Codes . . . . . . . . . . . . . . . . . 59

Variables and Distributions for Application of PFM . . . . . . . . . . 62

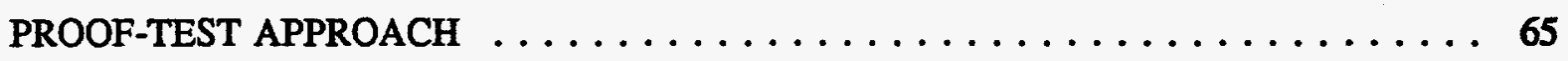

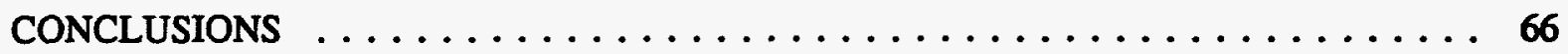

iii 
APPENDIX A: TEMPERATURE PROFILES WITHIN THE ANS CORE PRESSURE BOUNDARY TUBE 


\section{LIST OF FIGURES}

Figure

Page

1 Lower pressure boundary inside the reflector vessel of the ANS reactor . . . . . . 2

2 CPBT annulus and fuel element configuration $\ldots \ldots \ldots \ldots \ldots$

3 Detailed representation of the CPBT $\ldots \ldots \ldots \ldots \ldots \ldots \ldots \ldots$

4 Typical stress-strain curve for $6061-\mathrm{T} 6$ aluminum $\ldots \ldots \ldots \ldots$

$5 \quad \mathrm{~J}-\mathrm{R}$ curves for $6061-\mathrm{T} 6$ aluminum $\ldots \ldots \ldots \ldots \ldots$

6 Schematic illustration of a semielliptical part-through surface flaw . . . . . . . . 9

7 Illustration of a part-through surface flaw in a flat plate subjected to membrane and tensile stresses $\ldots \ldots \ldots \ldots \ldots \ldots \ldots \ldots \ldots$

8 Stresses associated with the cylindrical coordinate system $\ldots \ldots \ldots \ldots \ldots$

9 Stress intensity factor vs flaw size for the CPBT $(c=3 a) \ldots \ldots \ldots \ldots \ldots$

10 Comparison of four different calculations of stress intensity factor . . . . . . . . . 22

11 Stress intensity factor vs flaw size as a function of wall thickness . . . . . . . . . . 24

12 Typical probability of detection (POD) curve $\ldots \ldots \ldots \ldots \ldots$

13 Individual POD curves developed through application of expert judgment and a composite POD based on assumed independence . . . . . . . . . . 32

$14 \quad$ Estimated NDI capabilities for crack detection $\ldots \ldots \ldots \ldots \ldots \ldots$

15 POD plots of four NDE methods based on a single set of test specimens . . . . . . 35

16 NDE design limits based on NASA inspection results $\ldots \ldots \ldots \ldots \ldots$

17 Composite POD estimates for the CPBT $\ldots \ldots \ldots \ldots \ldots \ldots$

18 Fit to fully reversed $6061-\mathrm{T} 6$ aluminum fatigue data $\ldots \ldots \ldots \ldots$

19 Fatigue design curve constructed by reduction of the best fit data curve by a factor of 2 on stress and a factor of 20 on number of cycles to failure . . . . . 41

20 Effect of mean stress on alternating fatigue strength of aluminum

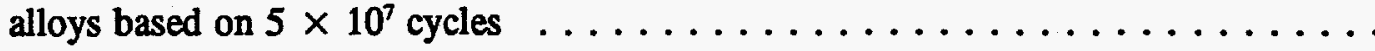


21 Fatigue design curve adjusted for mean stress effects through the application of the Gerber parabola adjustment $\ldots \ldots \ldots \ldots \ldots \ldots$

22 Crack growth rate vs stress intensity range for $6061-\mathrm{T} 6$ aluminum $\ldots \ldots \ldots$

23 Basic principle of $\mathrm{R}$-curves for use in determining $\mathrm{K}_{\mathrm{c}}$ under different conditions of initial crack length $a_{0} \ldots \ldots \ldots \ldots \ldots \ldots \ldots$

24 Relation between $\mathrm{K}_{\mathrm{Ic}}$ and CTOD test behavior; $\mathrm{K}_{\mathrm{Ic}} / \mathrm{CTOD}$ test setup and load displacement records from $\mathrm{K}_{\mathrm{lc}} / \mathrm{CTOD}$ tests $\ldots \ldots \ldots \ldots \ldots \ldots \ldots$

25 A typical failure assessment diagram (FAD) $\ldots \ldots \ldots \ldots \ldots \ldots \ldots \ldots$

26 A schematic illustrating the concept of probabilistic fracture analysis $\ldots \ldots \ldots 0$

27 Schematic diagram of the steps involved in execution of PRAISE $\ldots \ldots \ldots 1$ 


\section{LIST OF TABLES}

Table

Page

1 Typical fracture behavior of selected materials at ambient temperature $\ldots \ldots \ldots$

2 Stress intensity factor vs crack length for the CPBT $(c=3 a) \ldots \ldots \ldots 20$

3 Summary of interview results with inspection experts to develop POD models for ISI of the Yankee RPV . . . . . . . . . . . . . . . 30

4 POD parameters developed for Yankee RPV examination $\ldots \ldots \ldots \ldots \ldots \ldots$

$5 \quad$ Average POD for combination of three techniques $\ldots \ldots \ldots \ldots \ldots$

6 Estimates of the POD (CI, 95\%) capabilities of various inspection methods based on the NASA Space Shuttle study $\ldots \ldots \ldots \ldots \ldots \ldots$

7 Tabulated values of $\mathrm{H}_{1}$ for the EPRI Handbook J Solution . . . . . . . . . . 57 


$\begin{array}{ll}\text { ANS } & \text { Advanced Neutron Source } \\ \text { ASME } & \text { American Society of Mechanical Engineers } \\ \text { ASTM } & \text { American Society for Testing and Materials } \\ \text { CPBT } & \text { core pressure boundary tube } \\ \text { CTOD } & \text { crack-tip opening displacement } \\ \text { DAC } & \text { derived air concentration } \\ \text { EPRI } & \text { Electric Power Research Institute } \\ \text { FAD } & \text { failure assessment diagram } \\ \text { HFIR } & \text { High Flux Isotope Reactor } \\ \text { ISI } & \text { in-service inspection } \\ \text { LAD } & \text { life assessment diagram } \\ \text { LEFM } & \text { linear elastic fracture mechanics } \\ \text { NASA } & \text { National Aeronautics and Space Administration } \\ \text { NDE } & \text { nondestructive evaluation } \\ \text { NDI } & \text { nondestructive inspection } \\ \text { ORNL } & \text { Oak Ridge National Laboratory } \\ \text { PFM } & \text { probabilistic fracture mechanics } \\ \text { POD } & \text { probability of detection } \\ \text { RPV } & \text { reactor pressure vessel } \\ \text { USAF } & \text { U.S. Air Force } \\ \text { USNRC } & \text { U.S. Nuclear Regulatory Commission } \\ \text { UT } & \text { ultrasonic } \\ \text { WRC } & \text { Welding Research Council } \\ & \end{array}$


' 


\section{FOREWORD}

The work by K. C. Schulz described in this report was performed at Oak Ridge National Laboratory under sponsorship of the Oak Ridge Institute for Science and Education, which is a science/engineering education division funded through the U.S. Department of Energy. The program is managed by E. D. Aebischer. 



\begin{abstract}
The outer core pressure boundary tube (CPBT) of the Advanced Neutron Source (ANS) reactor being designed at Oak Ridge National Laboratory is currently specified as being composed of 6061-T6 aluminum. ASME Boiler and Pressure Vessel Code fracture analysis rules for nuclear components are based on the use of ferritic steels; the expressions, tables, charts and equations were all developed from tests and analyses conducted for ferritic steels. Because of the nature of the Code, design with thin aluminum requires analytical approaches that do not directly follow the Code. The intent of this report is to present a methodology comparable to the ASME Code for ensuring the prevention of nonductile fracture of the CPBT in the ANS reactor. 6061-T6 aluminum is known to be a relatively brittle material; the linear elastic fracture mechanics (LEFM) approach is utilized to determine allowable flaw sizes for the CPBT. A J-analysis following the procedure developed by the Electric Power Research Institute was conducted as a check; the results matched those for the LEFM analysis for the cases analyzed. Since 6061-T6 is known to embrittle when irradiated, the reduction in $\mathrm{K}_{\mathrm{Q}}$ due to irradiation is considered in the analysis. In anticipation of probable requirements regarding maximum allowable flaw size, a survey of nondestructive inspection capabilities is also presented. A discussion of probabilistic fracture mechanics approaches, principally Monte Carlo techniques, is included in this report as an introduction to what quantifying the probability of nonductile failure of the CPBT may entail.
\end{abstract}




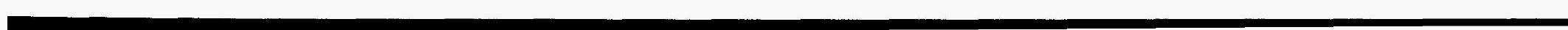




\section{INTRODUCTION}

The primary objective of this report is to outline a methodology for evaluating the outer core pressure boundary tube (CPBT) in the Advanced Neutron Source (ANS) reactor with respect to its susceptibility to brittle fracture. The ANS reactor (see Fig. 1) is being designed at Oak Ridge National Laboratory (ORNL). The CPBT surrounds the upper and lower core elements (see Fig. 2) and thus is exposed to high levels of irradiation. The CPBT is surrounded by heavy water (see Fig. 1). The CPBT is 6061-T6 aluminum with a wall thickness in the center region near the core set at 8.5 $\mathrm{mm}$ for this study, as illustrated in Fig. 3. Although aluminum has been used extensively in research reactors, most nuclear power plant pressure vessels are fabricated from ferritic steels. The current ASME Boiler and Pressure Vessel Code for Class 1 Nuclear Components (ASME Code) allows the use of ferritic and/or austenitic steels for Class 1 pressure vessels and piping. Section III, Article G-2000, states that "for sections less than 4 inches thick, the 1 inch deep defect is conservatively postulated...smaller defect sizes may be used on an individual case basis if a smaller size of maximum postulated defect can be ensured. ${ }^{11}$ Since the CPBT is only $8.5 \mathrm{~mm}$ thick, the crack depth would have to be $25.4 \mathrm{~mm}$ ( 1 in.), which is physically impossible; the motivation of this study is to determine the maximum defect size that can be tolerated, and should be conservatively postulated, in order to ensure the prevention of nonductile fracture of the CPBT. This report presents a linear elastic fracture mechanics (LEFM) methodology for analyzing cracks in the ANS CPBT.

To conduct a proper fracture mechanics analysis of the CPBT, the stresses in the part must be determined. The CPBT has two sources of significant stresses under ordinary operating conditions: membrane tension due to the difference between the pressures acting on the inner and outer surfaces and thermal stresses due to the radial thermal gradient across the wall thickness. A more complete analysis would also include the effects of seismic loads. To evaluate the fracture behavior of the CPBT under normal operating conditions, the stresses were determined at a number of axial positions along the tube and at a number of radial positions through the tube's thickness utilizing computer routines that have been developed at ORNL. ${ }^{2,3}$ The maximum stress state along the length of the CPBT was found to occur near the upper fuel element (see Fig. 2) in the tangential direction. A worst-case critical flaw is assumed to be an axial part-through semielliptical crack at the position in the CPBT where the maximum tangential stress occurs. Following the ASME Code, a flaw that has a depth of one-fourth of the section thickness and a length of 1.5 times the section thickness was initially postulated and subsequently evaluated. To evaluate the effect of crack size and geometry on the stress intensity factor, a number of crack lengths and depths were evaluated to determine the size and shape of critical flaws for the CPBT.

As is indicated in Table 1, precipitation-hardened aluminum is known typically to exhibit linear elastic fracture behavior. ${ }^{4}$ Figure 4 presents a typical stress-strain diagram for 6061-T6 aluminum, and Fig. 5 presents the J-R results of recent tests conducted on 6061-T6 aluminum at ORNL. ${ }^{5}$ Although ferritic steels exhibit a transition from ductile to brittle behavior when cooled through what is termed the transition range of temperature, 6061-T6 aluminum generally exhibits low levels of ductility at both low and relatively high temperatures and is known to embrittle when exposed to irradiation. ${ }^{5,6}$ Embrittlement is a function of neutron fluence, which tends to be highest near the fuel elements. In terms of fracture, the effects of embrittlement are a tendency to lower fracture toughness, $\mathrm{K}_{\mathrm{Q}}$, along with a corresponding reduction in the ductility at flaw tips. Because of the high levels of neutron flux near the reactor cores, the portion of the CPBT adjacent to the cores is expected to have the highest level of material degradation and, correspondingly, the lowest level of fracture toughness for the CPBT. The LEFM approach, with a small crack tip plasticity correction, has been utilized in this study to evaluate the susceptibility of the CPBT to brittle fracture. Other 


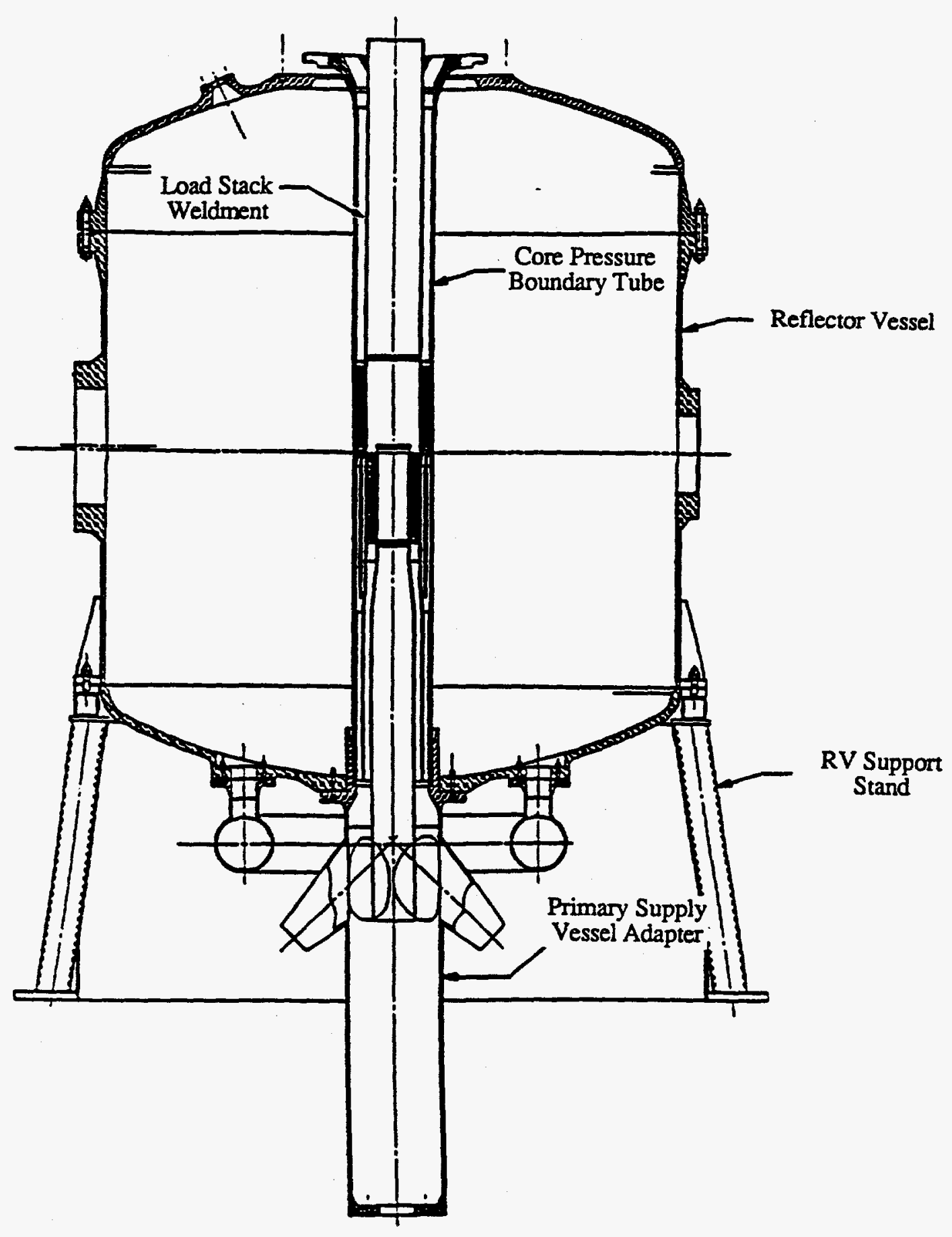

Fig. 1. Lower pressure boundary inside the reflector vessel of the ANS reactor. Source: P. Cento, ANS Preliminary Design Analysis of the CPBT, Martin Marietta Energy Systems Design Analysis and Calculations, Report No. DAC-XRT-017063-A002:ESOA8019AB1, December 1992. 


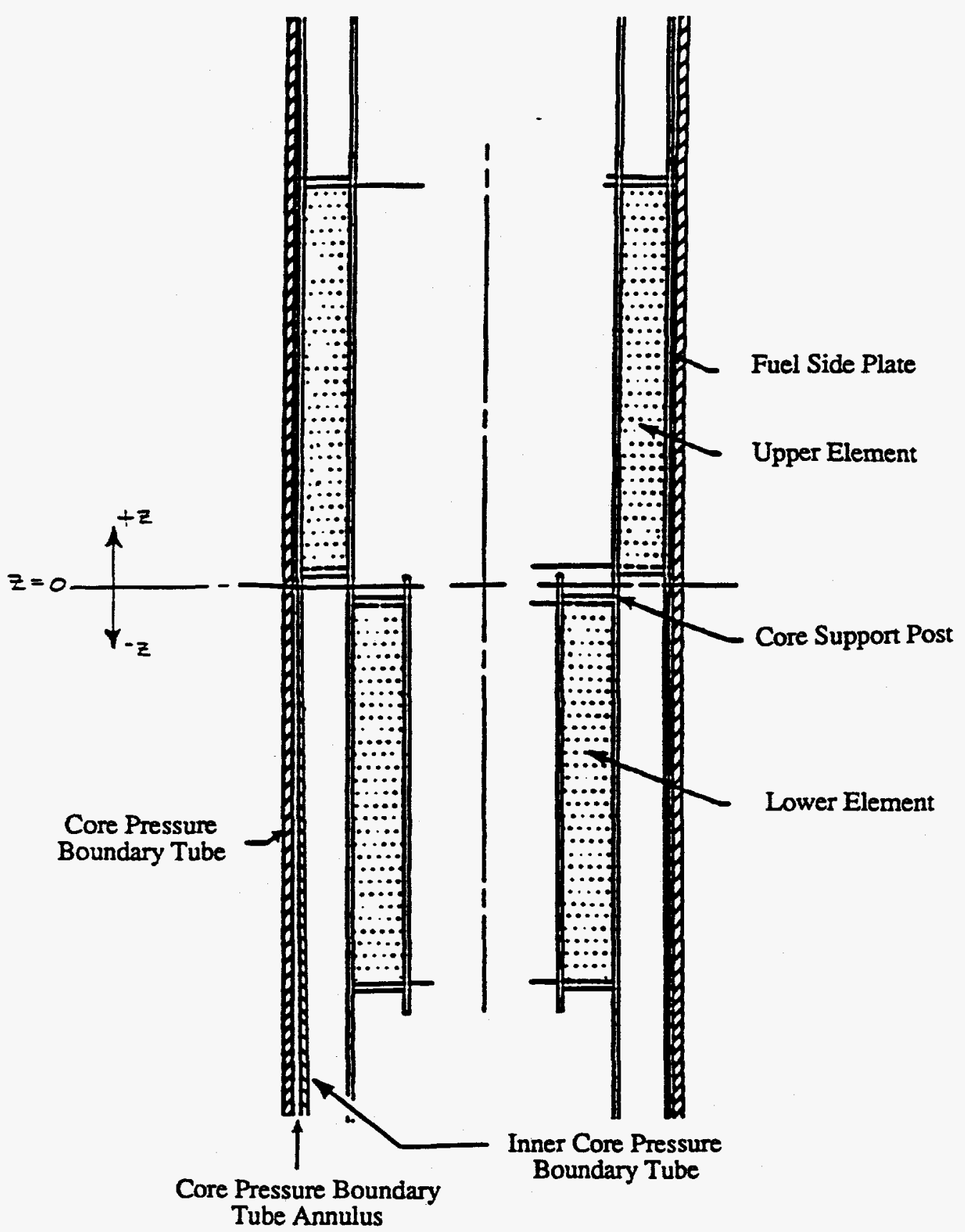

Fig. 2. CPBT annulus and fuel element configuration. Source: P. Cento, ANS Preliminary Design Analysis of the CPBT, Martin Marietta Energy Systems Design Analysis and Calculations, Report No. DAC-XRT-017063-A002:ESOA8019AB1, December 1992. 


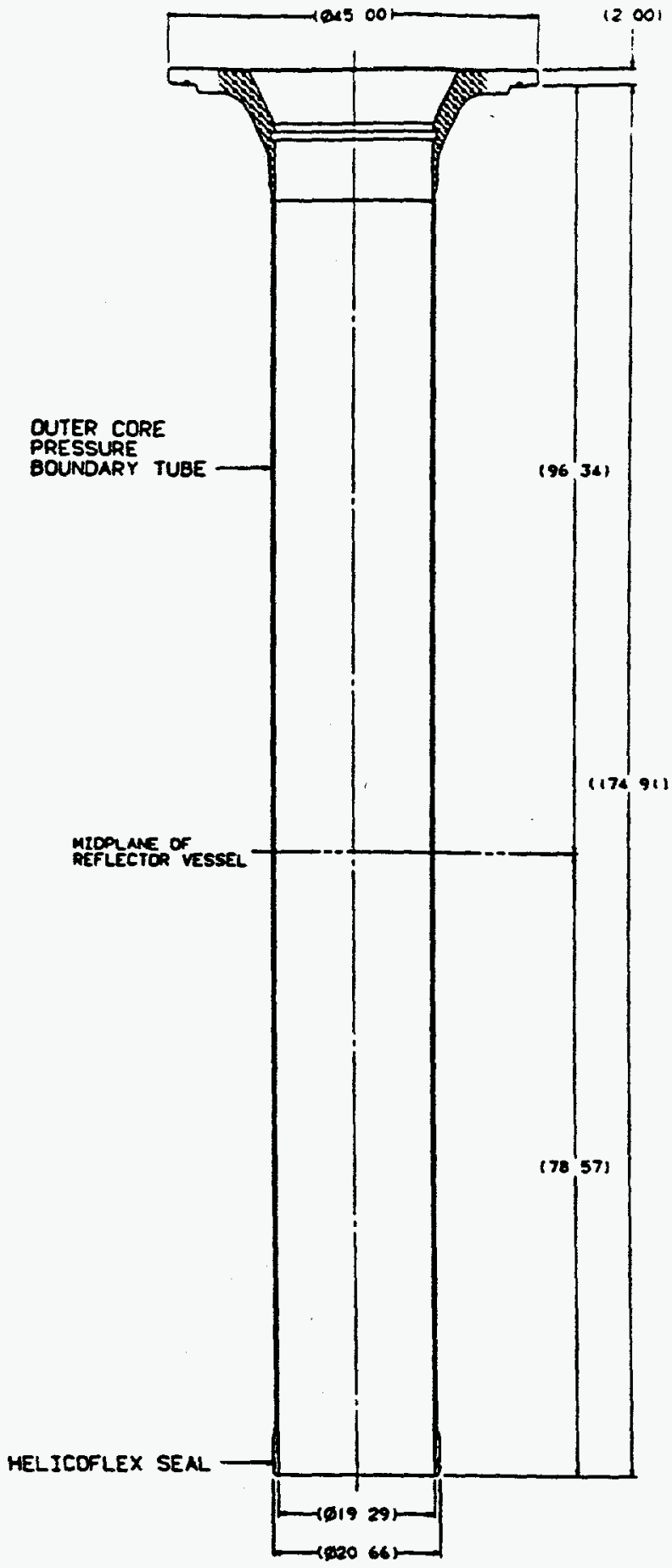

Fig. 3. Detailed representation of the CPBT. Source: P. Cento, ANS Preliminary Design Analysis of the CPBT, Martin Marietta Energy Systems Design Analysis and Calculations, Report No. DAC-XRT-017063-A002:ESOA8019AB1, December 1992. 
Table 1. Typical fracture behavior of selected materials at ambient temperature

\begin{tabular}{ll}
\hline \multicolumn{1}{c}{ Material } & \multicolumn{1}{c}{ Typical fracture behavior } \\
\hline High-strength steel & Linear elastic \\
Low- and medium-strength steel & Elastic-plastic/fully plastic \\
Austenitic stainless steel & Fully plastic \\
Precipitation-hardened aluminum & Linear elastic \\
Metals at high temperature & Viscoplastic \\
Metals at high strain rates & Dynamic-viscoplastic \\
Polymers (below $\mathrm{T}_{\S}{ }^{a}$ & Linear elastic/viscoelastic \\
Polymers (above $\mathrm{T}_{\S}{ }^{a}$ & Viscoelastic \\
Monolithic ceramics & Linear elastic \\
Ceramic composites & Linear elastic \\
Ceramics at high temperature & Viscoplastic \\
\hline \multicolumn{2}{c}{$\mathrm{T}_{\mathrm{g}}-$ Glass transition temperature. } \\
Source: Reprinted with permission from T. L. Anderson, Fracture Mechanics: \\
Fundamentals and Applications, CRC Press, Boca Raton, Fla., 1991.
\end{tabular}

approaches to fracture control are briefly discussed. An elastic-plastic J-analysis following the procedure outlined by the Electric Power Research Institute (EPRI) ${ }^{7}$ was conducted as a check on the LEFM procedure.

Because of the design requirement of a relatively thin CPBT composed of 6061-T6 aluminum, the allowable flaw sizes are expected to be quite small. In order to ensure the structural integrity of the CPBT, a review of current nondestructive inspection (NDI) capabilities is included in this report. It is currently the intention of the ANS Project to postulate a small maximum flaw size, significantly smaller than is permitted in thick ferritic steel vessels, and subsequently to ensure such a small size utilizing NDI techniques, prior to installation of the CPBT.

A methodology for predicting the fatigue growth of any flaws that are postulated must also be considered. Fatigue design curves have been presented for 6061-T6 aluminum by G. T. Yahr; a brief discussion concerning the growth of flaws in the CPBT due to fatigue cycling is presented.

Last, a review of possible probabilistic fracture mechanics approaches for evaluating the probability of brittle fracture of the CPBT is also presented.

\section{METHODOLOGY FOR EVALUATING POTENTIAL NONDUCTILE FAILURE OF THE CPBT}

Based on article G-2000 of Section XI of the ASME Code, ${ }^{9}$ Riccardella and Yukawa ${ }^{10}$ present three essential features of the fracture mechanics criteria developed for thick-walled pressure vessels as:

1. a postulated reference flaw of semielliptical geometry with a depth equal to one-fourth of the wall thickness; 


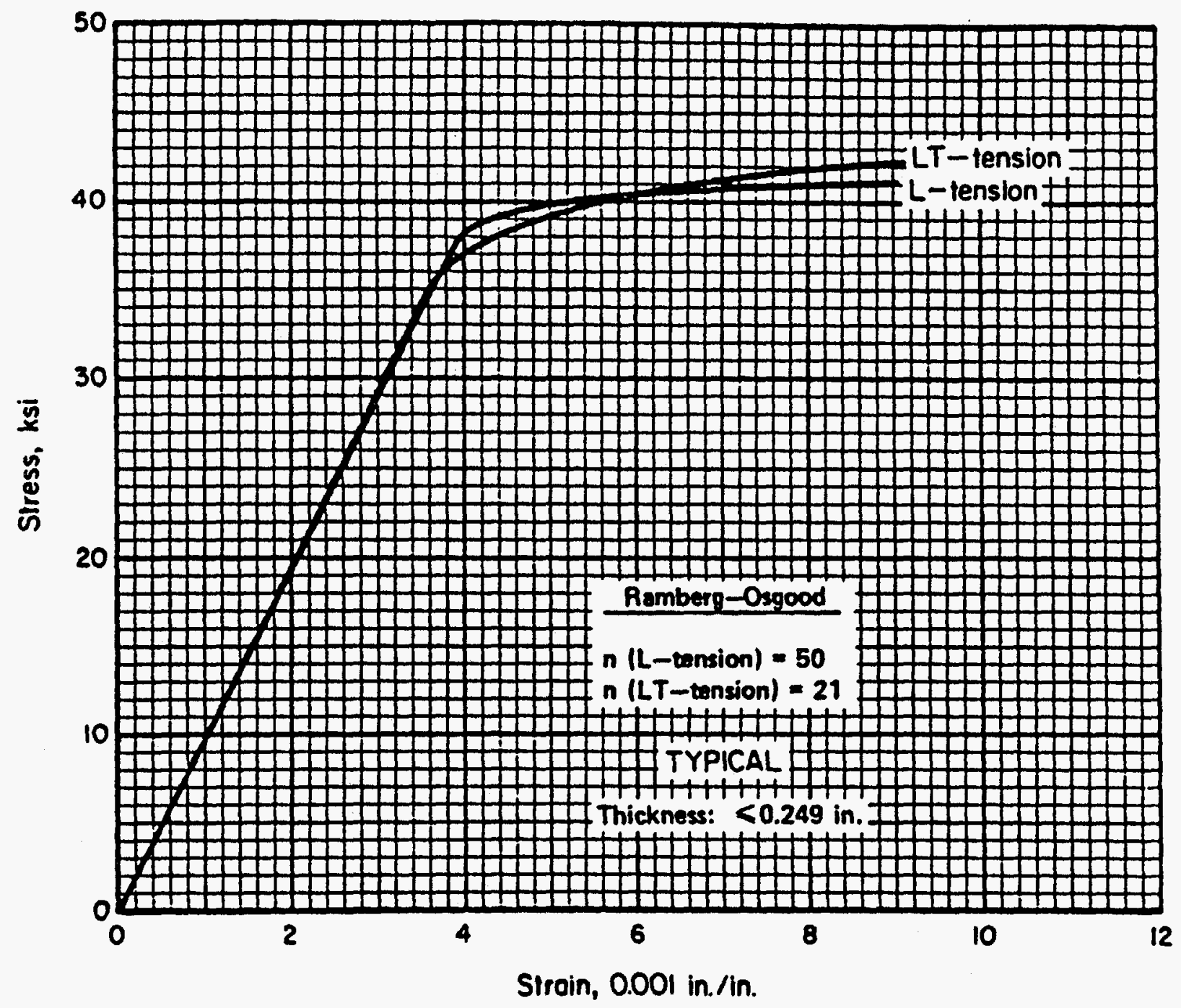

a

Fig. 4. Typical stress-strain curve for 6061-T6 aluminum. Source: Military Standardization Handbook, Metallic Materials and Elements for Aerospace Vehicle Structures, Vol. 1, MIL-HDBK-5D, Jan. 1, 1984. 

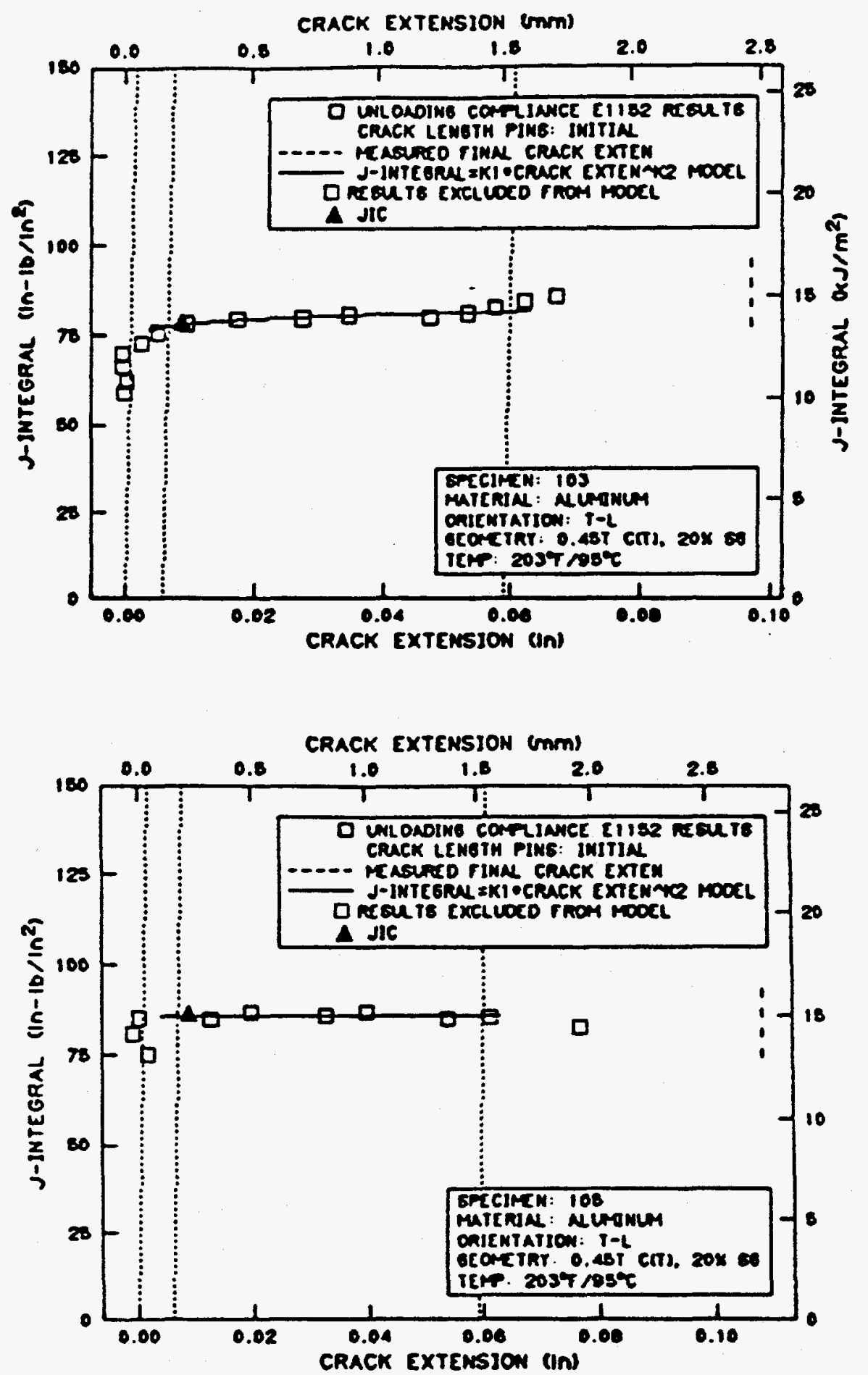

Fig. 5. J-R curves for 6061-T6 aluminum. Top-unirradiated condition; bottom-after 2-month equivalent CPBT irradiation exposure. 
2. $\mathrm{K}_{\mathrm{Q}}$ fracture toughness values as a function of temperature defined by a lower bound of the dynamic initiation and crack arrest toughness data; and

3. a margin factor equal to two primary stresses.

Similarly, the ASME Section XI Task Group on Reactor Vessel Integrity Requirements ${ }^{11}$ suggests the following fracture prevention criteria:

1. allowable fracture toughness derived from a lower bound of the available experimental toughness data;

2. very large postulated flaw; and

3. safety factor of 2 on the applied stress intensity factor, $\mathbf{K}_{\mathrm{I}}$.

The LEFM methodology presented in this report follows these basic guidelines to ensure the structural integrity of the CPBT. Following the current ASME Code, a semielliptical flaw with a depth equal to one-fourth of the wall thickness (quarter-t) located perpendicular to the maximum stress was initially postulated as the reference flaw (Fig. 6). It is suggested here that NDI techniques be applied to the CPBT to limit the size of the flaws that might be present in the CPBT prior to inservice operation. The critical crack size depends primarily on two factors: stress state and fracture toughness. The stress state at the tip of an axial part-through flaw extending from the inside wall of the CPBT, under conditions of maximum operating pressure and temperature, has been determined for the CPBT utilizing computer programs developed by Dixon ${ }^{2}$ and Cento. ${ }^{3}$ Unirradiated 6061-T6 aluminum is known to have a lower bound fracture toughness of $\sim 28 \mathrm{MPa} V \mathbf{m}^{12,13}$ Tests were conducted at Brookhaven National Laboratory ${ }^{6}$ to determine the effect of irradiation on the material properties of 6061-T6 aluminum. Subsized Charpy V-notch specimens were cut from highly irradiated parts that were removed from a reactor at Brookhaven. Although the service conditions were slightly more severe than are expected for the ANS reactor, Yahr ${ }^{14}$ utilized the Brookhaven Charpy results to estimate the fracture toughness of irradiated 6061-T6 aluminum when exposed to ANS operating conditions. Tests are currently being conducted by Alexander ${ }^{5}$ at ORNL to determine the fracture toughness of irradiated 6061-T6 aluminum under fluence levels equivalent to those expected for the ANS reactor.

In accordance with the ASME Code, ${ }^{1}$ a factor of safety of 2 has been applied to the stress intensity factor that results from primary stresses (the membrane, or hoop, stress for the case of the CPBT). Although the ASME Code cannot be applied directly in this case because of the use of relatively thin aluminum as opposed to the more commonly utilized thick ferritic steels, the essence of the ASME Code methodology has been applied, wherever possible, to analyze the relatively brittle fracture behavior of the ANS CPBT.

\section{LINEAR ELASTIC FRACTURE MECHANICS APPROACH}

The critical brittle fracture case for the ANS CPBT under the design pressure and thermal loading conditions is assumed to exist when a longitudinal part-through crack of length $2 c$ and depth a is present at the internal surface of the cylinder, as is depicted in the schematic cylinder shown in Figure $6 .^{15}$. Since the radius of the CPBT is $\sim 30$ times the wall thickness in the preliminary design, the stress intensity factor at the tip of the flaw can be approximated by the expression for a part- 

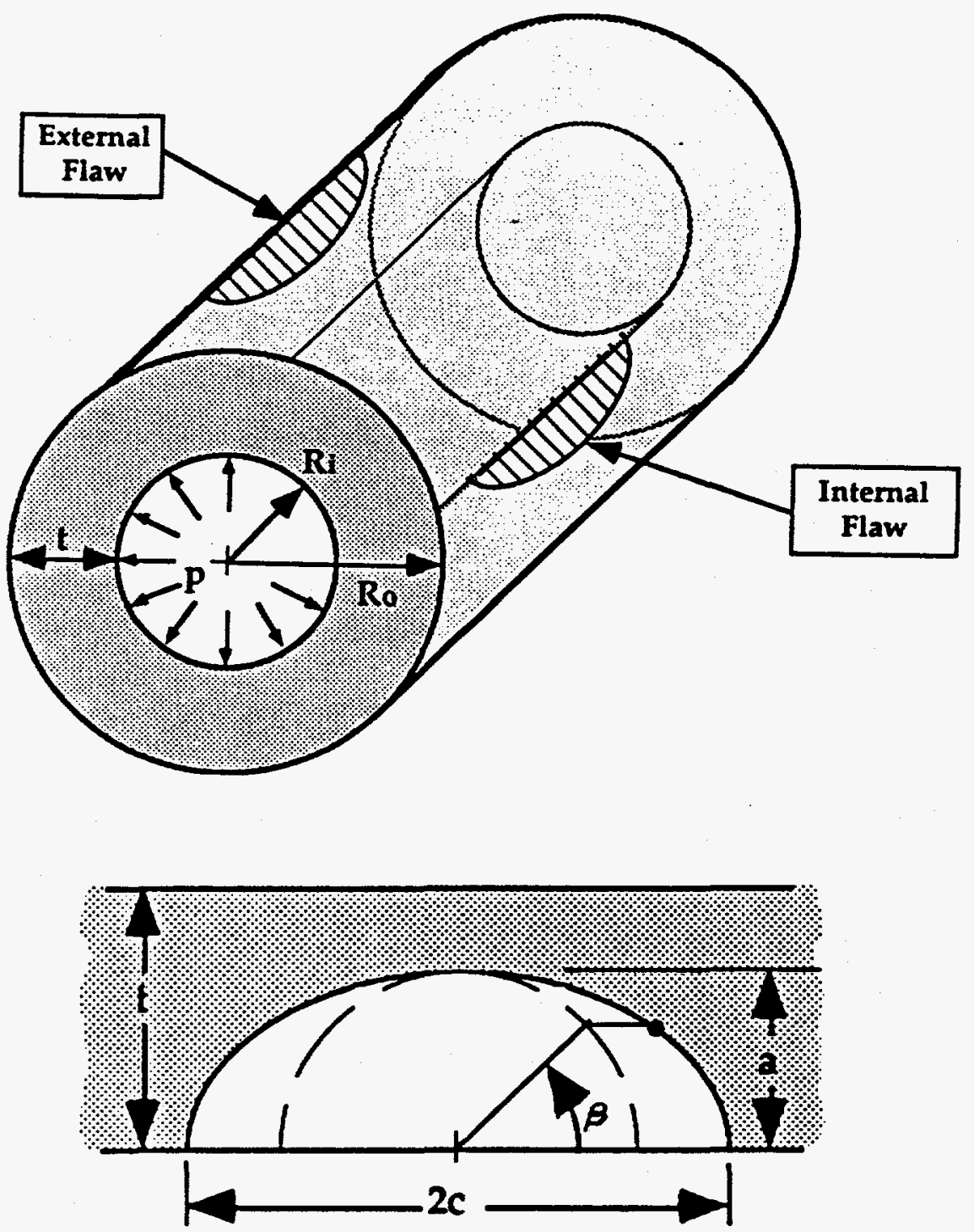

Fig. 6. Schematic illustration of a semielliptical part-through surface flaw. Reprinted with permission from T. L. Anderson, Fracture Mechanics: Fundamentals and Applications, CRC Press, Boca Raton, Fla., 1991. 
through semielliptical crack in an infinite plate subjected to a combination of tensile and bending load (see Fig. 7). ${ }^{16}$ The general expression for stress intensity factor $\left(K_{\mathrm{I}}\right)$ in terms of applied stress $(\sigma)$ and crack length (a) for an embedded elliptical flaw in an infinite body subjected to uniform tensile stress, $\sigma_{m}$, is given by ${ }^{17}$

$$
\mathrm{K}_{\mathrm{I}}=\frac{\sigma_{\mathrm{m}} \sqrt{\pi \mathrm{a}}}{\Phi_{\mathrm{o}}}\left[\sin ^{2} \beta+\frac{\mathrm{a}^{2}}{\mathrm{c}^{2}} \cos ^{2} \beta\right]^{1 / 4},
$$

where $\mathrm{K}_{\mathrm{I}}$ represents the effective value of the stress intensity factor for a point on the perimeter of the crack. The location of $\mathrm{K}_{\mathrm{I}}$ along the crack front is defined by the angle $\beta ; \Phi_{0}$ is defined by the elliptic integral of the second kind

$$
\Phi_{0}=\int_{0}^{\pi / 2}\left[1-\left[\frac{c^{2}-a^{2}}{c^{2}} \sin ^{2} \theta\right)\right]^{1 / 2} d \theta
$$

Expanding Eq. (2a) into a series, ${ }^{18}$

$$
\Phi_{0}=\frac{\pi}{2}\left[1-\frac{1}{4} \frac{c^{2}-a^{2}}{c^{2}}-\frac{3}{64}\left[\frac{c^{2}-a^{2}}{c^{2}}\right]^{2}-\ldots\right]
$$

If the third order and higher order terms are neglected, ${ }^{18} \Phi_{0}$ can be approximated by

$$
\Phi_{0}=\frac{3 \pi}{8}+\frac{\pi}{8} \frac{a^{2}}{c^{2}}
$$

The maximum stress intensity factor for an embedded elliptical crack in an infinite cylinder that is subjected to uniform pressure occurs at $\beta=\pi / 2$; for $\beta=\pi / 2$, the applied stress intensity factor can be expressed as

$$
\mathrm{K}_{\mathrm{I}}=\sigma \sqrt{\frac{\pi \mathrm{a}}{\mathrm{Q}}} \mathbf{F},
$$

where $F$ represents a geometric correction factor and $Q$ is a flaw shape parameter. $Q$ includes a crack tip plasticity correction term and is given by

$$
Q=\sqrt{\Phi_{0}^{2}-0.212 \frac{\sigma^{2}}{\sigma_{y z}^{2}}}
$$

The stress intensity factor for a part-through elliptical crack in an infinite plate subjected to uniform tensile stress [see Fig. 7 (Ref. 19)] can be computed through application of Eq. (3). F is replaced by a free-surface correction factor equal to 1.12 (semielliptical surface crack) and a 


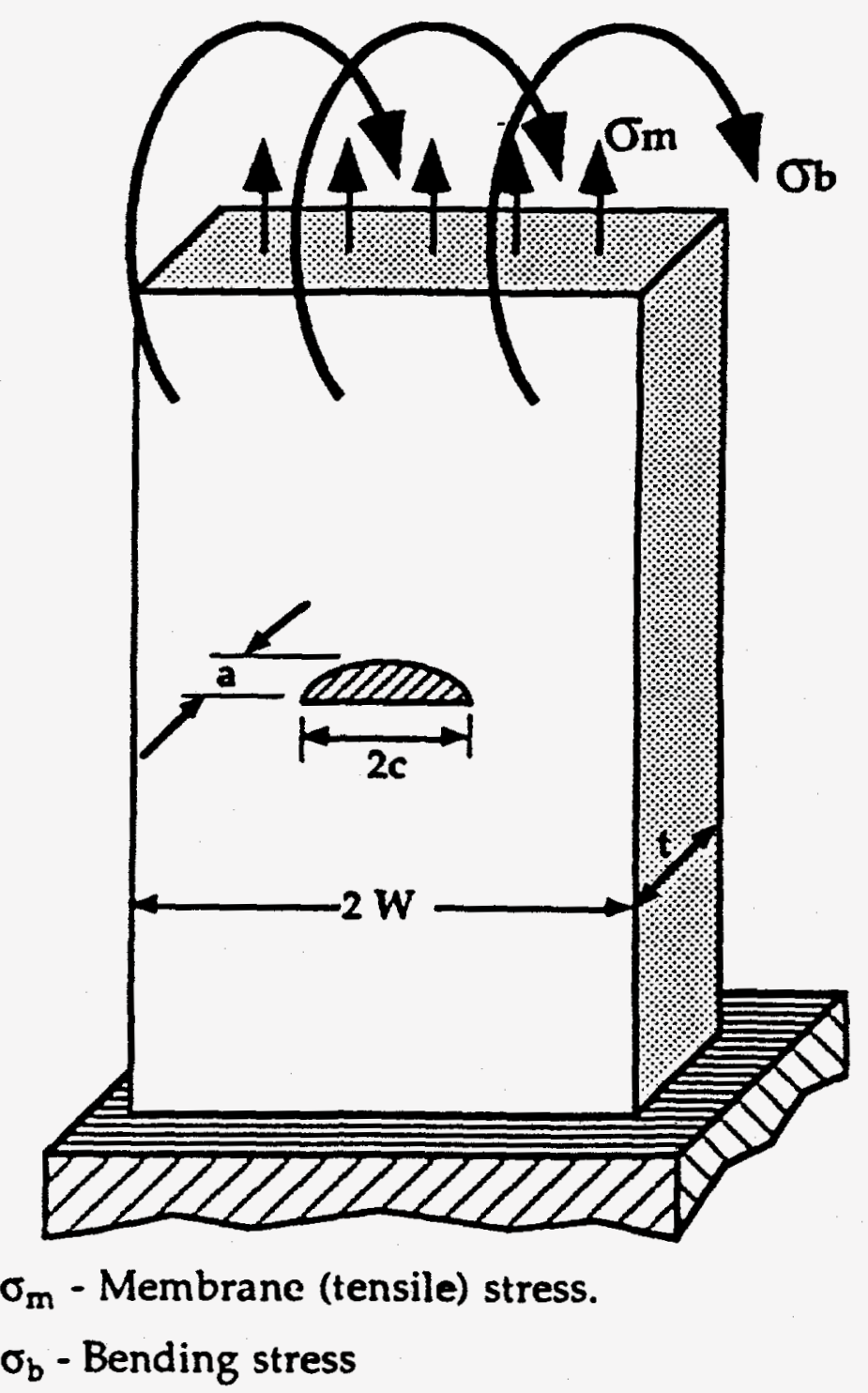

Fig. 7. Ilustration of a part-through surface flaw in a flat plate subjected to membrane and tensile stresses. Reprinted with permission from T. L. Anderson, Fracture Mechanics: Fundamentals and Applications, CRC Press, Boca Raton, Fla., 1991. 
magnification factor for deep flaws, $M_{k}$. The maximum stress intensity factor under uniform loading conditions, as is shown in Fig. 7 , occurs when $\beta=\pi / 2$. The membrane stress, $\sigma_{\text {Membrane, }}$ results in a stress intensity factor of

$$
\mathrm{K}_{\mathrm{I}_{\text {M }}}=1.12\left(\sigma_{\text {Membrane }}\right)\left(\mathrm{M}_{\mathrm{K}}\right) \sqrt{\frac{\pi \mathrm{a}}{\mathrm{Q}}} .
$$

$M_{k}$ is approximately 1.0 if the crack depth, a, is less than one-half of the wall thickness, $t{ }^{20}$ As a approaches $t, \mathbf{M}_{k}$ approaches approximately 1.6. A useful approximation is given by ${ }^{20}$

$$
M_{k}=1.0+1.2\left[\frac{a}{t}-0.5\right)
$$

The expression for the stress intensity factor, $K_{I}$, for a semielliptical part-through surface crack subjected to membrane tension, presented here as Eq. (5), is equivalent to the expression which the Pressure Vessel Research Committee of the Welding Research Council (WRC) proposed in Welding Research Council Bulletin 175 for the evaluation of part-through semielliptical flaws in pressure vessels ${ }^{21}$ except that a free surface correction of 1.1 is used instead of 1.12. The portions of Section XI of the ASME Code that address brittle fracture are based on WRC Bulletin 175.

In pressure vessel analysis, the only significant loadings for regions remote from structural discontinuities are those associated with general membrane stress due to pressure and thermal stresses due to radial thermal gradients across the section thickness. ${ }^{11}$ Thus the applied stress, $\sigma$, generally represents the sum of the primary stresses due to internal pressure and the secondary stresses due to the thermal gradients within the wall of the vessel. Effects of residual stress are not included because: peak values in a heat-treated component are less than $20 \%$ of the yield strength, service stresses and radiation effects both tend to reduce residual stresses during the life of the component, and conservatisms throughout the whole procedure and the safety factors applied appear to be ample to cover any incalculable adverse effects. ${ }^{21}$ According to the ASME Code,${ }^{1}$ the primary stresses due to pressure are termed membrane stresses. For the present case, $\sigma_{\text {Membreme }}$ is the hoop stress which results from the difference in the internal and external pressures that are applied to the CPBT while in service. Figures 1, 2, and 3 show the arrangement of the fuel elements within the reactor vessel and illustrate the positioning and shape of the CPBT. The internal CPBT surface is exposed to a high neutron flux and a coolant flow rate of up to $7 \mathrm{~m} / \mathrm{s}$ while the external surface is in direct contact with naturally circulating heavy water within the reflector vessel. The thermal stresses, $\sigma_{\text {Thermal, }}$ are a result of the temperature gradient in the walls created by the neutron and gamma flux which generates heat within the wall itself because of neutron interaction. The stress equations presented here were derived in cylindrical coordinates where $\sigma_{\mathrm{xr}}, \sigma_{\theta \theta}$ and $\sigma_{\mathrm{zz}}$ are the normal stresses along the three orthogonal directions $r, \theta$, and $z$ respectively [see Fig. 8 (Ref. 3 )].

The Welding Research Council ${ }^{21}$ suggests that the computation of the stress intensity factor at the tip of an infinitely long edge crack be based on the Irwin method. 20,23 Using this method, the stress intensity factor for a long edge crack in a vessel can be computed for all transient and steady-state temperature situations. If the shape of the steady-state temperature distribution is assumed to be

Recent analytical studies reported by J. G. Merkle in NUREG/CR-4219, Vol. 10, No. 1, indicate an error in Ref. 21. 


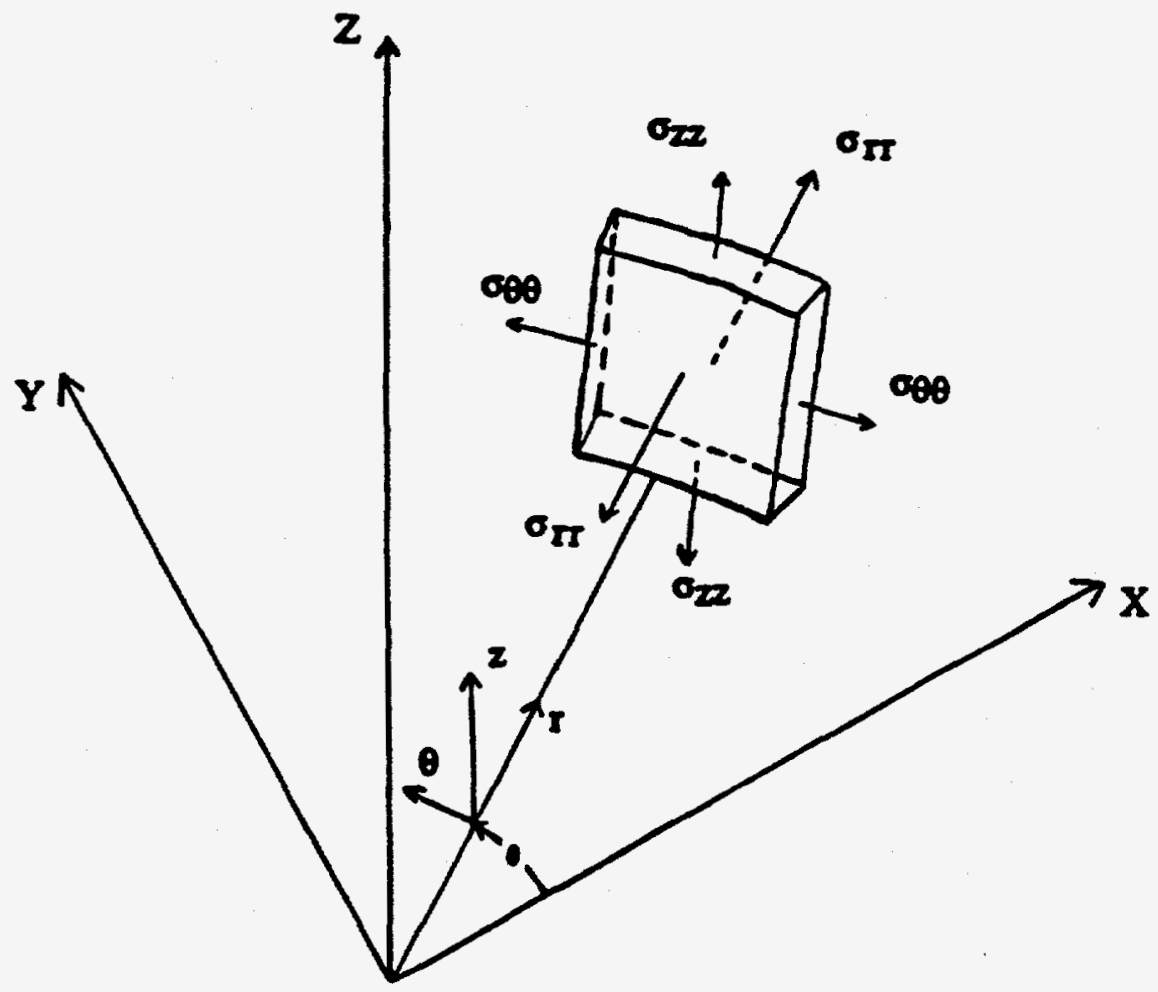

Fig. 8. Stresses associated with the cylindrical coordinate system. Source: P. Cento, ANS Preliminary Design Analysis of the CPBT, Martin Marietta Energy Systems Design Analysis and Calculations, Report No. DAC-XRT-017063-A002:ESOA8019AB1, December 1992. 
parabolic, the stress intensity factor for an infinitely long edge crack of depth equal to $t / 4$ can be expressed as

$$
\mathrm{K}_{\mathrm{I}}=0.823\left[\frac{2 \mathrm{E} \alpha \Delta \mathrm{T}}{3(1-\nu}\right] \sqrt{\mathrm{B}}
$$

where $\Delta \mathrm{T}$ is the temperature difference through the wall $\left({ }^{\circ} \mathrm{F}\right)$ and $\beta$ is the wall thickness (in.).

Equation (7) is based on empiricism and thus may not be appropriate for the 6061-T6 vessel being analyzed here. Because of uncertainties involved in using Eq. (7), a method of accurately predicting the stress state near crack tips due to thermal loading was developed at ORNL ${ }^{2,3}$ and utilized in the present analysis.

\section{CPBT Stress State}

A more accurate method of accounting for the effect of thermal loading on crack-tip stress intensities is to compute the stresses in the CPBT that are due to thermal loading and then utilize an expression similar to Eq. (5) based on a combination of tensile and bending stresses to compute the stress intensity factor at the tip of an assumed flaw due to thermal loading, $K_{L_{n}}$. A one-dimensional axisymmetric cylindrical thermal analysis of the CPBT was performed by Dixon ${ }^{2}$ to provide the radial distribution of temperatures at various positions along the tube. A computer routine utilizing TK Solver ${ }^{24}$ was developed that determines temperature profiles within the CPBT that vary radially and axially based on a set of input boundary design conditions. The current CPBT design, as of June 25 , 1993, is specified as follows:

- $45^{\circ} \mathrm{C}$ inlet temperature, $55^{\circ} \mathrm{C}$ mean reflector vessel temperature.

- 3.2-MPa primary coolant pressure, $0.3-\mathrm{MPa}$ reflector vessel pressure.

- $4.2-\mathrm{m} / \mathrm{s}$ flow velocity through the $5-\mathrm{mm}$ annulus.

- 330-MW power level.

- 8.5-mm wall thickness.

- $0.2470-\mathrm{m}$ inner wall radius, $0.2555-\mathrm{m}$ outer wall radius.

- $z=0$ at the core midplane.

Utilizing these parameters as input, Dixon's routine was used to generate the CPBT temperature profile tables that are presented in Appendix A. Temperature is presented as a function of axial position, $z$, and the radius through the wall thickness, $r$. The maximum temperature deviation for each $\mathrm{z}$ position occurred between the inner wall and the peak temperature for that position. The maximum deviation was found to occur at $\mathrm{z}=0.1367 \mathrm{~m}$, where

$$
\mathrm{T}_{\text {Inner }}=96.34^{\circ} \mathrm{C}, \mathrm{T}_{\text {Outer }}=115.34^{\circ} \mathrm{C} \text {, and } \mathrm{T}_{\text {Maximum }}=115.45^{\circ} \mathrm{C} \text { at } \mathrm{r}=0.2546 \mathrm{~m} \text {. }
$$

ASME Code ${ }^{1}$ assumes that the temperature distribution through the wall thickness has a parabolic shape that is constant for all heatup and cooldown rates in the range of 0 to $100^{\circ} \mathrm{F} / \mathrm{h}$. The results from Dixon's routine indicate that the temperature distribution through the wall thickness is parabolic for the CPBT. Temperature profile results were utilized as input into the thermal stress routine developed by Cento, ${ }^{3}$ which initially fits a parabolic curve through the temperature profile. Equation (9) was applied by Cento ${ }^{3}$ to determine the worst-case stress (maximum tangential) due to temperature 
gradients in the CPBT. The tangential hoop stress due to pressure $\left(\sigma_{\ominus \theta \mathrm{M}}\right)$, which results from the pressure differential between the inner and outer CPBT surfaces, can be expressed as $^{25}$

$$
\sigma_{\ominus \theta \mathrm{M}}=\frac{\Delta \mathrm{P}\left(\mathrm{R}_{\text {Outer }}^{2}+\mathrm{R}_{\mathrm{Imner}}^{2}\right)}{\left(\mathrm{R}_{\text {Outer }}^{2}-\mathrm{R}_{\text {Inser }}^{2}\right)} \text {, }
$$

where $\Delta P$ is $P_{\text {Internal }}-P_{\text {External }}, R_{\text {Outer }}$ is the outer wall radius, and $R_{\text {Imeer }}$ is the inner wall radius.

The stresses due to thermal gradients, which result from irradiation of the 6061-T6 aluminum shell, can be approximated by the closed-form solution for a flat plate with a circular boundary that contains a circular hole. Cento ${ }^{3}$ programmed the expression presented by Manson ${ }^{26}$ and Boley and Weiner ${ }^{27}$ for the resulting tangential stress due to thermal loading where

$$
\sigma_{\theta \Theta T}=\frac{\alpha E^{\prime}}{r^{2}}\left[\frac{r^{2}+a^{2}}{b^{2}-a_{2}} \int_{a}^{b} T(r) r d r+\int_{a}^{r} T(r) r d r-T(r) r^{2}\right] .
$$

where

$$
\begin{aligned}
& a=\text { coefficient of thermal expansion, } \\
& E^{\prime}=\text { modulus of elasticity for plane strain; } E^{\prime}=E /\left(1-\nu^{2},\right) \text { where } \nu \text { is Poisson's ratio, } \\
& r=\text { wall radius, } \\
& a=\text { inner wall radius, } \\
& b=\text { outer wall radius, } \\
& T(r)=\left(T_{a}-T_{m a x}\right) /\left(r_{m}-a\right)^{2}\left(r_{m}-r\right)^{2}+T_{\max } \\
& r_{m}=\text { radius at which the maximum temperature occurs for a given axial coordinate, } \\
& T_{\max }=\text { maximum temperature, and } \\
& T_{a}=\text { temperature at the inner wall for a given vertical location. }
\end{aligned}
$$

The tangential stress values at various positions through the thickness of the CPBT wall were generated through application of Eqs. (8) and (9) at the location of the highest thermal gradient, $z=$ $0.137 \mathrm{~m}$ from the CPBT midplane. The maximum and minimum stresses were found to occur at or near the inner and outer CPBT walls, respectively, where

$$
\sigma_{\text {eThermal }_{\text {LE }}}=34.1 \mathrm{MPa}, \sigma_{\text {eThermal }_{\text {Li }}}=-14.34 \mathrm{MPa} \text {, and } \sigma_{\text {eMembrane }}=85.75 \mathrm{MPa} \text {. }
$$

These values were used as the input values of $\sigma_{\text {eThermal }}$ and $\sigma_{\text {emombrame }}$ throughout the fracture analysis conducted in this study with a CPBT wall thickness of $8.5 \mathrm{~mm}$.

\section{Stress Intensity Factor Due to Thermal Stresses}

The stress intensity solution for a semielliptical surface flaw in a flat plate subjected to thermal stresses, which result from the thermal gradient, is assumed to be similar to the expression for a flat plate subjected to tensile stresses assuming that the stress distribution due to the thermal gradient is 
approximately linear. The thermally induced stresses are divided into membrane $\left(\sigma_{\text {өтм }}\right)$ and bending components $\left(\sigma_{\text {eтB }}\right)$, where ${ }^{4}$

$$
\sigma_{\text {OTM }}=\frac{\sigma_{\text {OThermal }} \text { max }}{}+\sigma_{\text {eThermal }_{\text {MiM }}}
$$

and

The stress intensity expression for the central tip of a semielliptical surface flaw, based on a linear thermal stress distribution, was developed utilizing the influence coefficient approach ${ }^{4}$ as

$$
\mathrm{K}_{\mathrm{L}_{\mathrm{MU}}}=1.12\left(\sigma_{\mathrm{\theta TM}}+\mathrm{H}_{2} \sigma_{\theta \mathrm{TSB}}\right)\left(\mathrm{M}_{\mathrm{K}}\right) \sqrt{\frac{\pi \mathrm{a}}{\mathrm{Q}}}
$$

Q represents the same flaw shape parameter as was presented in Eq. (5), $M_{k}$ represents the deep flaw correction as is presented in Eq. (6) and, assuming $\beta=90^{\circ}, \mathrm{H}_{2}$ can be expressed in terms of a, $c$, and $t$ as $^{4}$

$$
H_{2}=1+G_{1}\left(\frac{a}{t}\right)+G_{2}\left(\frac{a}{t}\right)^{2},
$$

where

$$
G_{1}=-1.22-0.12\left[\frac{a}{c}\right)
$$

and

$$
G_{2}=0.55-1.05\left(\frac{a}{c}\right)^{0.75}+0.47\left(\frac{a}{c}\right)^{1.5} .
$$

The critical fracture criterion in the ASME Code, Section XI (Ref. 9), is based on a factor of safety of 2 on primary (membrane) stresses. Thus the Code specifies

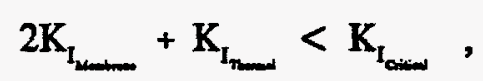

where $\mathrm{K}_{\mathrm{I}_{\text {citidu }}}$ represents an expression for fracture toughness. 
Sample Computation 1: Assuming that the CPBT wall thickness is $8.5 \mathrm{~mm}$, with $\mathrm{R}_{\text {Iner }}=247.0 \mathrm{~mm}$ and $R_{\text {outer }}=255.5 \mathrm{~mm}$, the wall is subjected to a membrane stress of $85.75 \mathrm{MPa}$ and thermal stresses of $\sigma_{\theta \mathrm{T}_{\text {um }}}=34.1 \mathrm{MPa}$ and $\sigma_{\theta \mathrm{T}_{\text {s. }}}=-14.36 \mathrm{MPa}$, where $\sigma_{\mathrm{Ys}}=230 \mathrm{MPa}$ for $6061-\mathrm{T} 6$ aluminum. What fracture toughness, $\mathrm{K}_{\mathrm{Q}}$, would be required for the irradiated 6061-T6 CPBT to avoid brittle failure if an ASME quarter-thickness axial part-through elliptical flaw is assumed to exist at the inner surface of the CPBT?

Solution: Following the ASME Code, a crack that has the dimensions of $a=t / 4$ and $2 c=1.5 t$ (see Fig. 6) is assumed to exist at the inner surface of the CPBT, where

$$
\mathrm{a}=\frac{\mathrm{t}}{4}=\frac{8.5 \mathrm{~mm}}{4}=2.125 \mathrm{~mm}
$$

and

$$
2 c=1.5 \mathrm{t}=1.5(8.5 \mathrm{~mm})=12.75 \mathrm{~mm} \text {. }
$$

Utilizing Eq. (2c), the approximate solution for the elliptic integral can be obtained where

$$
\Phi_{0}=\frac{3 \pi}{8}+\frac{\pi}{8} \frac{a^{2}}{c^{2}}=\frac{3 \pi}{8}+\frac{\pi}{8} \frac{(2.125)^{2}}{(6.375)^{2}}=1.2217
$$

The flaw shape parameter, Q, as expressed in Eq. (4), can be computed where the applied stress is taken as the sum of the thermal and membrane stresses. Thus,

$$
Q=\sqrt{(1.2217)^{2}-0.212 \frac{(126.8)^{2}}{(230)^{2}}}=1.195
$$

Since $a / t<0.5, M_{k}=1.0$. Substitution into Eq. (5) gives the stress intensity due to the applied pressure, where

$$
\mathrm{K}_{\mathrm{I}_{\mathrm{m} m}}=1.12(85.75)(1.0) \sqrt{\frac{\pi(0.002125)}{(1.195)}}=7.178 \mathrm{MPa} \sqrt{\mathrm{m}} .
$$

Similarly, utilizing Eqs. (10) through (13) to determine $\mathrm{K}_{\mathrm{t}_{\mathrm{m}}}$,

$$
\sigma_{\text {OTM }}=\frac{\sigma_{\text {OThermal }}+\sigma_{\text {UThermal }}+\sigma_{\text {Mi }}}{2}=\frac{34.1+(-14.36)}{2}=9.87 \mathrm{MPa}
$$




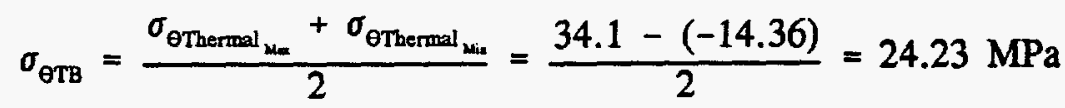

$$
\begin{aligned}
& G_{1}=-1.22-0.12\left[\frac{a}{c}\right]=-1.22-0.12\left[\frac{1}{3}\right]=-1.26 \\
& G_{2}=0.55-1.05\left[\frac{a}{c}\right]^{0.75}+0.47\left[\frac{a}{c}\right]^{1.5}=0.55-1.05\left[\frac{1}{3}\right]^{0.75}+0.47\left[\frac{1}{3}\right]^{1.5}=0.1798, \\
& \mathrm{H}_{2}=1+\mathrm{G}_{1}\left[\frac{\mathrm{a}}{\mathrm{t}}\right]+\mathrm{G}_{2}\left(\frac{\mathrm{a}}{\mathrm{t}}\right]^{2}=1+(-1.26)\left[\frac{1}{4}\right)+(0.179825)\left[\frac{1}{4}\right)^{2}=0.69624
\end{aligned}
$$

and

$$
\begin{aligned}
& \mathbf{K}_{h_{-}}=1.12\left\{[9.87+(0.69624)(24.23)](1.0) \sqrt{\frac{\pi(0.002125)}{(1.195)}}\right\}, \\
& \mathrm{K}_{\mathrm{L}_{\mathrm{m}}}=2.239 \mathrm{MPa} \sqrt{\mathrm{m}} \text {. }
\end{aligned}
$$

Safe design, according to ASME Code, Section XI (Ref. 28), requires that

$$
2 \mathrm{~K}_{\mathrm{I}_{\text {m }}}+\mathrm{K}_{\mathrm{L}_{\mathrm{m} m}}<\mathrm{K}_{\mathrm{I}_{\text {oid }}}
$$

solving for the left side of the inequality,

$$
2 \mathrm{~K}_{\mathrm{I}_{\mathrm{N}}}+\mathrm{K}_{\mathrm{I}_{\mathrm{n} m}}=2(7.178)+(2.239)=16.6 \mathrm{MPa} \sqrt{\mathrm{m}}
$$

Based on Eq. (14), the fracture toughness of irradiated 6061-T6 should be at least $16.6 \mathrm{MPa} \sqrt{\mathrm{m}}$ if the CBPT is to operate with a 2.125 -mm-deep by 12.75 -mm-long semielliptical part-through flaw.

The above approach should provide a satisfactory analytical approach to preliminary evaluation of the CPBT in terms of nonductile fracture, but a more detailed analysis will be required prior to construction of the ANS. The expressions for stress intensity factor in this approach are only approximate, and a number of simplifying assumptions have been made. The final fracture analysis should include both the effects of seismic loading and the effects of possible back-surface deformation of the CPBT in the near crack region that would effectively increase the stress intensity factor. A superposition-based influence coefficient approach or a finite element analysis will have to be conducted to determine more accurate values of stress intensity factor. Equation (12) was developed by Anderson ${ }^{4}$ using the influence coefficient approach. 
Parametric Analysis of Crack Size vs Stress Intensity Factor: f(a/c)

The equation solver software package TK solver ${ }^{24}$ was used to program the linear elastic fracture mechanics expressions presented as Eqs. (1) through (14). The effect of crack length and crack shape on stress intensity factor was analyzed parametrically. The stress intensity factor was computed for a semielliptical part-through crack in an infinite plate for crack depths of $a=0.5 \mathrm{~mm}$ through $\mathrm{a}=$ $8.5 \mathrm{~mm}$ at steps of $0.5 \mathrm{~mm}$. Analyses were conducted for the following six flaw shapes: $c=10 \mathrm{a}$, $c=6 a, c=3 a(A S M E), c=2 a, c=3 a / 4$, and $c=a$. The current CPBT design parameter values, as detailed earlier in this report, were utilized throughout the parametric analysis.

The results for $c=3 a$ are presented in Table 2, and a plot of stress intensity factor vs flaw depth is presented in Fig. 9. The plot indicates that $c=3 a$ flaws are generally conservative; the stress intensity factors for relatively long cracks, $c=10 \mathrm{a}$ flaws, are only slightly larger than the stress intensity factors for $c=3 a$ flaws for equivalent values of $a$, whereas the stress intensity factors for $c=a$ flaws were found to be somewhat lower (see Fig. 9). The quarter-t flaw assumption suggested by the ASME Code is therefore appropriate and was utilized to estimate the effect of CPBT wall thickness on fracture strength.

The approximations used in the development of Fig. 9 result in an inflection in the curves of stress intensity factor vs flaw depth. An approximation was used for the back-surface magnification, $\mathbf{M}_{\mathrm{K}}$, for deep flaws, that is

$$
\begin{gathered}
M_{K}=1.0 \text { for } \frac{a}{t}<0.5 \\
M_{K}=1+1.2\left(\frac{a}{t}-0.5\right) \text { for } \frac{a}{t} \geq 0.5,
\end{gathered}
$$

where $a$ is the crack depth and $t$ is the wall thickness. The inflection in the curves occurs at an a/t of 0.5. Three other solutions ${ }^{9,28,29}$ for tension loading of an 8.5 -mm-thick flat plate with a semielliptical surface flaw were applied to the CPBT. The curves are compared in Fig. 10. The curves all have an inflection at $a / t$ of 0.5 , but it is less pronounced than the one computed by Schulz.

The four solutions are in good agreement for cracks of less than one-quarter the thickness. The ASME XI curve based on the back-surface magnification factors, given in Fig. A-3300-3 of Appendix A of the ASME Boiler and Pressure Vessel Code, Section XI, gives higher values of $\mathrm{K}_{1}$ than the other three curves. If the ASME XI curve is used, then the allowable flaw size will be somewhat smaller than in Schulz's preliminary analysis. Conversely, the minimum required fracture toughness of the aluminum will be higher for a given flaw size.

The fracture toughness for unirradiated 6061-T6 is known to be approximately $28 \mathrm{MPa} \sqrt{\mathrm{m}}$, as is indicated in Fig. 9. Based on the unirradiated value of $\mathrm{K}_{\mathrm{Q}}$, the present analysis indicates that flaws up to $5.5 \mathrm{~mm}$ deep (16.5 mm long) could be present in the critical portion of the CPBT without causing brittle failure.

Alexander ${ }^{5}$ has conducted J-integral-resistance (JR) curve toughness tests on irradiated and unirradiated $0.45 \mathrm{~T}$ compact specimens $(28.6 \times 27.4 \times 11.4 \mathrm{~mm}$ thick) of 6061-T651 aluminum plate. The specimens were irradiated to a maximum thermal neutron fluence of $1 \times 10^{26} \mathrm{~m}^{-2}$. The specimen temperature during the irradiation was in the range of $60^{\circ} \mathrm{C}$ to $114^{\circ} \mathrm{C}$. Tests were conducted at room temperature, $95^{\circ} \mathrm{C}$, and at $150^{\circ} \mathrm{C}$. There was no degradation of the fracture toughness at $25^{\circ} \mathrm{C}$ or $95^{\circ} \mathrm{C}$ and only a slight decrease at $150^{\circ} \mathrm{C}$. 
Table 2. Stress intensity factor vs crack length for the CPBT $(c=3 a)$

\begin{tabular}{cllllll}
\hline $\begin{array}{c}\text { Title } \\
\text { element }\end{array}$ & \multicolumn{1}{c}{$\mathrm{a}$} & $\mathrm{c}$ & $\begin{array}{c}\mathrm{a}=\mathrm{c} / 3 \\
\text { DATA } \\
\mathrm{a} / \mathrm{t}\end{array}$ & KIMembrane & KIThermal & $\begin{array}{c}\text { KI }=2 * \text { KIM+KI } \\
\mathrm{T}\end{array}$ \\
\hline 1 & 0.0005 & 0.0015 & 0.059 & 3.47 & 1.31 & 8.25 \\
2 & 0.001 & 0.003 & 0.118 & 4.91 & 1.75 & 11.57 \\
3 & 0.0015 & 0.0045 & 0.176 & 6.01 & 2.02 & 14.05 \\
4 & 0.002 & 0.006 & 0.235 & 6.94 & 2.20 & 16.09 \\
5 & 0.0025 & 0.0075 & 0.294 & 7.76 & 2.31 & 17.84 \\
6 & 0.003 & 0.009 & 0.353 & 8.51 & 2.39 & 19.38 \\
7 & 0.0035 & 0.0105 & 0.412 & 9.19 & 2.39 & 20.76 \\
8 & 0.004 & 0.012 & 0.471 & 9.82 & 2.37 & 22.01 \\
9 & 0.0045 & 0.0135 & 0.530 & 10.78 & 2.41 & 23.98 \\
10 & 0.005 & 0.015 & 0.588 & 12.14 & 2.50 & 26.79 \\
11 & 0.0055 & 0.0165 & 0.647 & 13.55 & 2.55 & 29.65 \\
12 & 0.006 & 0.018 & 0.706 & 15.00 & 2.58 & 32.58 \\
13 & 0.0065 & 0.0195 & 0.765 & 16.50 & 2.56 & 35.55 \\
14 & 0.007 & 0.021 & 0.824 & 18.04 & 2.51 & 38.58 \\
15 & 0.0075 & 0.0225 & 0.882 & 19.62 & 2.41 & 41.65 \\
16 & 0.008 & 0.024 & 0.941 & 21.24 & 2.29 & 44.77 \\
17 & 0.0085 & 0.0255 & 1 & 22.91 & 2.12 & 47.93 \\
\hline
\end{tabular}

Parametric Analysis of Crack Size vs Stress Intensity Factor: $f(t)$

Assuming that $c=3 a$, a set of computer runs was conducted to determine the effect of CPBT wall thickness on its fracture behavior. Although thermal stresses slightly increase when wall thickness is increased, the membrane stresses are significantly reduced. The following procedure was followed to approximate the effect of wall thickness on fracture behavior of the CPBT.

Thermal stresses for various wall thicknesses were approximated using the expression proposed by Zudans, Yen, and Steigelmann, ${ }^{30}$ where

$$
T(X)=T_{0}+\frac{X}{L}\left(T_{L}-T_{0}\right)+\frac{H_{0}}{k^{2}}\left[\left(1-e^{-m x}\right)-\frac{X}{L}\left(1-e^{-m L}\right)\right] ;
$$

where

$T(x)=$ temperature at a distance $\mathrm{x}$ into the wall, $T_{0}=$ inner wall temperature, 


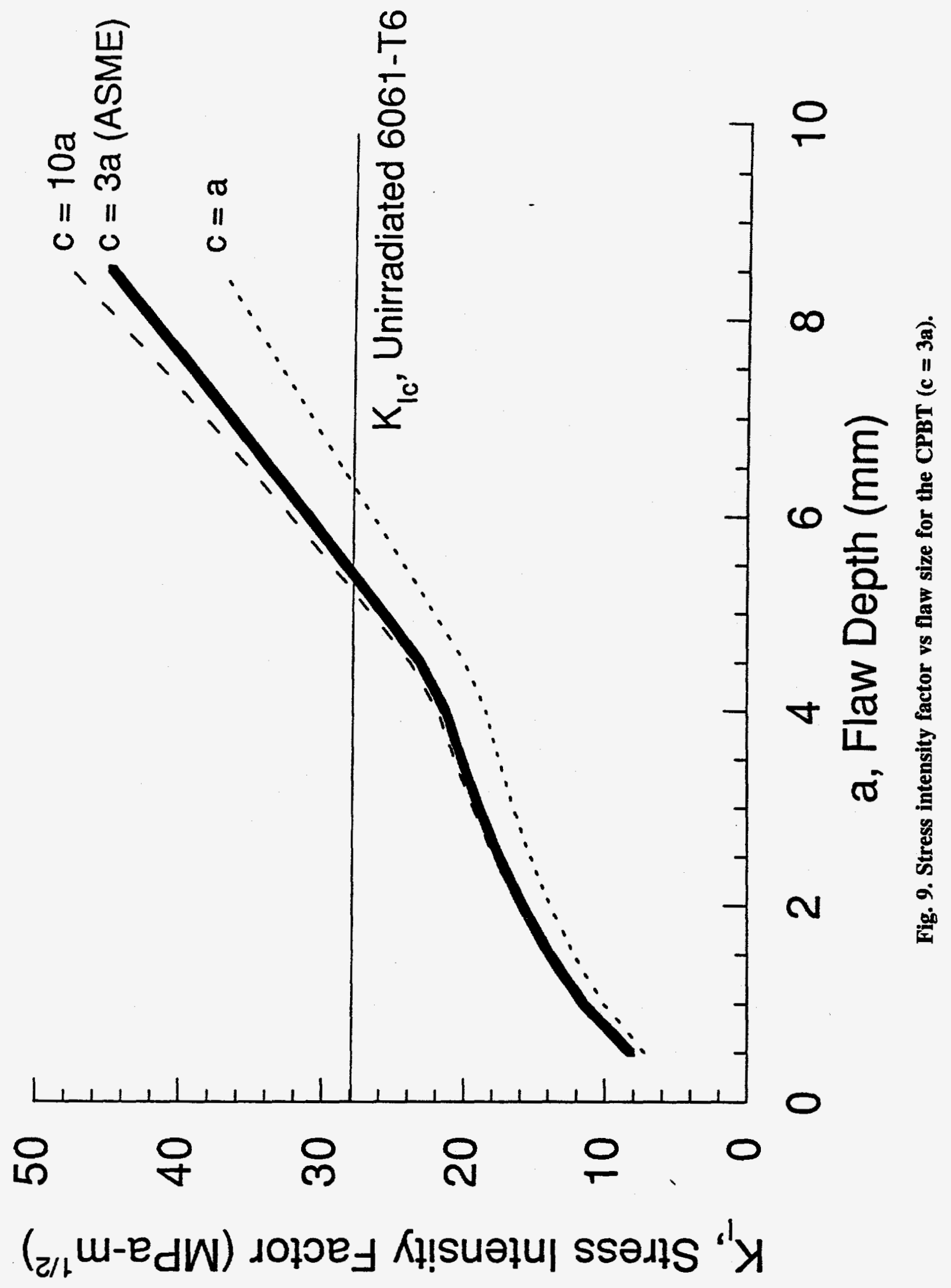




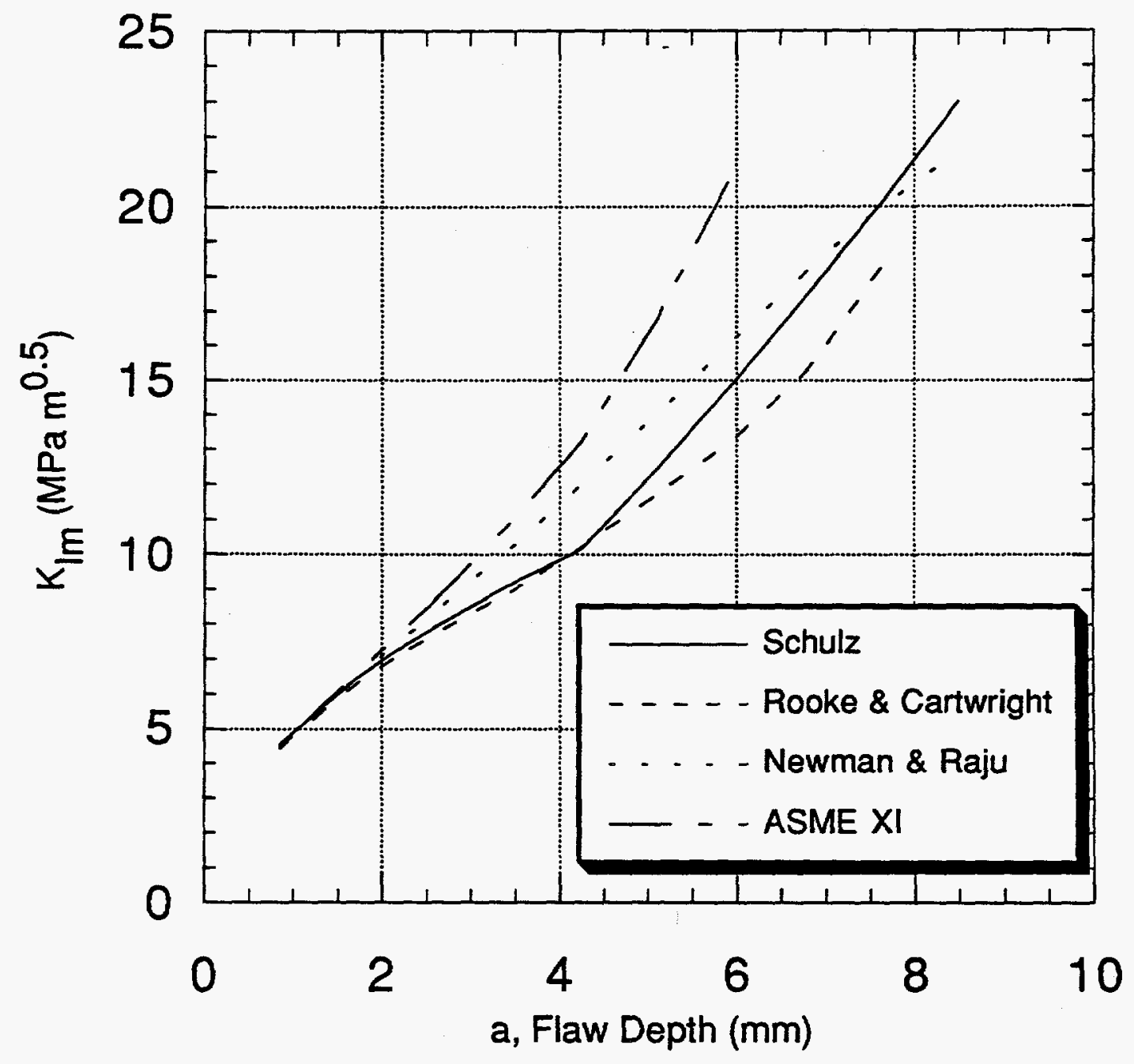

Fig. 10. Comparison of four different calculations of stress intensity factor. 
$\mathrm{x}=$ radial distance measured from the inner surface,

$\mathrm{L}=$ wall thickness,

$\mathrm{T}_{\mathrm{L}}=$ temperature at the outer surface,

$\mathrm{H}_{\mathrm{o}}=$ volumetric heating rate,

$\mathbf{k}=$ thermal conductivity, and

$\mathrm{m}=$ constant curve fitting parameter.

Utilizing Dixon's ${ }^{2}$ thermal variable values for the 8.5 -mm-thick CPBT of $\mathrm{H}_{0}=5.42 \mathrm{MW} / \mathrm{m}^{3}$ and $k=167 \mathrm{~W} / \mathrm{m}^{\circ} \mathrm{K}$ with $\mathrm{T}_{0}=96.34^{\circ} \mathrm{C}, \mathrm{x}=0, \mathrm{~L}=8.5 \mathrm{~mm}$, and $\mathrm{T}_{\mathrm{L}}=115.4^{\circ} \mathrm{C}$ as input into Eq. (15), the value of the constant " $\mathrm{m}$ " was iteratively determined to be 2.131 using TK Solver. Utilizing this value of " $\mathrm{m}$," the maximum temperature and its radial location were approximated through the application of Eq. (15) for the following thicknesses: $6.5 \mathrm{~mm}, 10.5 \mathrm{~mm}, 12.5 \mathrm{~mm}$, and $14.5 \mathrm{~mm}$. The maximum thermal gradient was assumed to equal the maximum value of $T(x)$ in Eq. (15) minus the inner wall temperature, which was assumed to remain at $96.34^{\circ} \mathrm{C}$ regardless of wall thickness. Utilizing these approximate temperature profiles, the maximum thermal and membrane tangential stresses were computed for each assumed wall thickness using Eqs. (8) and (9). These results were then substituted into Eqs. (5) and (10) to determine the stress intensity factors associated with the thermal and membrane stresses for several flaw depths for each of the wall thicknesses analyzed. The results for each thickness analyzed are plotted in Fig. 11.

The effect of wall thickness on the brittle fracture characteristics of the CPBT was found to be significant. Thermal stresses increase with increasing wall thickness because of the larger volume of irradiated material and the larger distances that heat must travel to reach the cooling water. Conversely, membrane stresses decrease with increasing wall thickness as a result of the larger volume of material available to carry the pressure-induced loads. As can be deduced from Fig. 11, increasing wall thickness increases the critical flaw depth for brittle fracture. Increasing the CPBT wall thickness from 8.5 to $14.5 \mathrm{~mm}$ approximately doubles the critical flaw size for the range of flaw sizes of interest. Assuming that $\mathrm{K}_{\mathrm{Q}}$ is that of unirradiated 6061-T6, the critical flaw depth for a wall thickness of $8.5 \mathrm{~mm}$ is approximately $5.5 \mathrm{~mm}$ as compared to a critical flaw depth of about $11 \mathrm{~mm}$ for a wall thickness of $14.5 \mathrm{~mm}$. A reduction in wall thickness from 8.5 to $6.5 \mathrm{~mm}$ would result in a critical flaw depth of only about $3.75 \mathrm{~mm}$. The actual wall thickness of the CPBT will depend on the $\mathrm{K}_{\mathrm{Q}}$ of irradiated $6061-\mathrm{T} 6$, the inspection capabilities at ORNL, and the desired safety factors on brittle fracture. Figure 11 can be used to approximate the effect of wall thickness on critical flaw size for the CPBT.

\section{FRACTURE TOUGHNESS}

Fracture toughness, $\mathrm{K}_{\mathrm{O}}$, is a material property that represents the stress intensity factor at which unstable crack growth occurs for conditions of static loading at a particular temperature. The lowerbound plane strain fracture toughness, $\mathrm{K}_{\mathrm{I}_{\mathrm{c}}}$, of unirradiated 6061-T6 aluminum is known to be - $28 \mathrm{MPa} \sqrt{ } \mathrm{m}$ (Ref. 13). The CPBT surrounds the fuel elements in the ANS reactor and will be subjected to nuclear irradiation throughout its service life. The effect of irradiation on the fracture toughness of 6061-T6 must be assessed to determine the service life of the CPBT.

Irradiation has the potential in time to reduce significantly the fracture toughness of 6061-T6 aluminum as a function of time. Subsize Charpy V-notch impact tests were conducted by Weeks, Czajkowski, and Farrell at Brookhaven National Laboratory ${ }^{31}$ on irradiated 6061-T6 aluminum. $\mathrm{Yahr}^{14}$ utilized a correlation between Charpy results and fracture toughness that was developed for steels to approximate the $\mathrm{K}_{\mathrm{Q}}$ of 6061-T6 aluminum after irradiation. The Brookhaven tests were found 


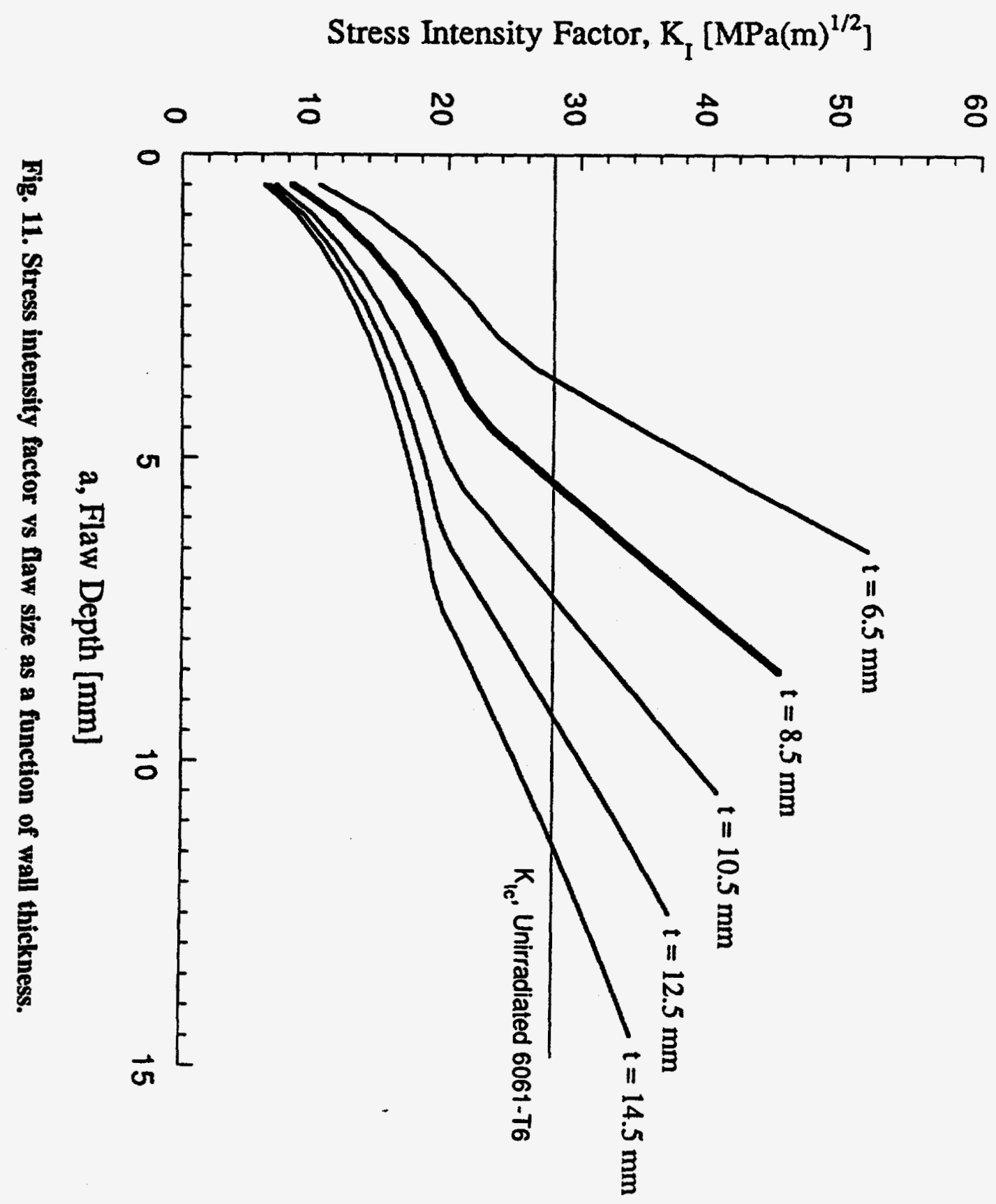


to be approximately equivalent to 82 months of operation of the ANS reactor at a power level of 330-350 MW in the wall adjacent to the core. ${ }^{3} \mathrm{Yahr}^{14}$ estimated that the predicted value of $\mathrm{K}_{\mathrm{Q}}$ for 6061-T6 aluminum dropped to $13 \mathrm{MPa} \sqrt{ } \mathrm{m}$ after the 82 months of operation under ANS-equivalent operating conditions. The maximum expected service life of the CPBT in the ANS reactor is currently set at $\sim 12$ months; thus the 82-month correlation does not represent an estimate of the value of $K_{Q}$ at the time the CPBT is replaced. Alexander ${ }^{5}$ conducted 6061-T6 aluminum irradiation tests at the High Flux Isotope Reactor (HFIR) at ORNL. The capsule, which contained 11.43-mm-thick compact tension test specimens, was irradiated for 62.5 days at $85 \mathrm{MW}$ for a total maximum fluence of $1.1 \times$ $10^{26}$ (thermal) and $5.5 \times 10^{25}$ (fast) neutrons $/ \mathrm{m}^{2}$. No degradation of the fracture toughness of the $6061-\mathrm{T} 6$ was observed at 20 and $95^{\circ} \mathrm{C}$, and only a slight decrease was observed at $150^{\circ} \mathrm{C}$.

Alexander's test program is still in progress. The results of this program should quantitatively determine the effect of irradiation on the fracture toughness of 6061-T6 aluminum, which is pertinent for the ANS reactor. Since the specimens being studied by Alexander are only $11.43 \mathrm{~mm}$ thick, they are clearly not in the plane strain region as specified by Eq. (16). The CPBT wall thickness is currently specified at $8.5 \mathrm{~mm}$. Utilizing the results of Alexander for fracture toughness should be slightly conservative and can be used in the CPBT fracture analysis. The brittle fracture prediction routine developed in this study was designed such that the $\mathrm{K}_{\mathrm{Q}}$ results obtained by Alexander can be easily utilized to determine the allowable flaw sizes for the ANS CPBT.

\section{INTEGRITY REQUIREMENTS AND NONDESTRUCTIVE EVALUATION}

In Section III of the ASME Code, ${ }^{1}$ the allowable stress intensity, $S_{m}$, for Class 1 components is determined as the lesser of two-thirds of the yield strength or one-third of the tensile strength specification minimums at room temperature or the expected minimums at higher temperatures. These criteria, in conjunction with the use of the maximum shear stress criterion in Section III, imply a nominal factor of safety of 3 on failure due to pressure. Section XI of the ASME Code purports that the allowable flaw indication during inspection of an operating vessel is a quarter-t deep flaw reduced by a factor of safety of 10 on size to account for possible flaw growth during service (even though flaw growth is usually found in actual calculations to be insignificant) and any uncertainties associated with inspection. The quarter-t reference flaw in Section III provides a conservative bound for any existing flaws in a vessel. The factor of 10 on flaw size in Section XI was established to maintain a nominal design margin of at least 3 for level $A$ and $B$ conditions. Since $K_{f}=f(V a)$, the safety factor on stress intensity factor based on flaw size is greater than 3; the Section III factor of safety of 3 is maintained. There was little confidence that in-service inspections (ISIs) could reliably detect or size flaws or that ISI would even be routinely performed at the time these standards were developed. The allowable indications are further conservatively adjusted to account for variations from an ideal semielliptical flaw geometry; all observed defects, such as crack-like defects, slag inclusions, porosity, lack of weld fusion, laminations, and any combinations thereof, are treated in the analysis as planar cracks. ${ }^{32}$ Significant advancements have been made in the reliability and capability of both NDI and nondestructive evaluation (NDE) since the introduction of ISI rules; the extreme Code conservatism regarding the presence of flaws no longer seems necessary.

The criteria for selection of a one-fourth thickness flaw in Section III of the ASME Code also involved consistency with the leak-before-break concept that was one of the structural integrity approaches being developed in the early 1970s. Calculations revealed that a one-fourth thickness flaw with a safety factor of 2 has nearly the same stress intensity factor as a through-thickness flaw of a length two times the thickness and a safety factor of $1 .^{11}$ This established that the reference flaw, plus the margin, provided equivalence to a leak-before-break criterion. The postulated Section III, ASME 
Code flaw is a semielliptical surface crack with a depth of one-fourth the section thickness and a length of 1.5 times the section thickness. For sections less than 4 in. thick, a 1-in.-deep flaw is postulated. For sections greater than 12 in. in thickness, the postulated maximum flaw for a 12-in. section is utilized. The ASME Code does allow for smaller flaw sizes: "Smaller flaw sizes may be used on an individual case basis if a smaller size of maximum postulated flaw can be ensured." The ANS CPBT is currently specified with a thickness of less than $15 \mathrm{~mm}$; assuming a 25.4-mm-deep (1-in.-deep) flaw according to the ASME Code is physically impossible and would completely invalidate any CPBT design based on brittle fracture. Since the Code does not indicate any specific criteria for individual case basis requirements concerning smaller allowable flaw sizes, the logical approach, which is being taken here, is to use NDI to ensure, with a high degree of reliability, that no flaws exist in the CPBT that are larger than a specified highly detectable size, $a_{\mathrm{DET}}$. A factor of safety can then be applied based on the difference between the detectable size, $a_{D E T}$, and the critical flaw size as determined by LEFM (see Fig. 9).

Based on the quarter-t assumption, ASME Code, Section XI, requires straight beam ultrasonic (UT) examination with $100 \%$ coverage from at least one surface. The acceptance criterion is a complete loss of back reflection in a circular area with a diameter equal to $76.2 \mathrm{~mm}(3 \mathrm{in}$.) or onehalf of the plate thickness, whichever is larger. Section III of the Code covering fabrication requires extensive radiography, and any linear flaws so detected greater than $2 \%$ of the wall are unacceptable under code requirements. ${ }^{11}$ WRC $175^{21}$ states, "It is not safe to assume that no defects larger than the code allowable ( $2 \%$ of wall) flaw will ever occur, but it does seem reasonable to assume that with the combination of examinations . . . there is a very low probability that a defect larger than about four times the code allowable will escape detection. The postulated defect is about 10 times the area of even that conservative value." At the time that WRC 175 was written, no attempts to assign numerical values to low probabilities were generally made, but it is now possible to make specific numerical estimates for low probabilities. ${ }^{11}$ The main purpose of this section on integrity and NDE is to establish a basis for determining the highly detectable flaw size, $a_{\mathrm{DET}}$, for ANS CPBT inspection. Emphasis is required here; $a_{\mathrm{DET}}$ must represent the largest size flaw that could be missed by examination requirements. We are not generally concerned with a system's ability to detect a myriad of minute flaws. Records of inspection findings are generally only useful as indirect input to the ultimate goal of establishing what flaws may have been missed during inspection.

Requirements for NDI and NDE of in-service reactor pressure vessels are entering a new phase. The ASME Code was developed based on the safe-life philosophy in which the expected life of the pressure vessel was established by tests using a predetermined safety factor. In the safe-life philosophy, NDI and NDE are required only when components are discovered which may cause failure of the vessel within its safe-life. Because the safe-life philosophy accepts that many vessels and components will be scrapped long before their useful life is exhausted, it is inherently inefficient as a means of life management. The logical alternative, often referred to as damage tolerance, is utilized extensively in the aircraft industry, where it has been applied safely and efficiently. ${ }^{33} \mathrm{NDI}$ and NDE play central roles in damage tolerance design where safety is assured by repeated inspections based on the assumption that NDI can reliably detect potentially serious defects before they reach a critical size. Predetermined safety levels can be maintained through interval inspection of critical components. Even though ISIs of the CPBT will not be conducted, this report proposes the use of preservice inspections as a means of ensuring safe operation of the CPBT in the ANS reactor.

Although a review of state-of-the-art UT testing capability with regard to the detection, location and sizing of flaws in pressurized water reactor vessels has recently been conducted, ${ }^{34}$ the flaw detection capabilities discussed refer to the detection of underclad flaws (cladding generally consists of an $\sim 6.5-\mathrm{mm}$-thick layer of stainless steel or Inconel). A recent EPRI evaluation of an advanced ultrasonic system ${ }^{35}$ indicated a flaw detection reliability of $90 \%$ probability of detection (POD) with 
$90 \%$ confidence for underclad flaws from 3 to $6 \mathrm{~mm}$ deep. Unfortunately, the EPRI results are of very little practical use for evaluation of the ANS CPBT since the critical flaws being evaluated are surface flaws; cladding is not required or specified for the ANS project. Fortunately, much of the NDI work that has been conducted in the space and aircraft industries ${ }^{33,36}$ has been concerned with the detection of surface flaws; inspection capabilities from these industries can be utilized to approximate current NDI capabilities for detection of surface flaws in the CPBT.

Determination of the POD for flaws is of paramount importance for the use of NDI results. The POD method of presenting NDI process information has become the industry standard method for NDI process data presentation. ${ }^{35}$ The POD model is essential because it enables an estimation of the number and size of flaws that could be missed in an inspection. These potentially missed flaws can be assigned a size distribution and included in the integrity analysis along with the found flaws. POD models are expressed as a functions of the essential flaw parameters such as size, shape, location, and orientation. NDI data, sampling methods, and statistical analysis can be utilized to develop the POD as a continuous function in terms of flaw size, as is shown schematically in Fig. 12. Different stateof-the-art methodologies can be utilized to estimate saturation level (the maximum POD as a function of flaw size) and the dependency on flaw size. Basic POD models are generally expressed as: ${ }^{37}$

$$
\operatorname{POD}(x)=A\left[1-e^{-b(x-x)}\right] \text { for } x \geq x_{0}
$$

and

$$
\operatorname{POD}(x)=0 \text { for } x<x_{0} \text {, }
$$

where

$\operatorname{POD}(x)=$ the probability of detecting a flaw with size between $x$ and $x+d x$,

$A=$ the saturation level, that is, the maximum POD,

$\mathbf{b}=$ a parameter in the argument of the exponential,

$x_{0}=$ the threshold of detection.

This POD model includes only one flaw parameter, the flaw size. More complicated models can be constructed to include other parameters, but the simple flaw size model expressed as Eq. (17) is suggested for simplicity.

Most statistical POD models assume that the detection process can be characterized by a binomial distribution where "success" (detection) has a probability of POD and "failure" (nondetection) is characterized by the probability 1 - POD. The POD can then be estimated by examining flawed specimens and counting the number of successes in a given number of attempts. The POD is usually assigned at a lower confidence level of 90 or $95 \% .^{37}$ The confidence in the POD estimate is the probability that the true POD (if it could be measured in a very large number of trials) is actually higher than this particular value. As an example, a POD of 0.90 with a $95 \%$ confidence means that there is a $95 \%$ chance that the true POD is 0.90 or greater. Confidence increases with increasing sample size. All of the methods of inspection that will be utilized for evaluation of the CPBT should be experimentally verified to have a predetermined POD through a number of trials prior to use on ANS components. Expressions based on Eq. (17) can be developed for each inspection technique as they pertain to the CPBT utilizing the results of experimental trials.

Since the POD must be high to give high confidence that no critical flaws will be missed, a relatively simple method of increasing the POD is to combine several independent techniques; the 


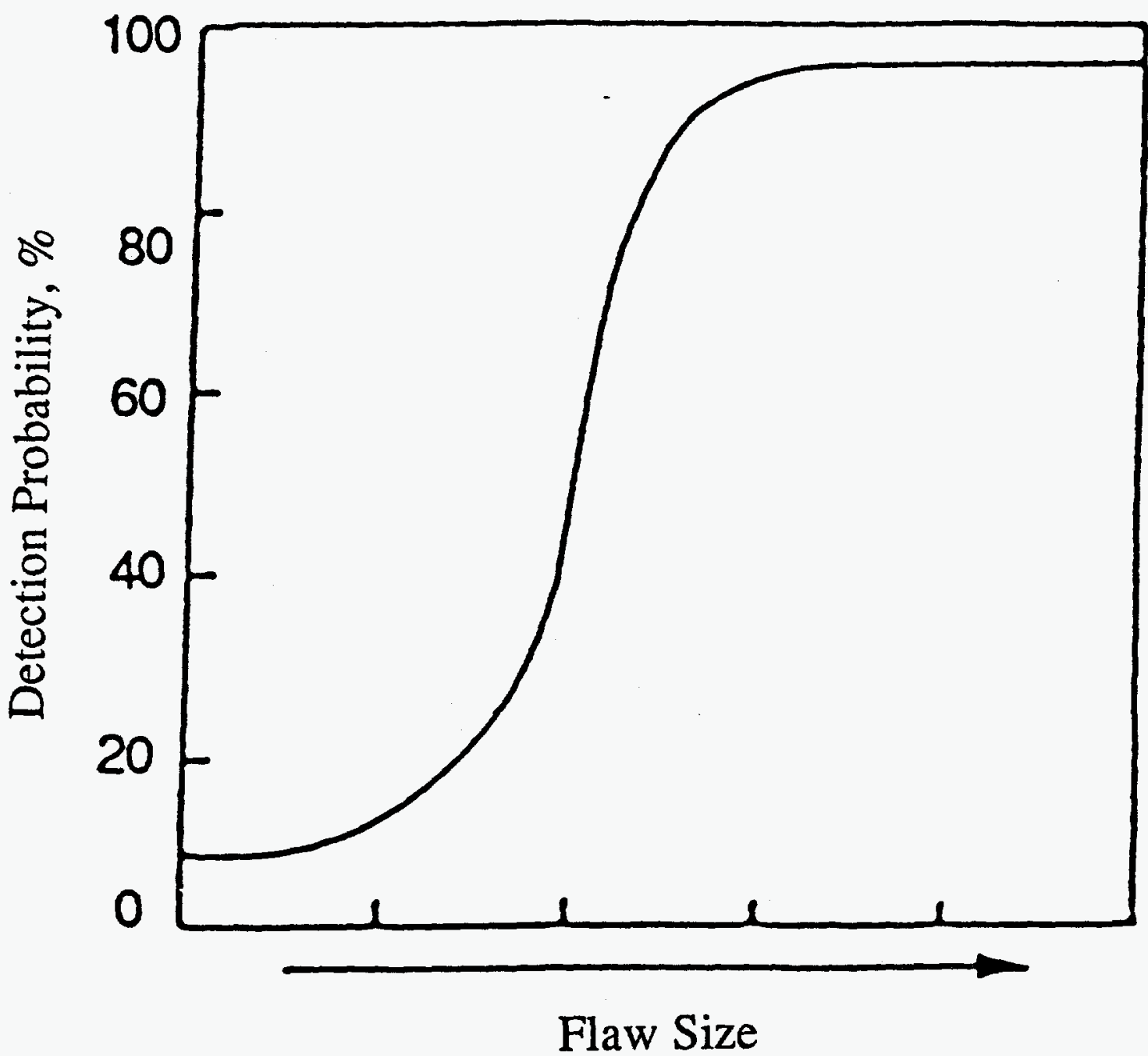

Fig. 12. Typical probability of detection (POD) curve. Source: W. D. Rummel, "Assessment and Demonstration of the Capabilities of NDI Processes, Equipment and Personnel," AGARD Conference Proceedings No. 462, Impact of Emerging NDE-NDI Methods of Aircraft Design, Manufacture and Maintenance, AGARD-CP-462, October 1989. 
composite POD for a combination of independent NDE techniques is higher than the POD for any one technique. Simply combining independent techniques results in a composite POD of

$$
\mathrm{POD}_{\text {Composite }}=1-\left(1-\mathrm{POD}_{1}\right)\left(1-\mathrm{POD}_{2}\right) \ldots\left(1-\mathrm{POD}_{\mathrm{n}}\right) \text {, }
$$

where $\mathrm{POD}_{1}, \mathrm{POD}_{2} \ldots \mathrm{POD}_{\mathrm{n}}$ are the PODs of the individual techniques. Two techniques are said to be independent if the outcome of an inspection by one of the techniques is not influenced in any way by the outcome of the other. ${ }^{37}$ Generally, eddy current, dye penetrant, radiography and ultrasonics can be considered independent since they rely on different phenomena to detect flaws.

Unfortunately, the likelihood of false calls increases when a combination of independent procedures is applied. A possible method of obtaining both high POD levels and low false call rates is to employ the "2-out-of-3" concept. In 2-out-of-3, three techniques are combined, and a detection is declared only if 2 or more channels register an indication. The probability of detection $\mathbf{P O D}_{2 / 3}$ is given by

$$
\mathrm{POD}_{2 / 3}=\mathbf{P}_{1} \mathbf{P}_{2}+\mathbf{P}_{1} \mathbf{P}_{3}+\mathbf{P}_{2} \mathbf{P}_{3}-2 \mathbf{P}_{1} \mathbf{P}_{2} \mathbf{P}_{3}
$$

To illustrate the technique, inspection results for the inner surface region of the Yankee reactor pressure vessel (RPV) ${ }^{37}$ by three independent techniques will be outlined. The RPV was inspected by

1. full-V ultrasonic angle beam examination (VPATH),

2. multimode ultrasonic examination (SLIC), and

3. eddy current examination (EDDY).

A summary of the expected inspection capabilities, based on expert opinion, are listed in Table 3. The following conservative assumptions were made in developing the POD model: ${ }^{.36}$

- It was assumed that POD does not saturate at 1.0 but at 0.95 to allow for unforeseen equipment and human errors that would preclude POD reaching 1.0.

- It was assumed that the flaw depth given for POD $=1.0$ actually corresponds to a POD that is $90 \%$ of saturation level.

- It was assumed that the flaw depth for a POD of $50 \%$ is difficult to estimate, and thus no credit was given to that estimate.

Parameters A, b, and $x_{0}$ in Eq. (17) were then determined for each method and are presented in Table 4. Combining the three independent techniques results in a composite POD where [with substitution into Eq. (18)]

$$
\operatorname{POD}_{\text {COM }}(x)=1-\left[1-P_{\text {EDDY }}(x)\right]\left[1-P_{\text {VPATH }}(x)\right]\left[1-P_{\text {SLI }}(x)\right] \text {. }
$$

PODs for the individual techniques and the POD for their combination are illustrated in Fig. 13 (Ref. 37). The combination POD is 0.987 for a flaw size of $4 \mathrm{~mm}$. Table 5 presents the results for the detection of flaws that are in the size interval from $1.5 \mathrm{~mm}$ to infinity. An expression in the form of Eq. (17) was developed for the Yankee RPV ${ }^{37}$ where 
Table 3. Summary of interview results with inspection experts to develop POD models for ISI of the Yankee RPV

\begin{tabular}{|c|c|c|c|}
\hline Method & EDDY & VPATH & SLIC \\
\hline I1. Minimum detectable flaw size & $\begin{array}{c}1.27 \mathrm{~mm} \\
(0.05 \mathrm{in} .)\end{array}$ & $\begin{array}{l}0.762 \mathrm{~mm} \\
(0.03 \mathrm{in} .)\end{array}$ & $\begin{array}{l}0.762 \mathrm{~mm} \\
(0.03 \mathrm{in} .)\end{array}$ \\
\hline 12. Flaw depth for $P O D=1.0$ & $\begin{array}{l}6.36 \mathrm{~mm} \\
(0.25 \mathrm{in} .)\end{array}$ & $\begin{array}{l}5.08 \mathrm{~mm} \\
(0.20 \mathrm{in.})\end{array}$ & $\begin{array}{l}4.572 \mathrm{~mm} \\
(0.18 \mathrm{in} .)\end{array}$ \\
\hline 13. Flaw depth for $P O D=0.5$ & $\begin{array}{l}3.175 \mathrm{~mm} \\
(0.125 \mathrm{in} .)\end{array}$ & $\begin{array}{l}3.81 \mathrm{~mm} \\
(0.150 \mathrm{in} .)\end{array}$ & $\begin{array}{l}1.524 \mathrm{~mm} \\
(0.060 \mathrm{in} .)\end{array}$ \\
\hline $\begin{array}{r}\text { I4. POD for flaw depth }=6.35 \\
(0.25 \text { in. })\end{array}$ & $\begin{array}{c}1.0 \\
(1.0)\end{array}$ & $\begin{array}{l}1.0 \\
(1.0)\end{array}$ & $\begin{array}{c}1.0 \\
(1.0)\end{array}$ \\
\hline
\end{tabular}

Source: V. Dimitrijevic et al., "White Paper on Use of Nondestructive Examination Data for Improved Reactor Pressure Vessel Integrity," presented at the ASME Task Group on NDE for Plant Operating Criteria, Nov. 30, 1992.

$$
\operatorname{POD}_{\text {COM }}(x)=0.999875\left[1-\mathrm{e}^{-32.89(x-0.03)}\right]
$$

A similar POD expression would be developed for flaws in the CPBT based on the applicable inspection techniques and their individual PODs.

An extensive test program was conducted by the National Aeronautics and Space Administration (NASA) ${ }^{38}$ to characterize the capabilities of various production NDI processes. Rummel, Grover, and Cooper $^{39}$ developed design requirements for the NASA space shuttle program utilizing inspection results from a total of 328 cracks that were grown in 118 specimens, with flaw lengths ranging from 0.3 to $18 \mathrm{~mm}$. Specimens were inspected by production X-radiography, ultrasonics, eddy current, liquid penetrant, and holographic interferometry procedures in the as-machined, after etching, and after proof-test conditions. The results were used to establish estimated NDI capabilities for crack detection within the NASA Space Shuttle program; NDI capabilities based on the NASA data were plotted as a function of flaw size and aspect ratio and are presented in Fig. 14. Figure 14 outlines the detection capabilities of the current NDI techniques for detecting part-through surface flaws. Note that the best levels of detection were obtained by eddy current, penetrant, ultrasonics, and 20-mil X-ray respectively. The resulting POD curves are shown in Fig. 15. An approximation of the POD capability for the CPBT was developed based on these curves. Estimates of the 95\% confidence POD capabilities of the four NDI methods used in the NASA Space Shuttle program are presented in Table 6. If the " 1 out of 3 " concept were applied to the detection of 0.5-mm-deep, 3-mm-long cracks utilizing the three best NDI techniques, the composite probability of detection for the CPBT would be given by

$$
\begin{aligned}
& \text { POD }_{\text {COMPOSTrE }}=1-\left(1-\text { POD }_{\text {PENET }}\right)\left(1-\text { POD }_{\text {ULTRA }}\left(1-\text { POD }_{\text {EDDY }}\right)\right. \\
& \text { POD }_{\text {COMPOSTRE }}=1-(1-0.85)(1-0.90)(1-0.95)=0.99925
\end{aligned}
$$

Similarly, if the " 2 out of 3 " methodology were adopted to address the problem of false calls, the same set of techniques would give a two out of three POD of 
Table 4. POD parameters developed for Yankee RPV examination

\begin{tabular}{lccc}
\hline \multicolumn{1}{c}{ Method } & EDDY & VPATH & SLIC \\
\hline A, saturation level & 0.95 & 0.95 & \\
& $(0.95)$ & $(0.95)$ & 0.95 \\
& & & $(0.95)$ \\
x $_{\text {o threshold of detection }}$ & $1.27 \mathrm{~mm}$ & $0.762 \mathrm{~mm}$ & $0.762 \mathrm{~mm}$ \\
& $(0.05 \mathrm{in})$. & $(0.03 \mathrm{in})$. & $(0.03 \mathrm{in})$. \\
b, exponential parameter & $0.45315 / \mathrm{mm}$ & $0.53307 / \mathrm{mm}$ & $0.60394 / \mathrm{mm}$ \\
& $(11.51 / \mathrm{in})$. & $(13.54 / \mathrm{in})$. & $(15.34 / \mathrm{in})$. \\
\hline
\end{tabular}

Source: V. Dimitrijevic et al., "White Paper on Use of Nondestructive Examination Data for Improved Reactor Pressure Vessel Integrity," presented at the ASME Task Group on NDE for Plant Operating Criteria, Nov. 30, 1992.

$$
\begin{gathered}
\mathrm{POD}_{2 / 3}=\mathrm{P}_{1} \mathrm{P}_{2}+\mathrm{P}_{1} \mathrm{P}_{3}+\mathrm{P}_{2} \mathrm{P}_{3}-2 \mathrm{P}_{1} \mathrm{P}_{2} \mathrm{P}_{3} \\
\mathrm{POD}_{2 / 3}=(0.85)(0.90)+(0.85)(0.95)+(0.90)(0.95)-2(0.85)(0.90)(0.95) \\
\mathrm{POD}_{2 / 3}=0.974
\end{gathered}
$$

Thus, it appears that a 0.5 -mm-deep, 3-mm-long flaw can be reliably detected by the currently available methods of inspection. Figure 16 presents a plot of composite POD vs crack length for both the 1-out-of-3 method and the 2-out-of-3 method applied to the $95 \%$ confidence POD values of the individual inspection techniques. Similarly, based on the results of the space shuttle data, a plot of design limits was developed for the CPBT, which is presented as Fig. 17. Note that Fig. 17 suggests that a 0.5 -mm-deep, 3-mm-long crack should be reliably detectable by standard NDE techniques. 


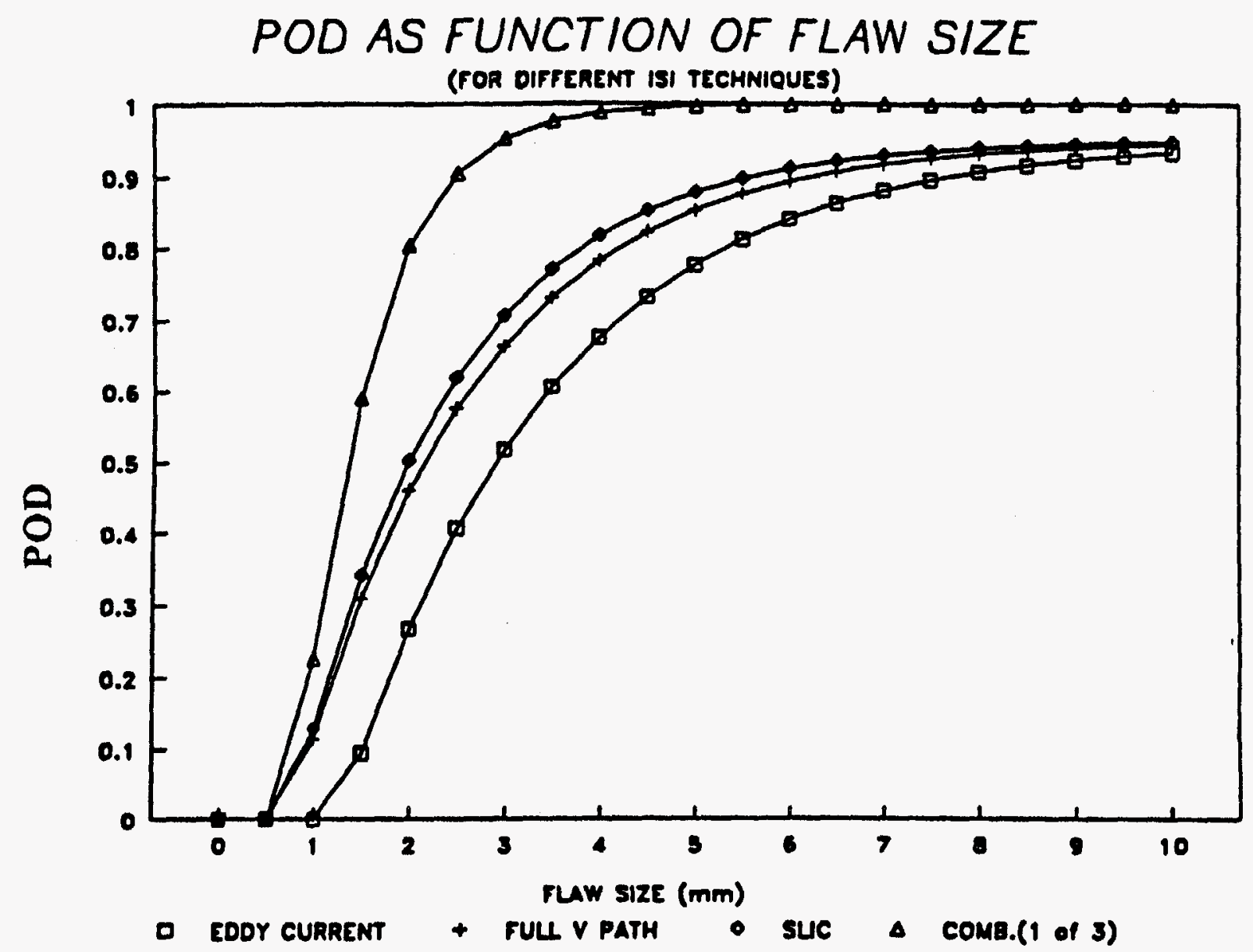

Fig. 13. Individual POD curves developed through application of expert judgment and a composite POD based on assumed independence. Reprinted with permission from V. Dimitrijevic et al., "White Paper on Use of Nondestructive Examination Data for Improved Reactor Pressure Vessel Integrity," presented at the ASME Task Group on NDE for Plant Operating Criteria, Nov. $30,1992$. 
Table 5. Average POD for combination of three techniques

\begin{tabular}{ccccc}
\hline Method & $\mathrm{POD}_{\mathrm{EDDY}}$ & $\mathrm{POD}_{\mathrm{VPATH}}$ & $\mathrm{POD}_{\text {SLIC }}$ & POD $_{\text {COMB }}$ \\
\hline $\begin{array}{c}\text { Flaw size in range } \\
{[0.0 \rightarrow \text { Infinity] }}\end{array}$ & 0.41 & 0.50 & 0.52 & 0.66 \\
$\begin{array}{c}\text { Flaw size in range } \\
{[1.5 \mathrm{~mm} \rightarrow \text { Infinity] }}\end{array}$ & 0.61 & 0.72 & 0.75 & 0.93 \\
\hline
\end{tabular}

Source: V. Dimitrijevic et al., "White Paper on Use of Nondestructive Examination Data for Improved Reactor Pressure Vessel Integrity," presented at the ASME Task Group on NDE for Plant Operating Criteria, Nov. 30, 1992.

Application of eddy current inspection should enable reliable detection of cracks that are only $0.35 \mathrm{~mm}$ deep by $2.5 \mathrm{~mm}$ long based on the space shuttle results. ${ }^{39}$

Fracture control technology was applied to the B-1 aircraft program, ${ }^{36}$ and requirements for quantification of NDI processes were rigorously applied to those structural components whose failure could cause loss of the aircraft. Surface flaws that were $3.175 \mathrm{~mm}$ deep and $6.35 \mathrm{~mm}$ long were imposed as initial design constraints because it was felt that flaws of this size could be readily detected by state-of-the-art production inspection processes. Statistical sampling methods were applied, and demonstration to a $95 \%$ confidence level was required by repetitive inspections.

Much less conservatively, the fracture control philosophy developed for the United States Air Force (USAF) turbine engine and airframe components recommends an initial flaw depth assumption of $0.75 \mathrm{~mm}$. ${ }^{40}$ This design recommendation is based on the initial flaw size that can be readily detected with fluorescent penetrant inspection where "These flaw sizes are intended to represent the maximum size of damage that can be present in a critical location after manufacture and/or inspection. The specification of these flaw sizes is based on the demonstrated flaw detection capability of the nondestructive inspection (NDI) method." The USAF report ${ }^{* 0}$ also asserts that the assumed initial flaw size that is appropriate for various NDI methods is $0.75-\mathrm{mm}$ surface length where the NDI method is fluorescent penetrant inspection and $0.25-\mathrm{mm}$ surface length where the NDI method is eddy current or ultrasonic inspection. Cowie ${ }^{40}$ also asserts that eddy current inspection has been shown to reliably detect surface flaws having depths of only $0.13 \mathrm{~mm}$. Thus, even the space shuttle estimates of NDI capabilities are conservative as compared to those published by the USAF. The actual NDI capabilities for the CPBT will have to be determined prior to the deployment of the ANS reactor. It is suggested here that a preliminary study be conducted to develop POD curves for application of the eddy current, liquid penetrant, and ultrasonic techniques to the CPBT.

The region of the CPBT that is adjacent to the core is considered to be the most susceptible to brittle failure because of both the high stress state in this region and the maximum irradiation effects near the cores. Higher ultrasonic recording sensitivity could be required in this region. The U.S. Nuclear Regulatory Commission (USNRC) issued a regulatory guide ${ }^{37}$ which recognized the potential safety significance of flaws that could be located in the inner $25 \%$ of the vessel wall thickness. The ad hoc committee recommended recording indications in this region at $20 \%$ derived air concentration (DAC), a level 2.5 times more sensitive than that used for the remaining $75 \%$ of the vessel wall thickness. A similar approach could be employed to ensure integrity of the CPBT in the near-core region. 


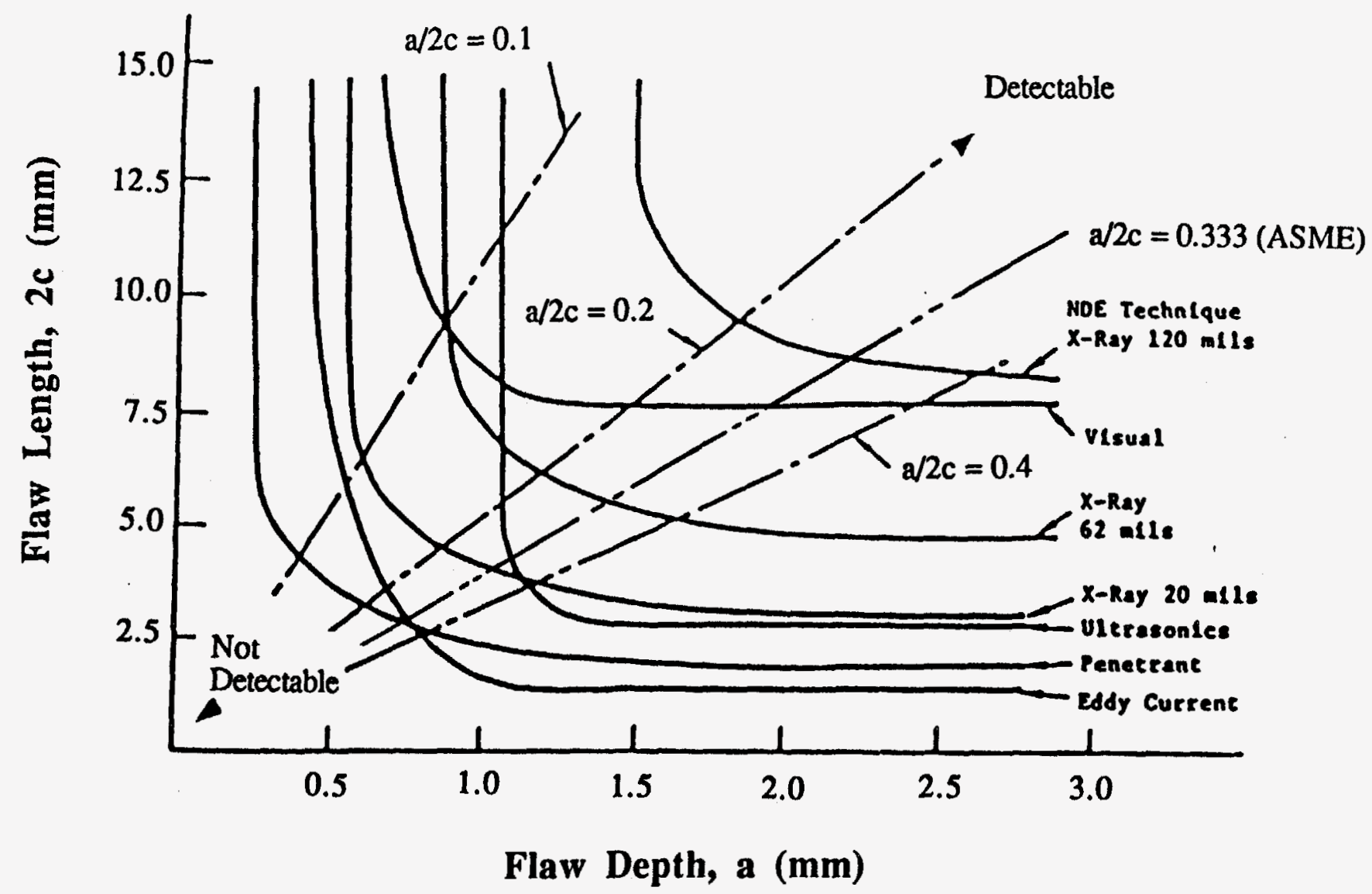

Fig. 14. Estimated NDI capabilities for crack detection. Source: W. D. Rummel, "Assessment and Demonstration of the Capabilities of NDI Processes, Equipment and Personnel," AGARD Conference Proceedings No. 462, Impact of Emerging NDE-NDI Methods of Aircraft Design, Manufacture and Maintenance, AGARD-CP-462, October 1989. 


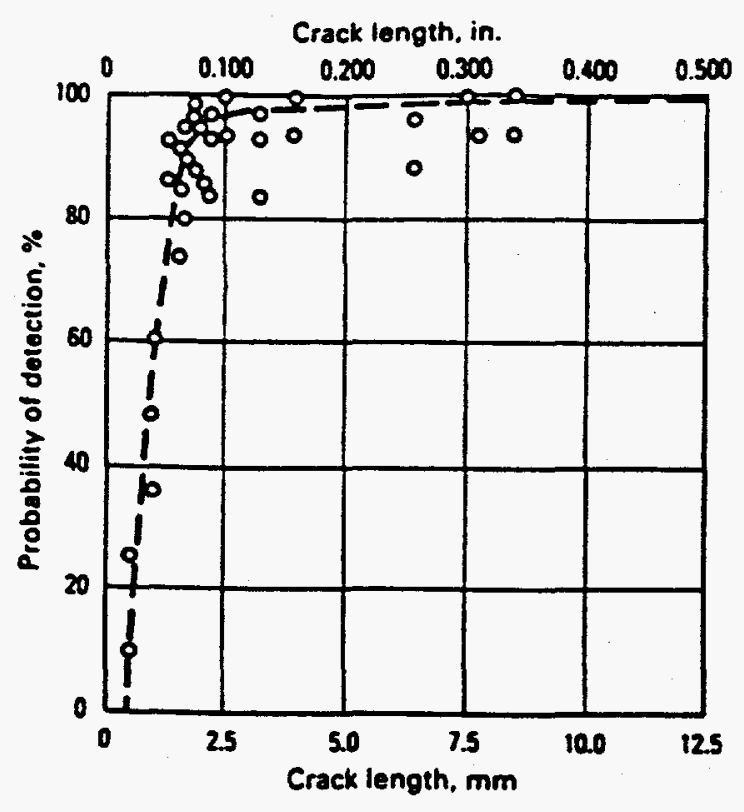

(a) Penetrant Inspection

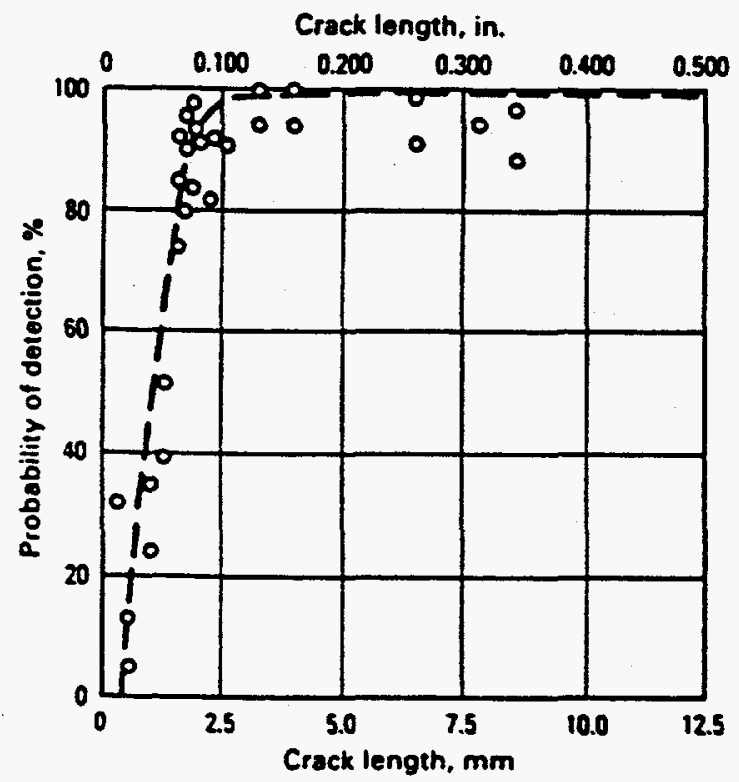

(c) Eddy Current Inspection

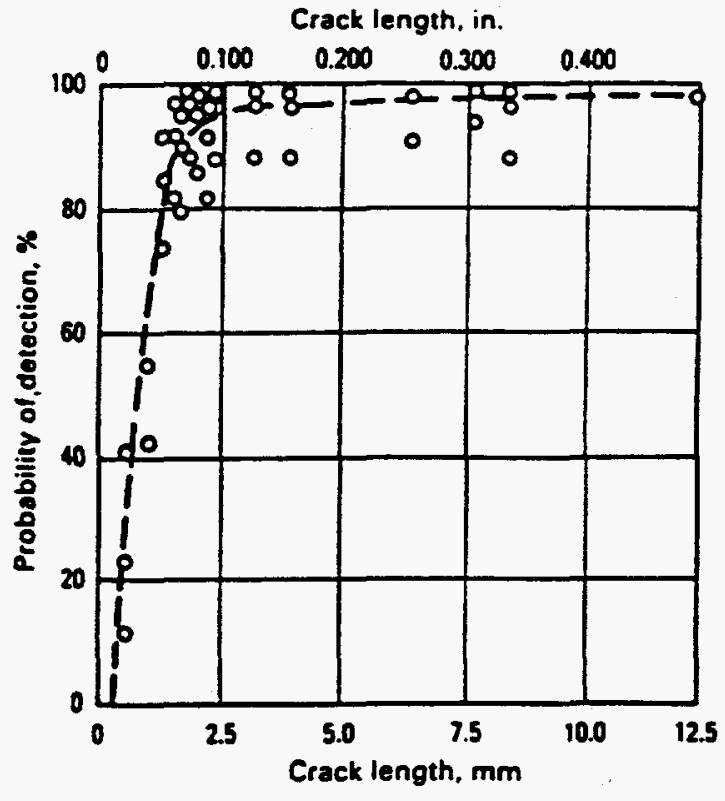

(b) Ultrasonic Inspection

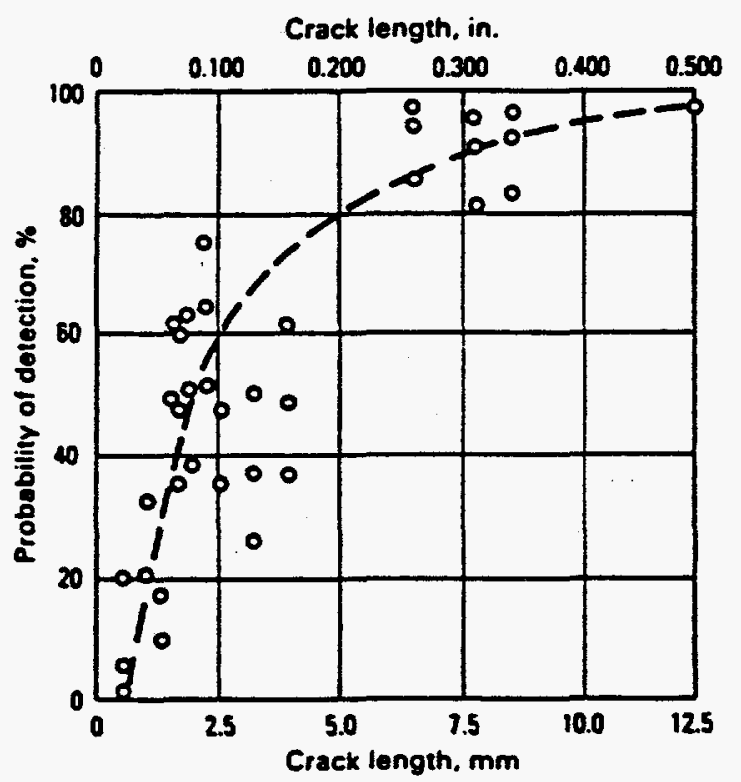

(d) Radiographic (X-Ray) Inspection

Fig. 15. POD plots of four NDE methods based on a single set of test specimens. Reprinted with permission from W. D. Rummel, L. H. Grover, and T. D. Cooper, "Applications of NDE Reliability to Systems," Metals Handbook on Nondestructive Testing and Quality Control, Vol. 17, American Society of Metals, 1989. 
Table 6. Estimates of the POD (CI, 95\%) capabilities of various inspection methods based on the NASA Space Shuttle study

\begin{tabular}{lrrrrr}
\hline \multirow{2}{*}{ NDI method } & \multicolumn{5}{c}{ Crack length, 2c } \\
\cline { 2 - 6 } & $1 \mathrm{~mm}$ & $2 \mathrm{~mm}$ & $3 \mathrm{~mm}$ & $4 \mathrm{~mm}$ & $5 \mathrm{~mm}$ \\
\hline Penetrant inspection & 0.25 & 0.85 & 0.85 & 0.90 & 0.92 \\
Ultrasonic inspection & 0.25 & 0.80 & 0.90 & 0.92 & 0.93 \\
Eddy current inspection & 0.25 & 0.80 & 0.95 & 0.95 & 0.95 \\
X-ray inspection & 0.15 & 0.35 & 0.35 & 0.40 & 0.75 \\
\hline
\end{tabular}

\section{EFFECT OF FATIGUE ON CRACK GROWTH IN THE CPBT}

Fatigue failure of nuclear components is addressed in Section III of the ASME Code by requiring that cyclic strain be evaluated at all strain concentration points. Elastic theory is generally utilized, and strain is assumed to be linearly proportional to stress. In fatigue design, the ASME Code requires that a fatigue design S-N (i.e., stress vs number of cycles to failure) be satisfied at all strain concentration locations using a linear cumulative damage theory. All of the anticipated cyclic loadings must be identified in the certified design specification for both normal and upset loading conditions. No procedure is explicitly documented in the ASME Code to account for the crack growth stage that follows fatigue crack initiation and precedes failure in an actual component. ${ }^{41}$ The cyclic loading spectrum for the CPBT has not yet been determined, but each CPBT is expected to be in service for only 6 months to 1 year because of the degradation of 6061-T6 upon exposure to nuclear irradiation. The aim of the CPBT fatigue analysis is to assess potential crack growth due to cyclic loading. The traditional approach to fatigue, which has been applied in Section III of the ASME Code, is the S-N method where cumulative damage expressions are applied to empirically derived S-N curves. Yahrs developed a set of fatigue design curves for 6061-T6 aluminum based on published S-N data from the literature ${ }^{42-46}$ along with the conservative approach recommended by the ASME Code. The combined 6061-T6 aluminum S-N data for fully reversed loading are presented as Fig. 18. Test temperature ranged from room temperature to $149^{\circ} \mathrm{C}$, and the low-cycle data $(<1000$ cycles) were taken from axial strain controlled tests. Yahr ${ }^{8}$ developed an expression for the S-N data utilizing the ASME Code expression

$$
S=\frac{E}{4 \sqrt{N}} \ln \left[\frac{100}{100-A}\right]+B
$$

where

$\mathrm{E}=$ elastic modulus,

$\mathbf{N}=$ the number of cycles to failure,

$S=$ strain amplitude $\times$ elastic modulus,

$A$ and $B=$ empirical constants. 


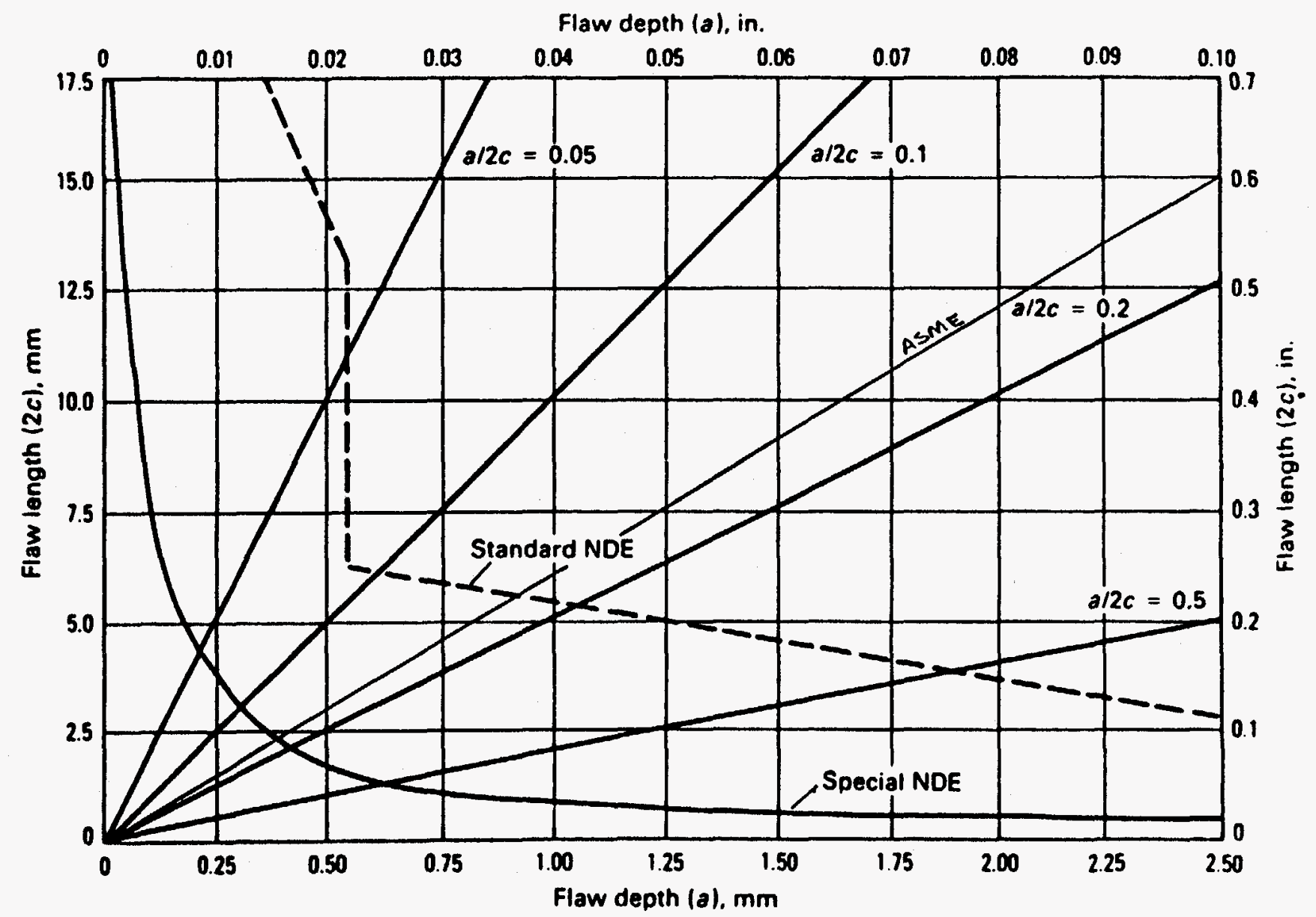

Fig. 16. NDE design limits based on NASA inspection results. Reprinted with permission from W. D. Rummel, L. H. Grover, and T. D. Cooper, "Applications of NDE Reliability to Systems," Metals Handbook on Nondestructive Testing and Quality Control, Vol. 17, American Society of Metals, 1989. 


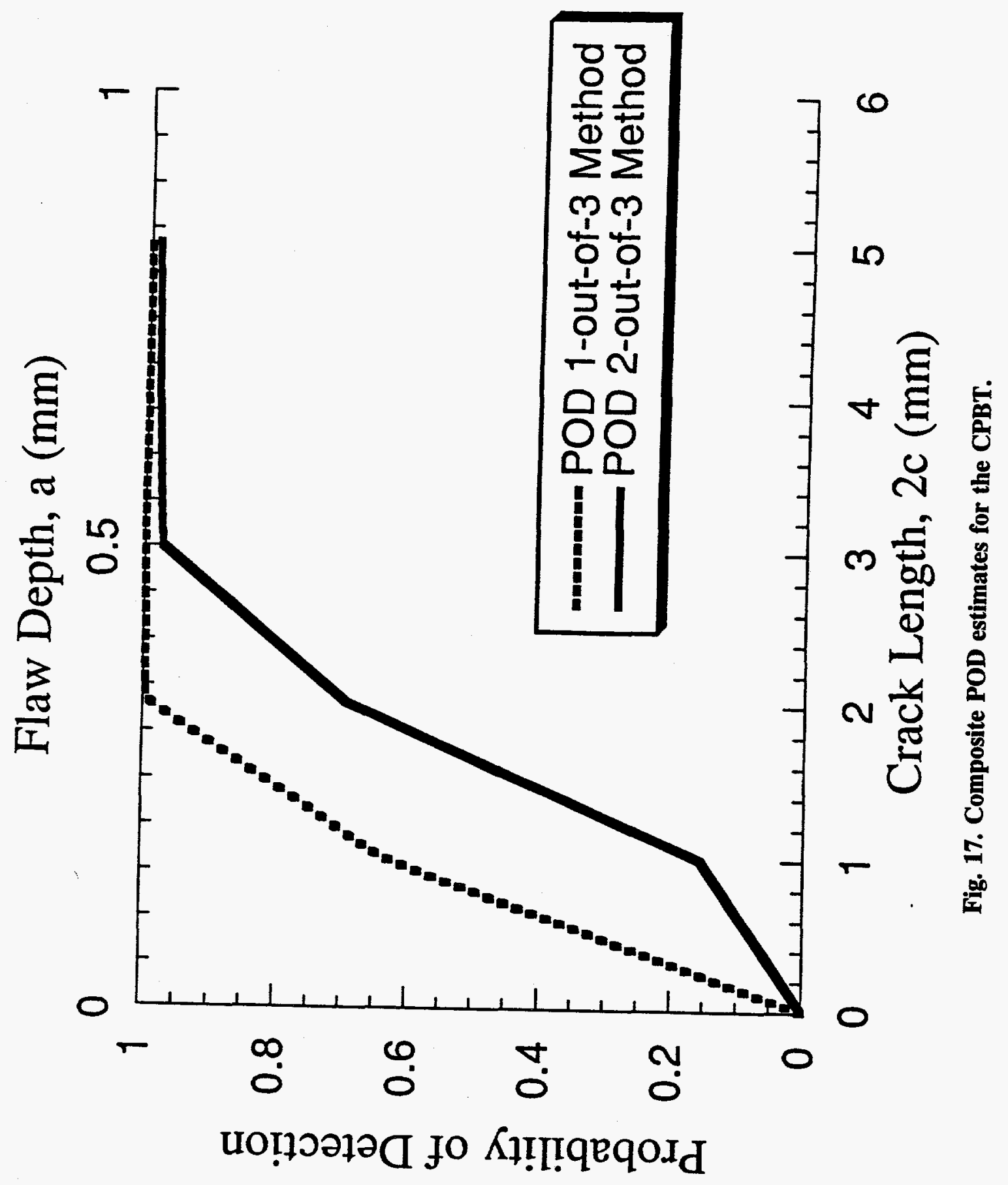




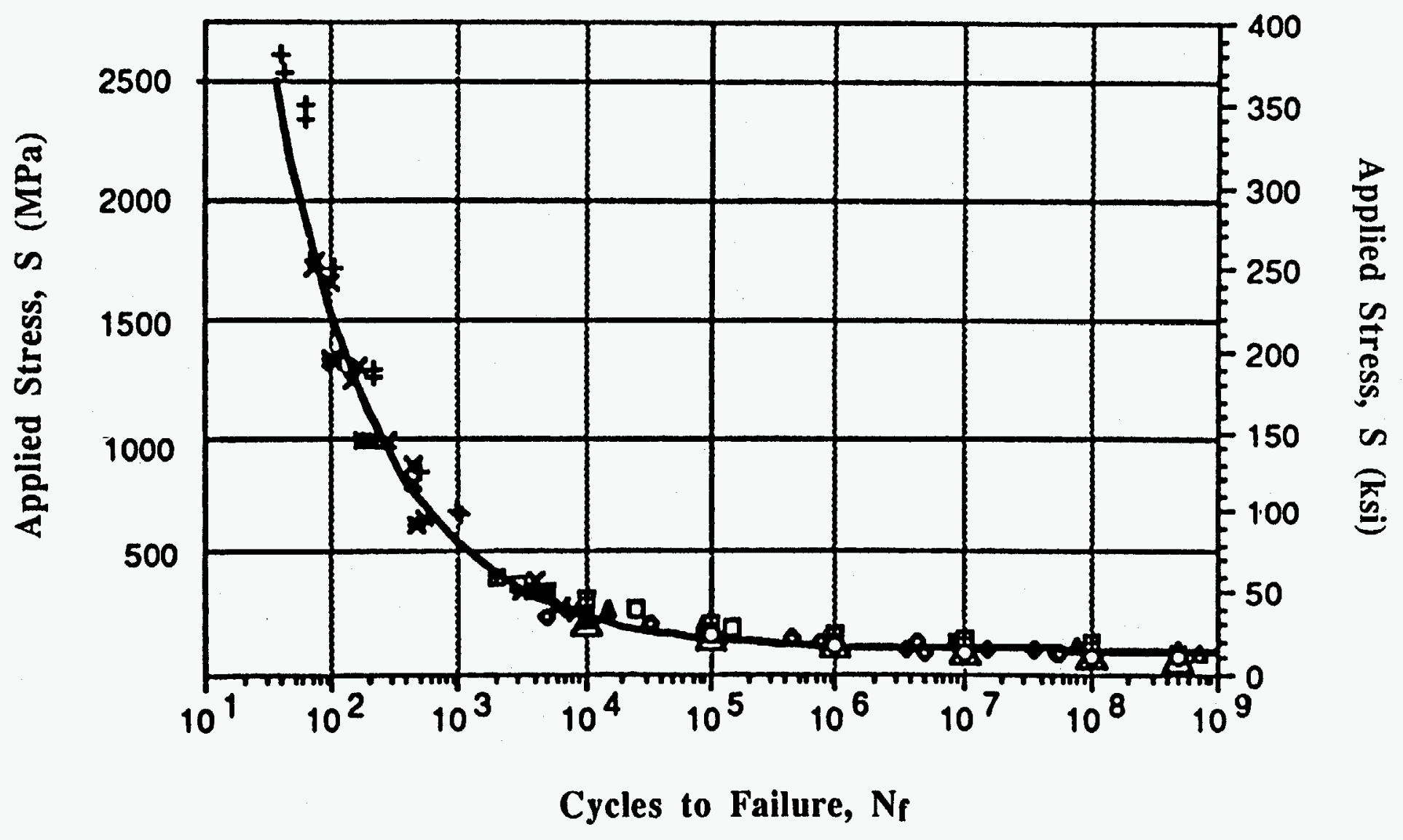

Fig. 18. Fit to fully reversed 6061-T6 aluminum fatigue data. Source: G. T. Yahr, "Fatigue Design Curves for 6061-T6 Aluminum," Codes and Standards in a Global Environment, James E. Staffiera, ed., PVP-Vol. 259, ASME, pp. 43-49, 1993. 
Using a value of $68,950 \mathrm{MPa}$ for the elastic modulus, taking $A$ as the percentage reduction in area during a tensile test, and letting $B$ equal the pseudoendurance limit," Yahr ${ }^{8}$ found that

$$
S=\frac{14479}{\sqrt{\mathrm{N}}}+96.5 \mathrm{MPa}
$$

for unirradiated 6061-T6 aluminum. This curve, from test data based on fully reversed loading, is shown in Fig. 18. Applying a factor of 2 on stress or a factor 20 on the number of cycles to failure (ASME Code) to adjust for the conversion of modified polished bar specimen data, the design curve for fully reversed loading of 6061-T6 aluminum shown in Fig. 19 was developed.

In the case of non-fully reversed loading, the effect of mean stress must be taken into account. Figure 20 (Ref. 47) illustrates the effect of mean stress on alternating fatigue strength of aluminum alloys. Note that most of the data fall between the straight and curved lines. The straight line is the modified Goodman line where

$$
S_{f}^{\prime}=S_{f}\left[1-\frac{S_{m}}{S_{u}}\right],
$$

and the curved line is the Gerber parabola where

$$
S_{f}^{\prime}=S_{f}\left[1-\left(\frac{S_{m}}{S_{u}}\right)^{2}\right],
$$

where

$S_{\mathrm{f}}^{\prime}=$ fatigue strength in the presence of mean stress,

$S_{f}=$ fatigue strength under fully reversed cycling,

$S_{\mathrm{m}}=$ mean stress,

$S_{u}=$ ultimate strength.

Yahr $^{8}$ applied the Gerber equation to the 6061-T6 data with Su $=290 \mathrm{MPa}$ and reduced the applied stress by a factor of 2 and the number of cycles to failure by a factor of 20 to obtain the design curve that accounts for mean stress effects, as is shown in Fig. 21. This curve serves as the overall fatigue design curve and can be used with cumulative damage theory to predict the life of a component.

The first cumulative damage theory, which is presented as the linear damage theory in the ASME Code, was developed by Palmgren and Miner. ${ }^{43}$ By definition of the S-N curve, operation at a constant stress amplitude $S_{1}$ will produce complete damage, or failure, in $N_{1}$ cycles. Operation at $S_{1}$ for $n_{1}$ cycles smaller than $N_{1}$ will produce a fractional amount of damage, $D_{1}$. Operation over a spectrum of different stress levels results in a damage fraction $D_{i}$ for each of the different stress levels

\footnotetext{
Aluminum does not generally exhibit a true endurance limit, but the expression for S-N provided a good fit to the data.
} 


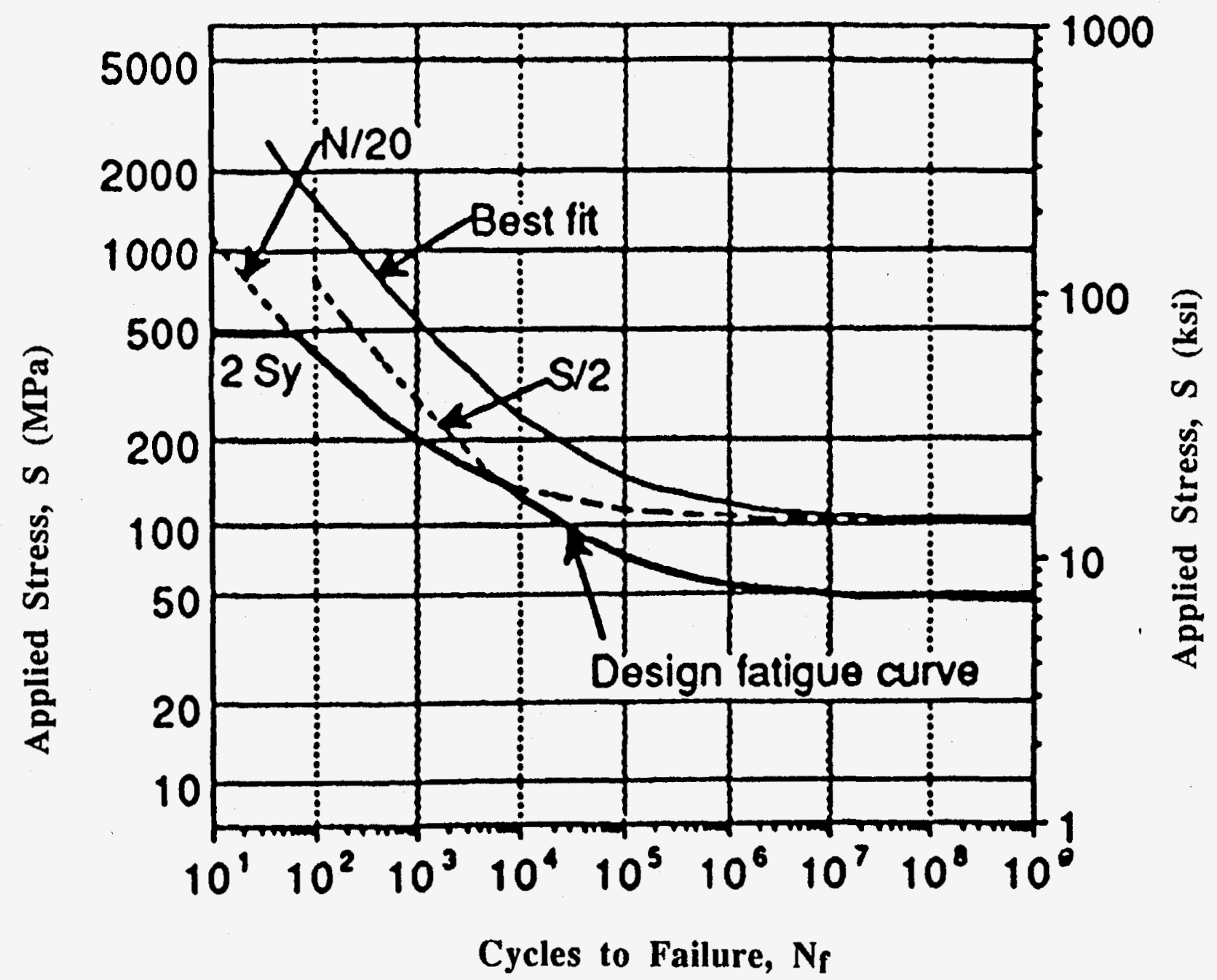

Fig. 19. Fatigue design curve constructed by reduction of the best fit data curve by a factor of 2 on stress and a factor of 20 on number of cycles to failure. Source: G. T. Yahr, "Fatigue Design Curves for 6061-T6 Aluminum," Codes and Standards in a Global Environment, James E. Staffiera, ed., PVP-Vol. 259, ASME, pp. 43-49, 1993. 


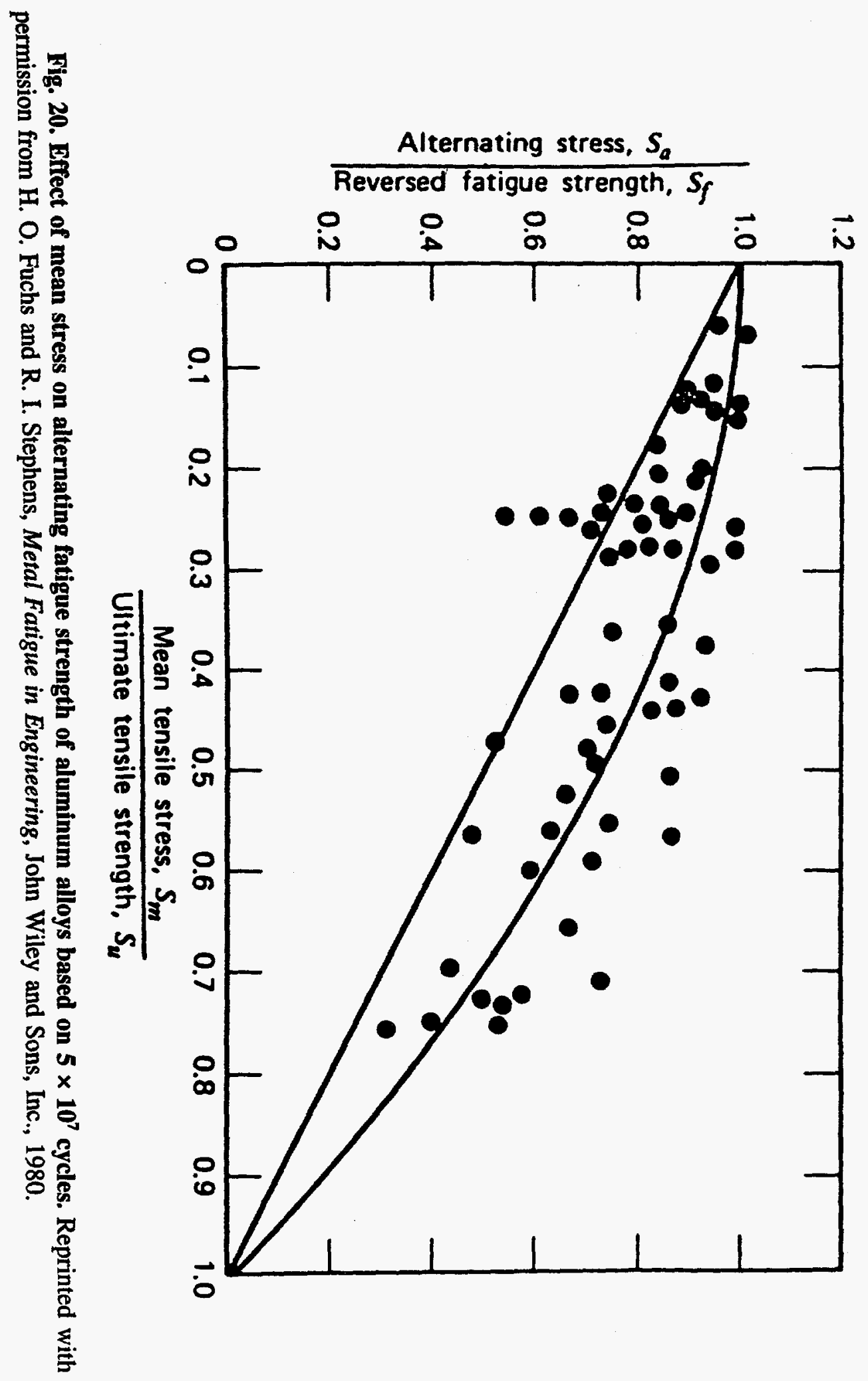




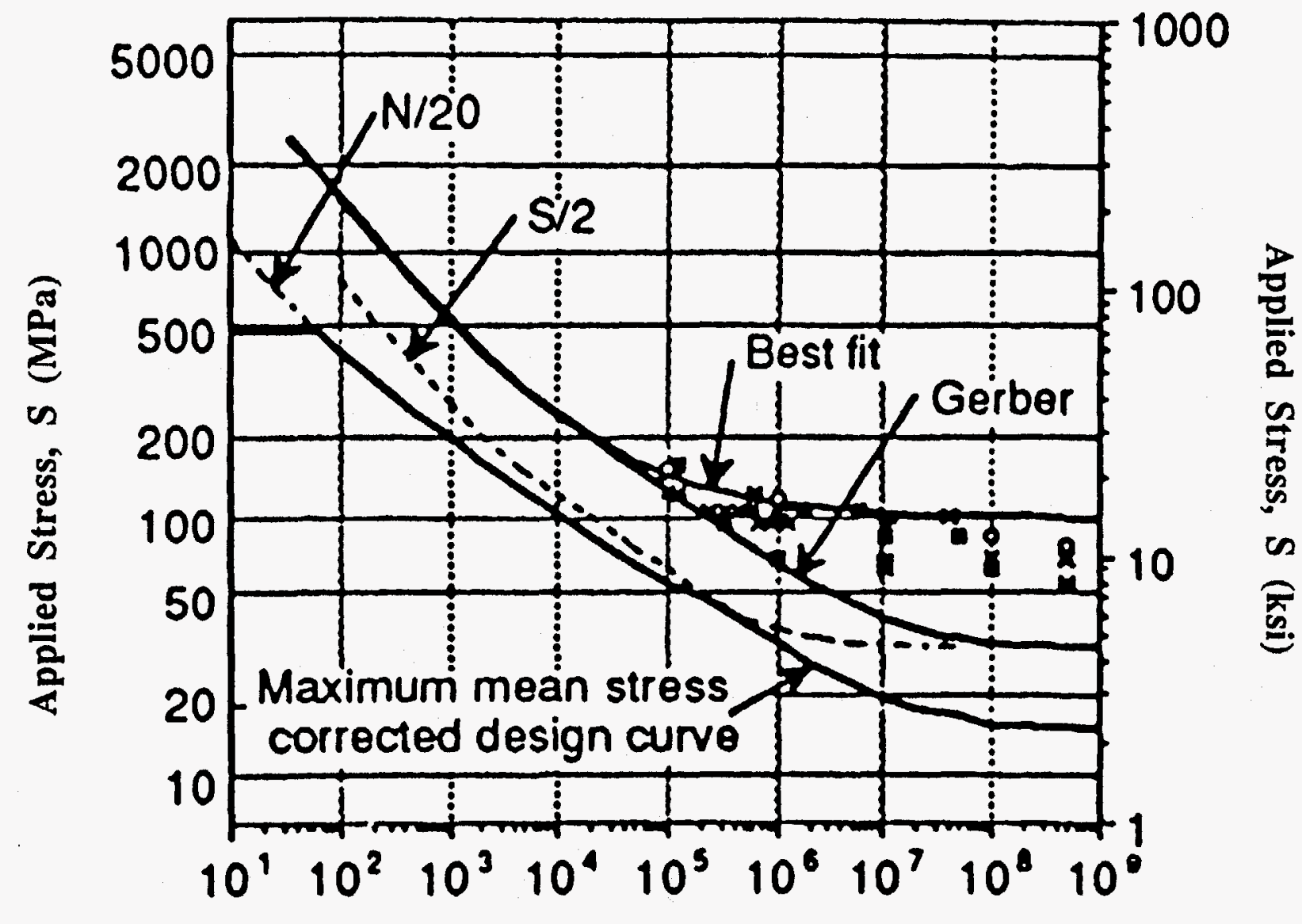

\section{Cycles to Failure, $\mathbf{N}_{\mathbf{f}}$}

Fig. 21. Fatigue design curve adjusted for mean stress effects through the application of the Gerber parabola adjustment. Source: G. T. Yahr, "Fatigue Design Curves for 6061-T6 Aluminum," Codes and Standards in a Global Environment, James E. Staffiera, ed., PVP-Vol. 259, ASME, pp. 43-49, 1993. 
$S_{\mathrm{i}}$ in the spectrum. When these damage fractions sum to unity, failure is predicted. Based on Miner's Law, failure is predicted to occur if

$$
D_{1}+D_{2}+\ldots+D_{i} \geq 1
$$

thus the damage fraction at any stress level $S_{\mathrm{i}}$ is linearly proportional to the ratio of the number of cycles of operation at $S_{i}$ to the total number of cycles required to produce failure at $S_{\mathrm{i}}$. The damage due to $n_{i}$ cycles at stress level $S_{i}$ is given by

$$
D_{i}=\frac{n_{i}}{N_{i}}
$$

Substitution results in the following failure criterion based on high-cycle fatigue:

$$
\frac{n_{1}}{N_{1}}+\frac{n_{2}}{N_{2}}+\ldots+\frac{n_{i}}{N_{i}} \geq 1
$$

Although simple to apply, the major shortcoming of Miner's Law is that the order of application of various stress levels has no influence on the amount of predicted damage; experimental results have shown that the order, or sequence, of the applied cycles can significantly influence fatigue life. A number of damage theories have been proposed to account for sequence effects in fatigue cycling ${ }^{\text {agst }}$ and could be applied to the CPBT, but since the CPBT is only expected to be in service for a relatively short period of time, the conservative Miner's approach as presented in Section III of the ASME Code is suggested as a simple means of accounting for fatigue. The $S-N$ curve shown in Fig. 21 can be utilized with Eq. (28) to estimate conservatively the cumulative damage in the CPBT after 6 months or 1 year of operation. If the summation of damage is less than one, the CPBT should not fail in fatigue during its service life.

The S-N approach purported in Section III of the ASME Code makes no assumption concerning the presence of flaws; Section XI of the ASME Code specifies ISI requirements for nuclear power plant components and contains acceptance standards for the evaluation of detected flaws. Appendix A of Section XI is a simple structural integrity analysis based on LEFM that includes consideration of flaw growth due to fatigue. Jones et al. ${ }^{41}$ summarize the procedure as follows:

1. A flaw is assumed to be of simple elliptical shape and to lie in a plane perpendicular to the line of action of the principal tensile stress.

2. The cyclic stresses at the flaw are calculated for each anticipated normal, upset, and test cycle.

3. The range of stress intensity factor, $\Delta \mathrm{K}$, at the flaw tip due to the first cycle is calculated.

4. The incremental flaw growth, $\Delta \mathrm{a}$, corresponding to one cycle at the stress intensity range, $\Delta \mathrm{K}$, is calculated from a crack growth equation: 


$$
\Delta \mathbf{a}=C(\Delta K)^{\mathbf{m}}
$$

where $\mathrm{C}$ and $\mathrm{m}$ are empirical constants.

5. The crack depth is updated to "a $+\Delta \mathrm{a}$ " and the procedure returns to Step 3 for the second cycle, and then the third, etc., until all of the expected cycles are evaluated and an end-of-life flaw depth is obtained.

Although Eq. (29), often referred to as the Paris Law, is a simplistic representation of fatigue crack growth that ignores retardation effects, which generally follow high-amplitude load cycles, the procedure is conservative and applies the basic concepts of modern fracture-mechanics-based fatigue analysis.

Figure 22 presents a fatigue curve of crack growth rate (da/dN) as a function of $\Delta \mathrm{K}_{\mathrm{l}}$ for $6061-\mathrm{T} 6$ plate aluminum. ${ }^{55} \mathrm{High}$-cycle fatigue crack growth rates can be obtained at consecutive positions along the $\mathrm{da} / \mathrm{dN}$ vs $\Delta \mathrm{K}$ curve. The linear relationship between $\log \mathrm{da} / \mathrm{dN}$ and $\log \Delta \mathrm{K}_{\mathrm{I}}$ can be expressed in terms of the Paris $\mathrm{Law}^{47}$ as

$$
\frac{\mathrm{da}}{\mathrm{dN}}=\mathrm{C}\left(\Delta \mathrm{K}_{\mathrm{l}}\right)^{\mathrm{m}}
$$

or, equivalently,

$$
\log \frac{\mathrm{da}}{\mathrm{dN}}=\log \mathrm{C}+\mathrm{m} \log \Delta \mathrm{K}_{\mathrm{I}}
$$

where $\mathrm{m}$ is the slope of the curve and $\mathrm{C}$ is the coefficient found by extending the straight line to $\Delta \mathrm{K}_{\mathrm{I}}$ $1 \mathrm{MPa} V \mathrm{~m} .{ }^{47}$ Conservative estimates for $\mathrm{C}$ and $\mathrm{m}$ for $6061-\mathrm{T} 6 \mathrm{can}$ be obtained from Fig. 22, where $\mathrm{C}=4 \times 10^{-12}$ and $\mathrm{m}=4.723$. The effect of mean stress is generally accounted for through the stress ratio $\mathrm{R}=\mathrm{K}_{\min } / \mathrm{K}_{\max }$. The most commonly used equation that adjusts the Paris equation for mean stress effects is the Forman equation, ${ }^{56}$

$$
\frac{\mathrm{da}}{\mathrm{dN}}=\frac{\mathrm{C}(\Delta \mathrm{K})^{\mathrm{m}}}{(1-\mathrm{R}) \mathrm{K}_{\mathrm{c}}-\Delta \mathrm{K}}
$$

where $C$ and $m$ are empirical fatigue constants and $K_{c}$ is the applicable fracture toughness for the material and thickness. Similarly, Walker ${ }^{57}$ considers the effect of mean stress on fatigue crack growth through an effective stress intensity range as

$$
\frac{\mathrm{da}}{\mathrm{dN}}=\mathrm{C}\left(\Delta \mathrm{K}_{\mathrm{eff}}\right)^{\mathrm{m}}
$$

where $\Delta \mathrm{K}_{\mathrm{eff}}$ can be expressed as 


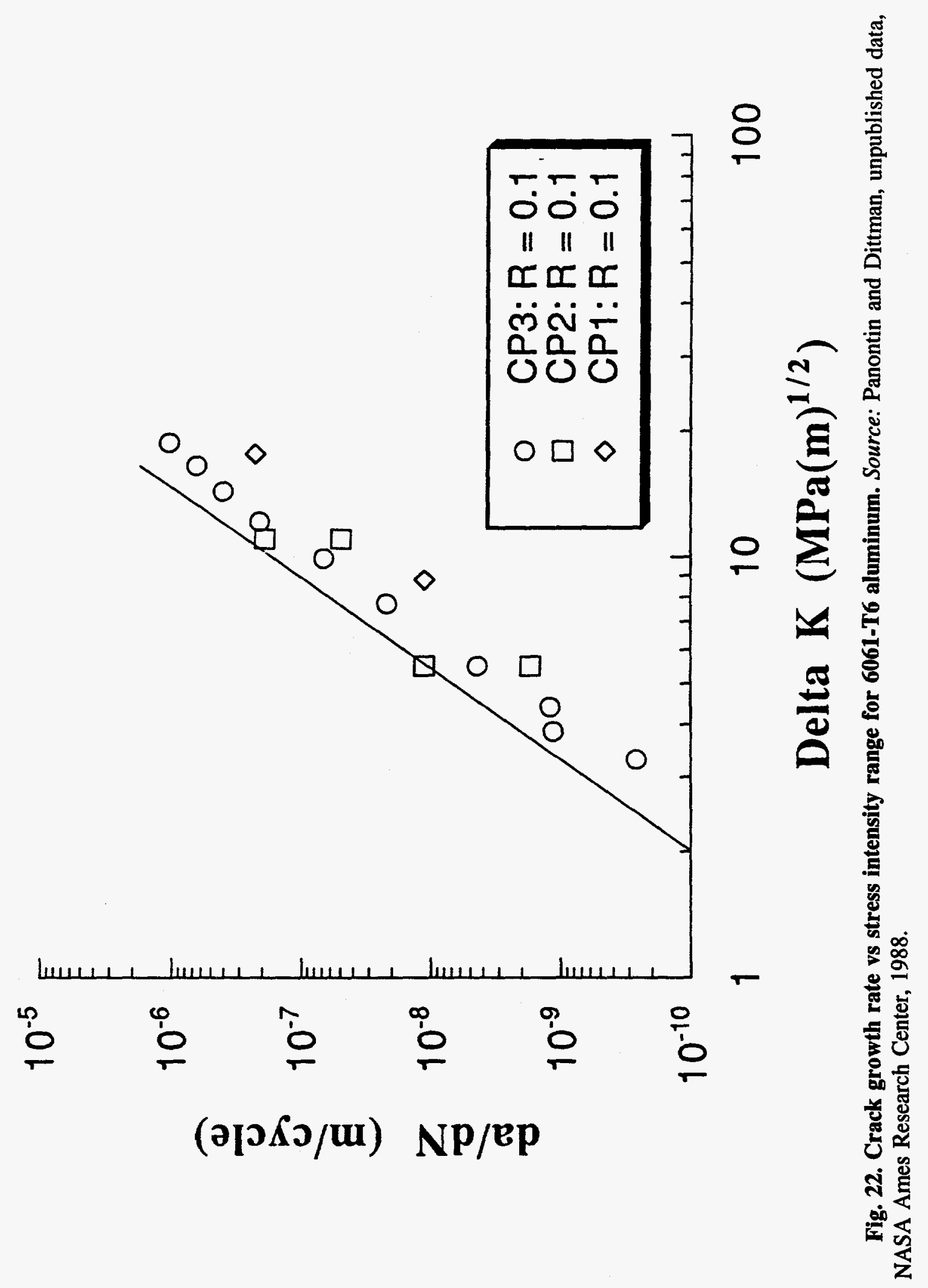




$$
\Delta \mathrm{K}_{\mathrm{eff}}=\frac{\Delta \mathrm{K}}{(1-\mathrm{R})^{\mathrm{n}}}
$$

Residual stresses due to tensile overloads can be taken into account through application of the Wheeler ${ }^{58}$ or Willenborg ${ }^{59}$ models. In the Willenborg model, an effective stress intensity range is computed where the effective compressive stress due to tensile overload is subtracted from the cyclic minimum and maximum applied stress. In terms of the Forman equation, the Willenborg model can be expressed as

$$
\frac{\mathrm{da}}{\mathrm{dN}}=\frac{\mathrm{C}\left(\Delta \mathrm{K}_{\mathrm{eff}}\right)^{\mathrm{m}}}{\left(1-\mathrm{R}_{\mathrm{eff}}\right) \mathrm{K}_{\mathrm{c}}-\Delta \mathrm{K}_{\mathrm{eff}}}
$$

Fatigue crack growth can also be affected by cyclic frequency, temperature, and the environment, but the main effect of concern in the CPBT is the effect of irradiation on crack growth. A da/dN vs $\Delta \mathrm{K}$ curve should be developed for irradiated 6061-T6 and utilized as a conservative approximation for the evaluation of fatigue crack growth in the CPBT. Integration of a crack growth equation to determine crack growth generally involves numerical methods since the flaw depth and flaw shape correction factors in the expressions for $K_{\mathrm{I}}$ are dependent on crack size. $\Delta \mathrm{K}$ as a function of crack depth is directly computed for each cycle. The $\Delta \mathrm{K}$ range is then substituted into the Forman or Walker expression and is integrated to determine the increase in flaw size for a given number of cycles. Once the design loading spectrum for the CPBT is known and a da/dN vs $\Delta K$ curve is available for irradiated 6061-T6 aluminum, the above approach can be applied to approximate the expected crack growth for the flaw size that is assumed to be present after NDI.

\section{ELASTIC-PLASTIC APPROACHES TO FRACTURE ANALYSIS}

Although 6061-T6 aluminum has been shown to exhibit nearly linear elastic behavior in both the unirradiated and irradiated condition, much effort has been put forth in the past $\mathbf{3 0}$ years to develop fracture analysis techniques that are applicable beyond the linear elastic region. If the CPBT for the ANS reactor is constructed with 6061-T6 aluminum, as is currently specified, then the linear elastic analysis developed in this report provides an adequate fracture assessment methodology. If a different material is selected, linear elastic analysis may not suffice. LEFM analysis techniques are essentially based on brittle fracture behavior, and thus LEFM can seriously overestimate the flaw tolerance potential of tough, ductile materials. Fracture analysis in the plastic regime must address a number of complications not present in the elastic case. Inherent nonlinearities in material deformation and large geometrical changes, along with the fact that flaws will propagate in a stable manner prior to final fracture, present difficulties in handling nonbrittle behavior. The key element in the development of an elastic-plastic fracture methodology is probably the development of a crack-tip criterion that is valid in the presence of large-scale plastic deformation. An outline of the elastic-plastic techniques that have been developed recently is provided in this section. The application of any of these methods to a CPBT composed of 6061-T6 should exhibit results very near the solution provided by the linear elastic analysis outlined in this report. 
The four primary extensions of LEFM into the elastic-plastic region are as follows:

1. R-curve analysis,

2. crack-tip opening displacement (CTOD) approach,

3. life assessment diagrams (LADs), and

4. J-integral approach.

An elastic-plastic J-integral analysis was conducted for the CPBT as a check on the LEFM approach developed in this report and is presented in this section.

\section{R-Curve Analysis}

$R$-curves characterize the resistance to fracture of materials during incremental slow stable crack extension and provide a record of fracture toughness development as a crack is driven stably under increasing loads. They are dependent on thickness, temperature, and loading rate. An R-curve is a plot of crack growth resistance (J, G, or $\mathrm{K}$ ) in a material as a function of effective crack extension; as $J, G$, or $\mathbf{K}$ is increased for a given crack situation, the response is an extension of the crack. R-curves can be developed in the linear-elastic realm in terms of stress intensity factor, but most R-curves are developed in terms of $J . J_{R}$ is termed the crack growth resistance and represents the driving force required to produce stable crack growth $(\Delta a)$. R-curves generally consist of a plot of $J_{R} v s \quad \Delta a$; $J_{Q}$ is the value of $J_{R}$ associated with the point of tangency between the applied load line and the $R$-curve, as is illustrated in Fig. 23..$^{\circ}$ The R-curve describes the complete variation of $\mathrm{J}_{\mathrm{Q}}$ with changes in initial crack length, $a_{0}$, and illustrates the changing resistance to fracture with increasing crack length. Crack extension first takes on the form of some minor lengthening due to flow and blunting of the tip until the conditions for tearing develop, whereupon increments of tearing extension, $\Delta \mathrm{a}$, proceed with added increments of $J$. Hence the $J-R$ curve, which is a plot of $J$ vs $\Delta \mathrm{a}$, is a unique plot of a material's crack extension characteristics as loading progresses on a cracked specimen of the material. R-curves are generally used in conjunction with analytical methods, such as LEFM, CTOD, J-analysis or failure assessment diagrams (FADs), to evaluate the integrity of structures.

\section{Crack-Tip Opening Displacement}

Wells ${ }^{61}$ proposed that the fracture behavior in the vicinity of a sharp crack could be characterized by the opening of the notch faces. The quantitative amount of opening as depicted in Fig. 24 has been termed the crack-tip opening displacement (CTOD). CTOD was shown to be analogous to the critical energy release rate, $G_{c}{ }^{61}$ and thus CTOD values have been related to fracture toughness, $K_{\mathrm{rc}}$. Since CTOD can be measured even when significant plastic deformation accompanies crack growth, CTOD can be utilized under conditions of elastic-plastic or fully plastic behavior. ${ }^{20}$

Dugdale $^{62}$ developed the basic expression for CTOD $(\delta)$ as

$$
\delta=\frac{8 \mathrm{a} \sigma_{\mathrm{yz}}}{\pi \mathrm{E}}\left[\frac{1}{2}\left[\frac{\pi \sigma}{2 \sigma_{\mathrm{yz}}}\right]^{2}+\frac{1}{12}\left[\frac{\pi \sigma}{2 \sigma_{\mathrm{yz}}}\right]^{4}+\frac{1}{45}\left(\frac{\pi \sigma}{2 \sigma_{\mathrm{yz}}}\right]^{6}\right]
$$




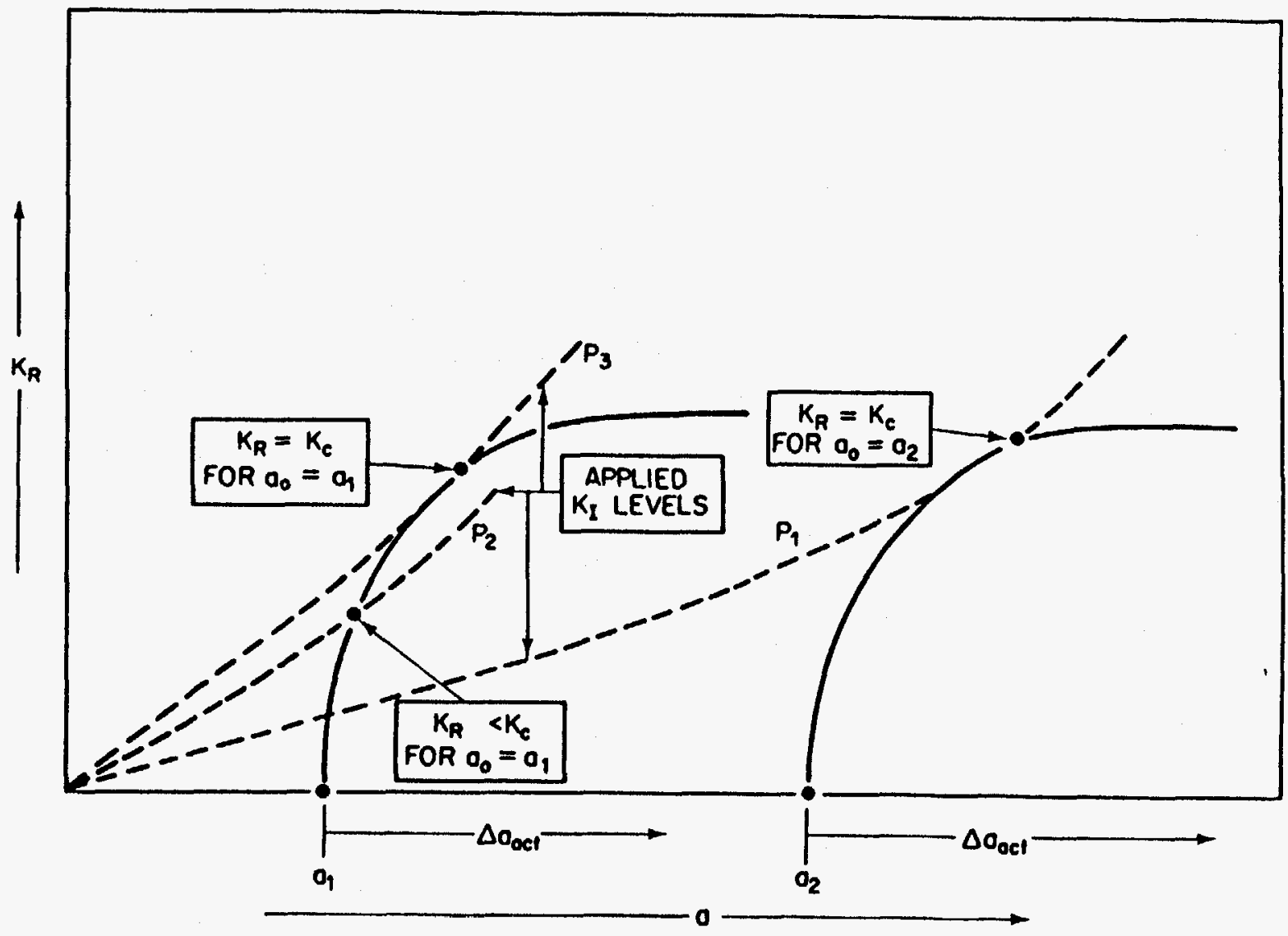

Fig. 23. Basic principle of R-curves for use in determining $K_{c}$ under different conditions of initial crack length $a_{0}$. Reprinted with permission from V. Kumar, M. D. German, and C. F. Shih, An Engineering Approach for Elastic Plastic Fracture Analysis, EPRI Report NP 1931, Electric Power Research Institute, July 1981. 

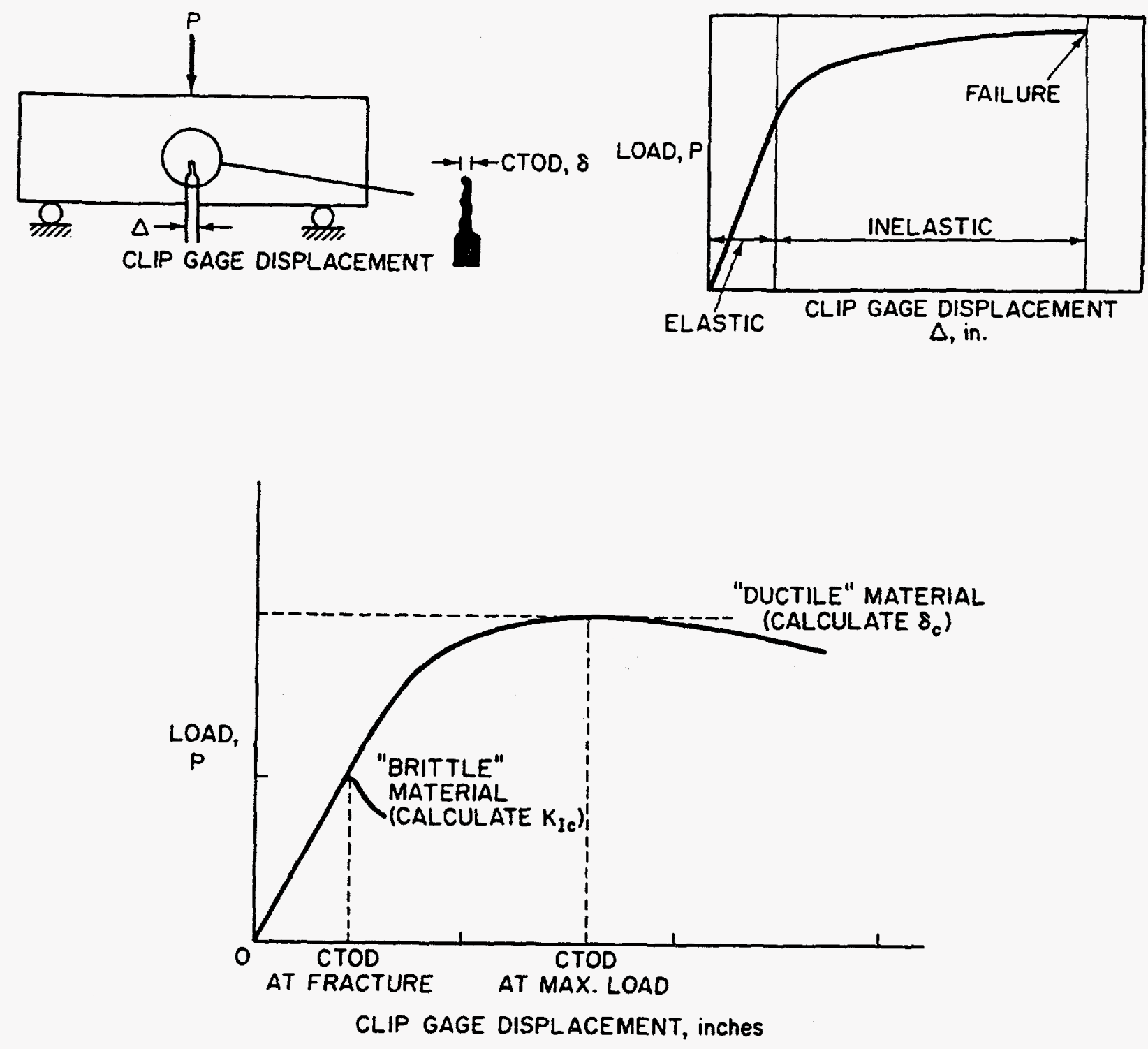

Fig. 24. Relation between $K_{I c}$ and CTOD test behavior; $K_{\mathrm{I}} / C T O D$ test setup and load displacement records from $K_{\mathrm{I}} /$ CTOD tests. Reprinted with permission from J. M. Barsom and $S$. $T$. Rolfe, Fracture and Fatigue Control in Structures: Applications in Fracture Mechanics, Prentice-Hall, Inc., Englewood Cliffs, N.J., 1987. 
where

$$
\begin{aligned}
& \sigma=\text { nominal stress, } \\
& \sigma_{\mathrm{yz}}=\text { yield strength, } \\
& \mathrm{a}=\text { the half crack length, } \\
& \mathrm{E}=\text { elastic modulus. }
\end{aligned}
$$

Under plane stress conditions, CTOD is directly related to the stress intensity factor in the linearelastic region where

$$
\delta=\epsilon_{\mathrm{yz}}\left(\frac{\mathrm{K}_{\mathrm{l}}}{\sigma_{\mathrm{yz}}}\right)^{2}
$$

The onset of crack instability occurs when $\delta$ reaches a critical value $\delta_{Q}$, which is equivalent to $\mathrm{K}_{\mathrm{I}}$ reaching $\mathrm{K}_{\mathrm{Q}}$ in the linear-elastic case. The main advantage of the CTOD approach is that CTOD values can be measured throughout the entire linear-elastic, elastic-plastic and fully plastic, behavior regions, whereas fracture toughness applies only to the linear-elastic region and the early portions of the elastic-plastic region.

\section{Failure Assessment Diagrams}

Structures made from materials with sufficient toughness may not be susceptible to brittle fracture, but they can fail by plastic collapse if they are overloaded. Dowling and Townley and Harrison, Loosemore, and Milne ${ }^{64}$ introduced the concept of two-criteria FADs to describe the interaction between fracture and collapse. The method ensures that the model predicts failure as the applied stress approaches the collapse (or yield) stress. The stress ratio, $S_{r}$, and stress intensity factor ratio, $K_{r}$, are defined $b^{4}$

$$
S_{r}=\frac{\sigma}{\sigma_{c}} \text { and } K_{r}=\frac{K_{1}}{K_{e f f}}
$$

where $\sigma$ is applied stress and $\sigma_{c}$ is collapse stress.

Utilizing an expression for $K_{r}=f\left(S_{r}\right)$, a FAD can be plotted as is shown in Fig. 25. The curve represents the locus of predicted failure points and can be utilized to assess the integrity of a specific part. The stress intensity ratio for the part, $K_{r}$ (part), is equal to $K_{l} / K_{\mathrm{lc}}$. If the applied conditions for the part place it inside the FAD, the part is considered safe.

The R6 approach ${ }^{65}$ refers to a fracture analysis methodology that applies the FAD to real structures. There are three options in the R6 method:

1. When relevant stress-strain data are not available, the lower-bound FAD is defined by

$$
\mathrm{K}_{\mathrm{r}}\left(1-0.14 \mathrm{~L}_{\mathrm{r}}^{2}\right)\left[0.3+0.7 \exp \left(-0.65 \mathrm{~L}_{\mathrm{r}}^{6}\right)\right]
$$

where $\mathrm{L}_{\mathrm{r}}=\sigma_{\mathrm{zef}} / \sigma_{\mathrm{y}}$ and $\sigma_{\mathrm{ref}}$ is the effective net-section stress. 


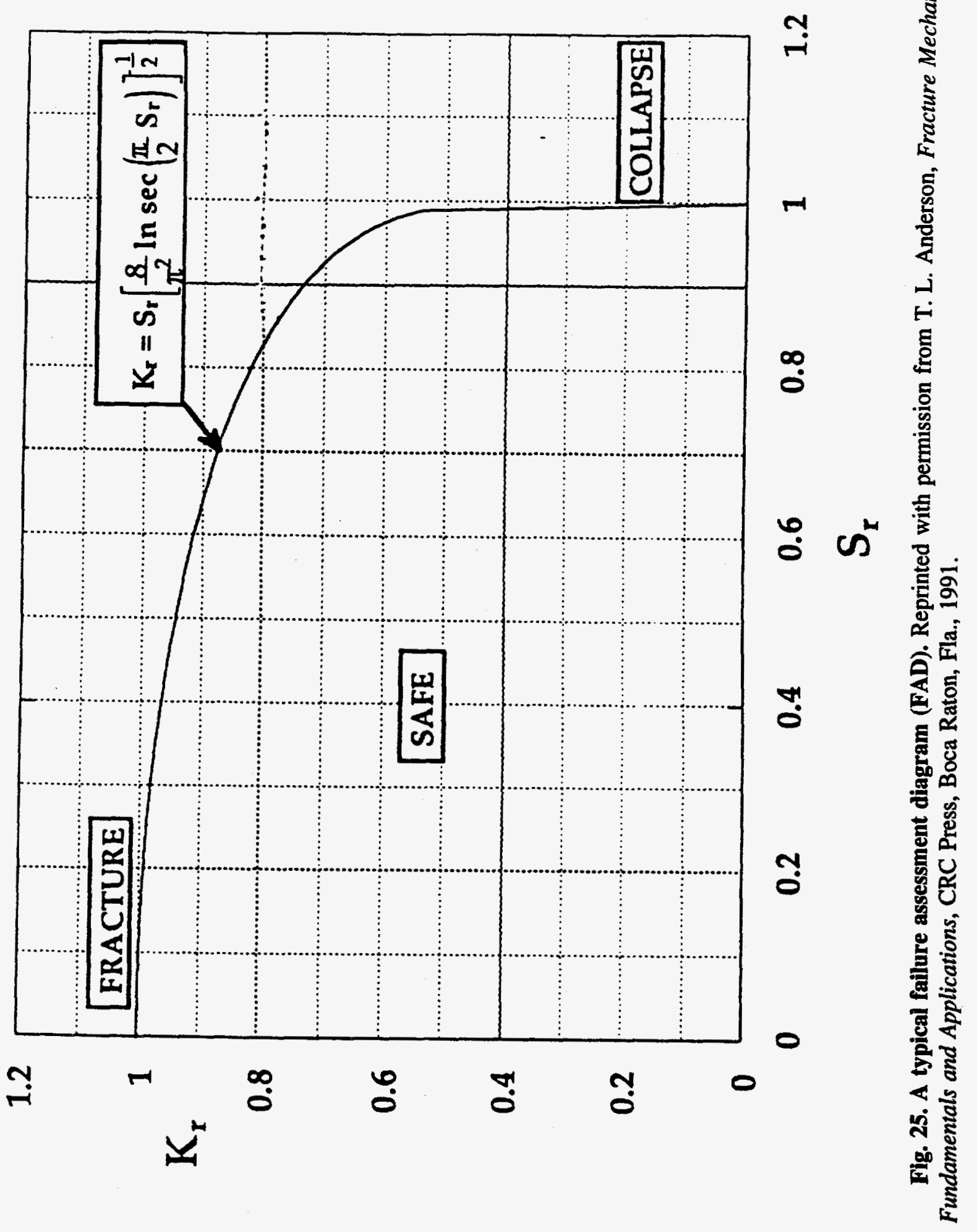


2. If the stress-strain curve for the material is available, then

$$
K_{r}=\frac{E \epsilon_{\text {sef }}}{L_{r} \sigma_{y y}}+\frac{L_{r}^{3} \sigma_{y z}}{2 E \epsilon_{r e f}} .
$$

3. The FAD is inferred from a J-integral solution for the specific structure of interest. The method requires an elastic-plastic finite-element analysis and provides the most accurate, yet very expensive, solution.

\section{J-Integral Approach}

The J-integral method of analysis can be viewed as a direct extension of the methods of LEFM into the elastic-plastic and fully plastic regimes. J represents the intensity parameter for the crack-tip stress field for the elastic-plastic regime as the stress intensity factor represents the intensity of stress for the linear-elastic regime. Furthermore, failure is purported to occur when the value of $J$ is equal to or greater than the critical value of $J$, which is expressed $J_{0}$. Thus a basic failure criterion based on $\mathrm{J}$ can be simply expressed as

$$
\mathrm{J}_{1} \geq \mathrm{J}_{\mathrm{Q}}
$$

The $\mathrm{J}$ failure criterion for the linear-elastic case is identical to the $\mathrm{K}_{\mathrm{Q}}$ failure criterion where $\mathrm{J}_{\mathrm{Q}}$ and $\mathrm{K}_{\mathrm{Q}}$ are directly related, for conditions of plane strain, through ${ }^{20}$

$$
\mathrm{J}_{\mathrm{Q}}=\frac{\left(1-v^{2}\right) \mathrm{K}_{\mathrm{Q}}^{2}}{\mathrm{E}}
$$

The advantage that $\mathrm{J}$ analysis presents is that $\mathrm{J}$ remains valid under conditions of nonlinear elasticplastic fracture while LEFM can be applied only when material response is linear elastic.

The term J refers to the path-independent J-integral that was proposed by Rice $^{66}$ which characterizes the stress-strain field at the tip of a crack by an integration path taken sufficiently far from the crack tip to be analyzed and then substituted for a path close to the crack-tip region. Thus, even when considerable yielding may occur in the vicinity of the crack tip, if the region away from the crack tip can be analyzed, behavior of the crack-tip region can be inferred.

The J-integral is a mathematical expression that involves a line or surface integral that encloses the crack front from one crack surface to the other. The line integral is defined as

$$
J=\oint_{0} W d y-T\left[\frac{\delta \bar{u}}{\delta x}\right] d s
$$


where

$\mathrm{G}=$ any contour surrounding the crack tip,
$\mathrm{W}=$ loading work per unit volume,
$\mathrm{T}=$ the outward normal traction vector at ds along $\mathrm{G}$,
$\mathrm{u}=$ displacement vector at ds,
$\mathrm{ds}=$ arc length along contour $\mathrm{G}$,
$\mathrm{T}\left[\frac{\delta \overline{\mathrm{u}}}{\delta \mathrm{x}}\right] \mathrm{ds}=$ rate of work input from the stress field into the area enclosed by $\mathrm{G}$.

Rice $^{66}$ showed that $\mathrm{J}=0$ for any closed path within a body not crossing the path of a crack. Since the contribution to $\mathrm{J}$ along a crack surface is zero, $\mathrm{J}$ can be obtained from stress analysis using stress and strain results away from the crack tip. In effect, $J$ represents the energy that is available at the crack tip per unit increase in crack area, $\Delta \mathrm{a}$; thus, under elastic conditions, $J$ is equivalent to the energy release rate, $G$.

Direct evaluation of $\mathrm{J}$ using Eq. (43) has proven to be a formidable task for most practical engineering situations. A number of approximation methods for the determination of $J$ have been developed. Finite element analysis can be used but tends to be complex and expensive. Begley and Landes ${ }^{67}$ developed a multispecimen method for determining $\mathrm{J}_{\mathrm{Q}}$. Single-specimen methods have since been developed and incorporated into American Society for Testing and Materials (ASTM) standards. Although this method can only be utilized in the laboratory to measure fracture toughness, these approximations for computing $\mathbf{J}$ assist in the practical application of $\mathbf{J}$.

Two engineering approaches using handbook solutions, graphical methods, and estimation procedures were combined in the present analysis. The first method was originated by Kumar, German, and Shih ${ }^{68}$ and developed by Zahoor ${ }^{69}$ under the sponsorship of EPRI. J solutions for various specimen geometries and pressure vessel elements are presented in handbook form. The second approach, developed by Riccardella, ${ }^{70}$ involves the use of the program pc-CRACK, which was coded for use on personal computers and is relatively easy to use. Both methods incorporate the constants $\alpha$, $\sigma_{o}, \epsilon_{o}$, and $\mathrm{n}$ in the Ramberg-Osgood stress-strain relation, where

$$
\frac{\epsilon}{\epsilon_{0}}=\frac{\sigma}{\sigma_{0}}+\alpha\left[\frac{\sigma}{\sigma_{0}}\right]^{\mathrm{n}}
$$

The Ramberg-Osgood stress-strain law option in pc-CRACK ${ }^{\text {x }}$ was run to determine the constants

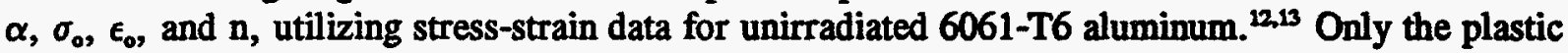
portion of the curve shown in Fig. 4 (Ref. 13) was utilized. The Ramberg-Osgood fit to the 6061-T6 data is excellent. The constants, using a reference value of $\sigma_{0}=230 \mathrm{MPa}$ with $\epsilon_{0}$ computed as

$$
\epsilon_{0}=\frac{\sigma_{0}}{E}=\frac{230}{68300}=0.00337 \frac{\mathrm{m}}{\mathrm{m}},
$$

were found to be

$$
\alpha_{\mathrm{PL}}=0.02898 \text { and } \mathrm{n}_{\mathrm{PL}}=20.598 \text {. }
$$


These values of a and $\mathrm{n}$ were utilized throughout the J-based analysis.

\section{Determination of the Critical Value of $\mathbf{J}, \mathbf{J}_{\mathbf{Q}}$}

Based on Eq. (42), $J_{Q}$ for 6061-T6 aluminum can be estimated from the known $K_{Q}$ value. $K_{Q}$ for irradiated aluminum is not known at the present time. The standard unirradiated value will be used in the following examples, but the actual irradiated values for $\mathrm{K}_{\mathrm{Q}}$ and $\mathrm{J}_{\mathrm{Q}}$ should be used for accurate fracture analysis once they have been determined. $K_{Q}$ for unirradiated $6061-T 6$ is approximately $28 \mathrm{MPa} \sqrt{\mathrm{m}}(25 \mathrm{ksi} \sqrt{ }$ in.); substitution into Eq. (42) gives

$$
J_{Q}=\frac{\left(1-\nu^{2}\right) K_{Q}^{2}}{E}=\frac{\left[1-(0.33)^{2}\right](28)^{2}}{68300}=\left[10.23 \frac{\mathrm{KJ}}{\mathrm{m}^{2}}\right]
$$

Alexander, ${ }^{5}$ at ORNL, experimentally determined the $\mathrm{J}_{0}$ of unirradiated $6061-\mathrm{T} 6$ and found that $J_{Q} \cong 13.5\left(\mathrm{KJ} / \mathrm{m}^{2}\right)$. The $\mathrm{J}_{\mathrm{Q}}$ results from Alexander's tests on irradiated $6061-\mathrm{T} 6$ should be used in the CPBT analysis once they are available.

\section{EPRI Ductile Fracture Handbook Solution}

The EPRI ductile fracture handbook analysis ${ }^{69}$ for an axial part-throughwall internal flaw under conditions of internal pressure is based on the deepest point of the semielliptical surface flaw (see Figs. 6 and 7). The expression for J-integral developed by EPRI is given by

$$
J=(\pi)(\mathrm{t})(\mathrm{f}) \frac{\sigma_{\mathrm{h}}^{2}}{\mathrm{E}^{\prime}}+(\alpha)\left(\sigma_{\mathrm{o}}\right)\left(\epsilon_{\mathrm{o}}\right)(\mathrm{t})\left(\mathrm{H}_{1}\right)\left[\frac{\sigma_{\mathrm{h}}}{\sigma_{0}}\right]^{\mathrm{n}+1}
$$

where

$$
\begin{aligned}
& f=\left[0.25+0.4759 \alpha_{e}+0.1262 \alpha_{e}{ }^{2}\right]^{2}, \\
& F=0.25+0.4759 \alpha+0.1262 \alpha^{2},
\end{aligned}
$$

$\alpha_{c}=\frac{\left[\frac{a}{t}\right]+\left[\frac{F^{2}}{6} \frac{n-1}{n+1}\right] \frac{\left(\sigma_{h} / \sigma_{0}\right)^{2}}{1+B_{0}\left(\sigma_{h} / \sigma_{0}\right)^{2}}}{\left[\frac{a}{c}\right]^{0.58}}$,

$$
\sigma_{\mathrm{h}}=\Delta \mathrm{P} \frac{\left(\mathrm{R}_{0}^{2}+\mathrm{R}_{\mathrm{i}}^{2}\right)}{\left(\mathrm{R}_{0}^{2}-\mathrm{R}_{\mathrm{i}}^{2}\right)}
$$




$$
\begin{aligned}
& X=\frac{a}{t}, \\
& \alpha=\frac{(a / t)}{(a / c)} 0.58, \\
& B_{0}=1.0453\left[\frac{1-\left[\frac{x}{B_{1}}\right]}{1-x}\right] \\
& B_{1}=\sqrt{1+0.1533\left(\frac{c}{t}\right]^{2}} .
\end{aligned}
$$

$\Delta P$ is the difference in pressure between the inner and outer surfaces of the CPBT. $H_{1}$ depends on $a / c, a / t, n$, and $R_{i} / t$; the empirical values of $H_{1}$ have been tabularized (see Table 7). Plane strain crack-tip conditions are conservatively assumed. $R_{0}, R_{\mathfrak{i}}$, and $t$ are the cylinder outer radius, inner radius, and wall thickness, respectively. $E^{\prime}=E /\left(1-\nu^{2}\right)$ for plain strain (may substitute $E$ for $E^{\prime}$ under conditions of plane stress) where $\mathrm{E}$ and $\nu$ are the elastic modulus and Poisson's ratio respectively. $\alpha^{\prime}, \sigma_{0}, \epsilon_{0}$, and $n$ are the Ramberg-Osgood stress-strain constants, where $\epsilon_{0}=\sigma_{\delta} / E{ }^{0}$

Sample Computation 2: Assuming the same conditions as were used in Sample Computation 1, the CPBT wall thickness is $8.5 \mathrm{~mm}$ with $R_{\mathrm{fmor}}=247.0 \mathrm{~mm}$ and $R_{\text {outer }}=255.5 \mathrm{~mm}$. The wall is subjected to a membrane stress of $85.75 \mathrm{MPa}$ and a maximum thermal stress of $34.1 \mathrm{MPa}$ where $\sigma_{\mathrm{Ys}}=230 \mathrm{MPa}$ for $6061-\mathrm{T} 6$ aluminum. What fracture toughness, $\mathrm{J}_{\mathrm{Q}}$, would be required for the irradiated 6061-T6 CPBT to avoid brittle failure if an ASME quarter-thickness axial part-through elliptical flaw is assumed to exist at the inner surface of the CPBT?

Solution: The following parameters are assumed for the purposes of this example: $n=20$ (use $n=7$ for determination of $\mathrm{H}_{1}, \mathrm{n}=7$ is the maximum value tabulated in the EPRI handbook and approximates the condition of a relatively flat $\sigma-\epsilon$ curve), $\alpha^{\prime}=0.00736, \sigma_{0}=230 \mathrm{MPa}$, $\mathrm{E}=68,590 \mathrm{MPa}, \nu=0.33$, and, since the applied stresses are both membrane and thermal, an approximate applied stress based on thermal plus membrane stress is used. Taking the ASME Code safety factor of 2 on membrane stress into account, the hoop stress, $\sigma_{b}$, was set to the following value:

$$
\sigma_{\mathrm{h}}=2 \sigma_{\text {Membraso }}+\sigma_{\text {Thermal }}=2(85.75)+(34.1)=205.6 \mathrm{MPa} \text {. }
$$

Substitution of the computed parameter values into the expressions of Eq. (47) gives:

$$
\begin{gathered}
\alpha=0.473, \mathrm{~F}=0.475, \mathrm{x}=0.25, \mathrm{~B}_{1}=1.042, \mathrm{~B}_{\circ}=1.060, \\
\alpha_{\mathrm{c}}=0.503, \mathrm{f}=0.272, \mathrm{E}^{\prime}=76,972 \mathrm{MPa}, \epsilon_{\mathrm{o}}=0.00299, \\
\mathrm{H}_{1}=2.653 \text { (from Table 7), and }
\end{gathered}
$$


Table 7. Tabulated values of $\mathbf{H}_{1}$ for the EPRI Handbook J Solution $\mathrm{H}_{1}$ for finite length axial part-throughwall flaw

\begin{tabular}{|c|c|c|c|c|c|c|}
\hline \multirow{2}{*}{$a / t$} & \multicolumn{6}{|c|}{$a / 2 c$} \\
\hline & $1 / 3$ & $1 / 4$ & $1 / 6$ & $1 / 10$ & $1 / 20$ & $1 / 40$ \\
\hline 0.100 & 0.856 & 0.925 & 0.954 & 1.028 & 1.218 & 1.440 \\
\hline 0.125 & 1.010 & 1.106 & 1.169 & 1.322 & 1.662 & 2.008 \\
\hline 0.150 & 1.126 & 1.296 & 1.414 & 1.686 & 2.227 & 2.728 \\
\hline 0.200 & 1.386 & 1.672 & 2.050 & 2.620 & 3.720 & 4.626 \\
\hline 0.250 & 1.602 & 2.039 & 2.653 & 3.842 & 5.704 & 7.145 \\
\hline 0.300 & 1.906 & 2.406 & 3.440 & 5.352 & 8.172 & 10.272 \\
\hline 0.325 & 2.079 & 2.691 & 4.023 & 6.446 & 9.942 & 12.510 \\
\hline 0.350 & 2.237 & 2.980 & 4.648 & 7.640 & 11.879 & 14.960 \\
\hline 0.375 & 2.449 & 3.391 & 5.505 & 9.254 & 14.481 & 18.240 \\
\hline 0.400 & 2.714 & 3.907 & 6.584 & 11.283 & 17.750 & 22.370 \\
\hline 0.425 & 3.065 & 4.584 & 7.996 & 13.936 & 22.020 & 27.750 \\
\hline 0.450 & 3.551 & 5.233 & 9.424 & 16.670 & 26.420 & 33.300 \\
\hline 0.475 & 4.071 & 6.734 & 12.485 & 22.360 & 35.550 & 44.800 \\
\hline 0.500 & 5.197 & 9.051 & 17.238 & 31.220 & 49.730 & 62.700 \\
\hline 0.525 & 6.458 & 11.125 & 21.710 & 39.700 & 63.400 & 79.800 \\
\hline 0.550 & 8.958 & 15.927 & 31.780 & 58.590 & 93.700 & 118.000 \\
\hline 0.575 & 11.448 & 20.975 & 42.720 & 79.300 & 126.900 & 159.800 \\
\hline 0.600 & 16.288 & 30.703 & 63.690 & 119.000 & 190.600 & 240.000 \\
\hline 0.625 & 23.267 & 45.047 & 95.000 & 178.500 & 286.000 & 360.000 \\
\hline 0.650 & 32.556 & 64.636 & 138.400 & 261.300 & 419.000 & 527.000 \\
\hline 0.700 & 74.827 & 155.500 & 341.900 & 650.000 & 1043.000 & 1310.000 \\
\hline 0.750 & 206.387 & 446.337 & 1002.600 & 1918.000 & 3074.000 & 3860.000 \\
\hline 0.800 & 738.377 & 1653.025 & 3779.000 & 7257.000 & 11625.000 & 14585.000 \\
\hline
\end{tabular}

Source: Reprinted with permission from P. C. Riccardella, pc-CRACK: Fracture Mechanics Software Version 2.0, Structural Integrity Associates, Inc., San Jose, Calif., 1989.

$$
J_{I}=(4.576+0.047)=4.62 \frac{\mathrm{KJ}}{\mathrm{m}^{2}}
$$

The above J-analysis indicates that for the assumed specifications of a quarter-t flaw under the current design conditions for the CPBT, the critical value of $J$ for safe operation of the CPBT would 
have to be a minimum of $4.62\left(\mathrm{KJ} / \mathrm{m}^{2}\right)$. A comparison to Eq. (46) indicates that the CPBT should be safe with a $1 / 4 \mathrm{t}$ flaw under the assumed conditions.

A comparison of the LEFM solution, K-based, to the elastic-plastic fracture mechanics solutions, $\mathrm{J}$-based, supports the assumption that LEFM analysis is appropriate for the 6061-T6 aluminum. The plastic strain contribution to $J$ is less than $1 \%$ for the conditions analyzed in the present study. For the linear-elastic case, $\mathrm{K}$ is related to $\mathrm{J}$ by the expression ${ }^{71}$

$$
\mathrm{K}_{\mathrm{I}}=\sqrt{\mathrm{J}_{\mathrm{I}} \mathrm{E}^{\prime}}
$$

Substitution of $\mathrm{J}_{\mathrm{I}}$ and $\mathrm{E}^{\prime}$ from Sample Computation 2 gives

$$
\mathrm{K}_{\mathrm{I}}=\sqrt{\mathrm{I}_{\mathrm{I}} \mathrm{E}^{\prime}}=\sqrt{(4.62)(76972)}=18.86 \mathrm{MPa} \sqrt{\mathrm{m}} .
$$

The computed value of $\mathrm{K}_{\mathrm{I}}$ in Sample Computation 1 under a similar set of input conditions (note that in the J-analysis the thermal stresses were treated as membrane stresses) was $16.34 \mathrm{MPa} V \mathrm{~m}$.

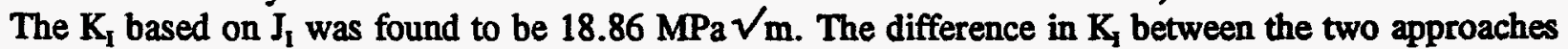
is probably due to the treatment of thermal stress; the plastic portion of the $J$ analysis was shown to be insignificant.

\section{PROBABILISTIC FRACTURE MECHANICS}

Probabilistic analysis methods use fracture mechanics calculational methods similar to those employed in the deterministic approaches except that distributed variables, rather than fixed values, are incorporated into the analyses. The increased need for high performance or very high degrees of reliability has led to an increased interest in probabilistic analysis of structural reliability. ${ }^{2}$ As an example, since fracture toughness data are often widely scattered, it seems inappropriate to view fracture toughness as a single-valued material constant. Factors such as the number, sizes, orientations, and locations of flaws can be treated as probabilistic terms. Even extraordinary events, such as earthquakes, hurricanes, and nuclear accidents, can result in stresses that are significantly higher than were assumed for design purposes. Up to a dozen random variables may be required in a vessel analysis. ${ }^{73}$ Because of complexities and uncertainties, many current fracture analyses are based on probabilistic rather than deterministic models. An initial population of cracks is generally considered to be randomly distributed. These initial cracks can be detected with a certain probability during preservice and possible ISIs. Cracks that escape detection and repair can potentially grow, through fatigue or stress corrosion, and cause failure of the component under consideration. To analyze the fracture potential of a component, a stress history or expected loading spectrum including design transients, earthquakes, and vibrations must be available. ${ }^{34}$ The probability of failure for the CPBT is equal to the probability of a crack growing to the corresponding critical size prior to detection. The establishment of safety goals in terms of failure probability or structural reliability is a new approach to the old problem of safety quantification. ${ }^{75}$ Structural reliability is the statistical statement of structural safety. Mathematically, it is defined as 1 minus the failure probability of the structural component. If the failure probability is 0 , then the reliability is $1(100 \%)$. In terms of brittle fracture, reliability $(R)$ can be expressed as 


$$
R=P\left(K_{1}<K_{10}\right)=1-P_{f}
$$

where $P_{f}$ is the probability of structural failure due to brittle fracture.

Traditionally, inputs into ASME Code analyses for structural integrity are treated as deterministic values. In most instances, these deterministic values are worst-case quantities that, when considered in total, could give an unrealistically conservative estimate of the safety of structural components such as the CPBT. The probability that these worst-case quantities occur simultaneously, as is assumed in the ASME Code, is extremely low. Probabilistic fracture mechanics provides a means of quantifying the degree of inherent safety for parts or entire structures.

A schematic representation of probabilistic fracture analysis is shown in Fig. 26 (Ref. 4). The curve on the left represents the actual stress intensity distribution, which depends on the flaw and stress distributions, and the curve on the right represents the distribution of fracture toughness. Deterministic fracture mechanics can be used to determine the critical stress intensity corresponding to a particular stress state and flaw size as presented in previous sections of this report. When the distributions of critical and actual stress intensity overlap, there is a finite probability of failure, as is indicated by the shaded area in Fig. 26. Even time-dependent crack growth, such as fatigue, can be taken into account through application of an appropriate crack growth law; the distribution moves to the right with time, increasing the failure probability.

Most of the currently used probabilistic fracture mechanics analyses involve the use of Monte Carlo techniques. A Monte Carlo simulation cycle represents a single computer experiment conducted to determine if a single occurrence of a specific event will produce failure. Each cycle of the Monte Carlo simulation involves the random selection of specific parameter values but utilizes deterministic expressions of stress intensity factor to determine whether or not $K_{1}>K_{Q}$ for each individual random parameter combination. To estimate the likelihood of failure, the process is repeated after new values of the random variables are generated, up to millions of random combinations; a large number of CPBTs, each with a different combination of the various values of the different parameters involved in the analysis of flaw behavior, would be evaluated deterministically to determine the number of vessels for which failure is predicted. The failure rate is then estimated by the ratio of the number of predicted failures per number of analyzed vessels. The cumulative probability of failure at any time is simply the probability of having a crack at that time equal to or larger than the critical flaw size.

\section{PFM Analytical Codes}

A number of computer codes have been developed for application of probabilistic fracture mechanics (PFM), most of them utilizing the Monte Carlo technique, to generate estimates of the conditional probability of failure for various components. The following is a list of some of the available codes:

1. OCTAVIA ${ }^{76}$ was developed by the USNRC to calculate pressure vessel probability failure rates for pressurized water reactors. Monte Carlo techniques are applied and failure pressures are calculated deterministically for different sized axially oriented flaws.

2. PRAISE ${ }^{2}$ was developed at Lawrence Livermore Laboratory and uses Monte Carlo simulation techniques to estimate time to first failure for a girth butt weld joint in nuclear reactor piping that is subjected to normal operating conditions, anticipated transients, and seismic events for various magnitudes. Figure 27 presents a schematic diagram of the steps involved in running the PRAISE code. 

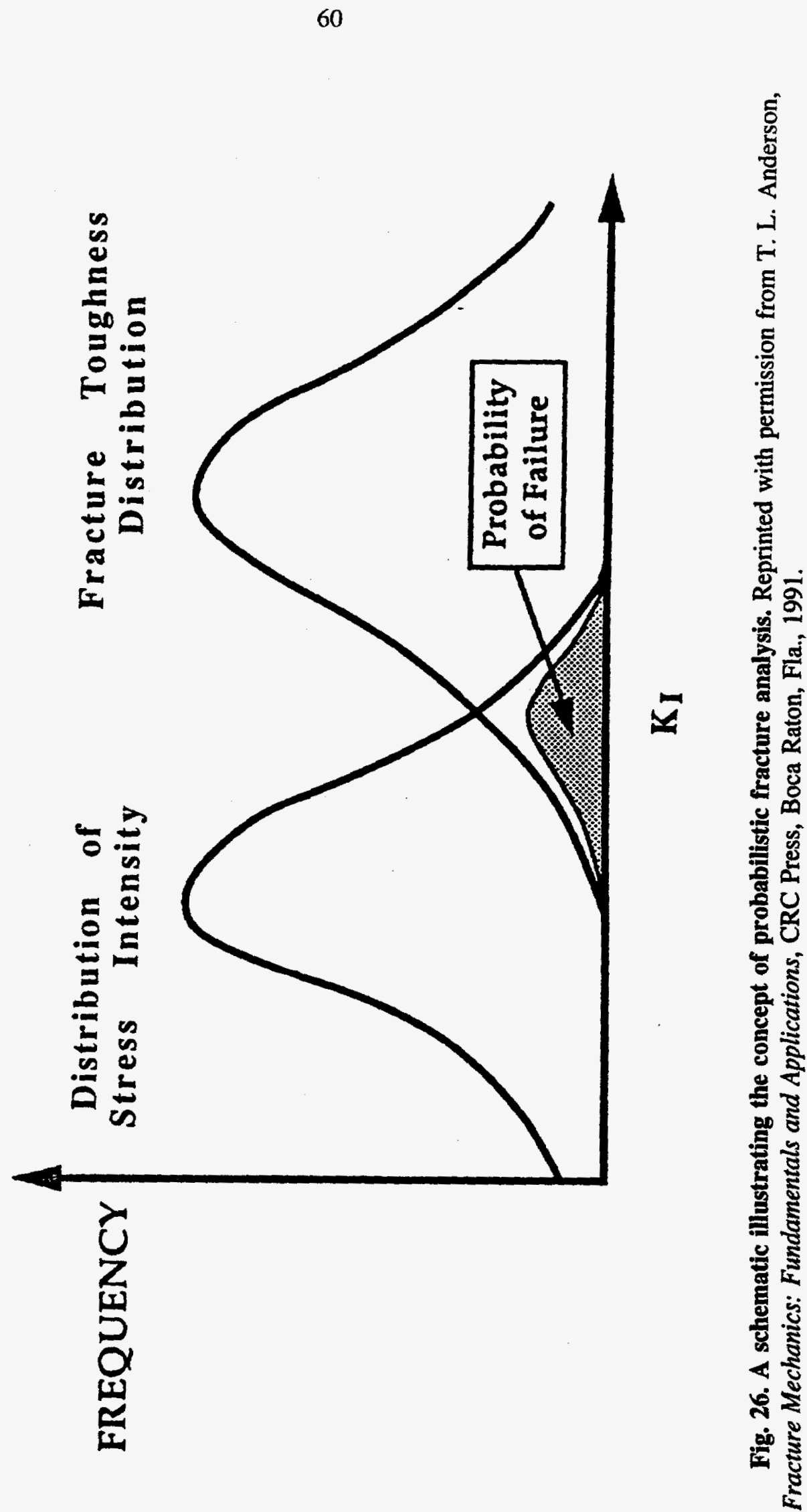


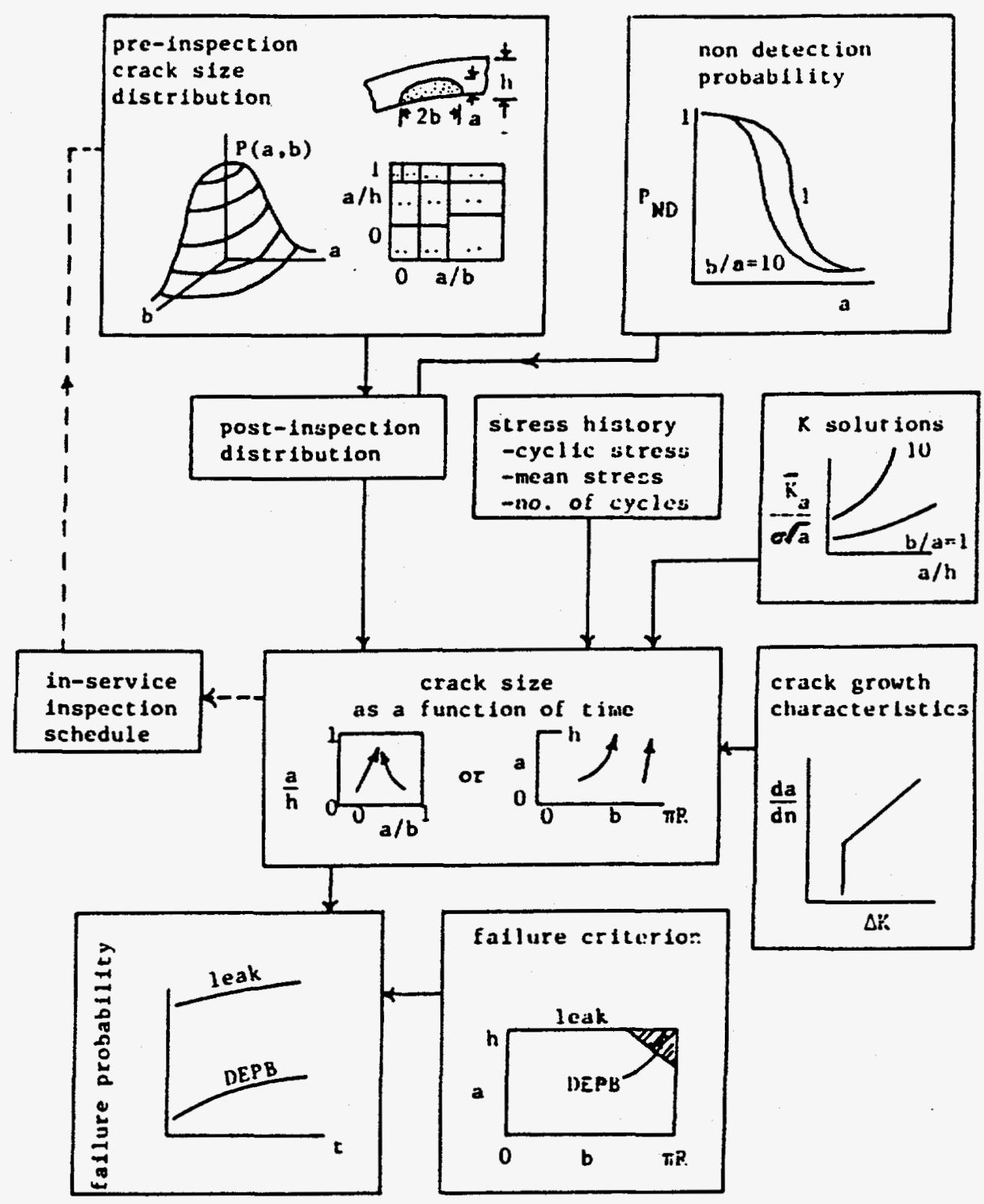

Fig. 27. Schematic diagram of the steps involved in execution of PRAISE. Source: D. $O$. Harris, E. Y. Lim, and D. D. Dedhia, Probability of Pipe Fracture in the Primary Coolant Loop of a PWR Plant, Probabilistic Fracture Mechanics Analysis, NUREG/CR-2189, Vol. 5, August 1981. 
3. USNRC's NUREG-0778 Code ${ }^{n}$ was developed to calculate the probability of a flaw-induced failure in the beltline region of irradiated pressurized water reactor pressure vessels. Utilizing Monte Carlo simulation, the code uses mathematical expressions based on LEFM to model the variable interactions and to estimate failure rates.

4. ISPRA's COVASTOL ${ }^{78}$ handles all data in a probabilistic form and utilizes probabilistic data concerning defects, material properties, and loading conditions. The computation time is much less than that required for the application of the Monte Carlo technique.

5. OCA-P ${ }^{79}$ was developed for evaluation of pressurized water reactor integrity during pressurized thermal-shock transients. The model utilizes Monte Carlo simulation based on LEFM to model significant variables and to estimate the probability of catastrophic failure.

\section{Variables and Distributions for Application of PFM}

The possibility of failure of the CPBT could result from the combined effects of (1) pressure, thermal, seismic, and other loading transients; (2) radiation-induced damage to the vessel material through a lowering of fracture toughness; and (3) the existence, location, and sizes of flaws within the CPBT wall. Reports by Woo and Simonen ${ }^{20}$ indicate that the following variables would be required for the probabilistic analysis of the CPBT:

1. Associated properties of the CPBT.

2. CPBT geometry: vessel cross-section dimensions.

3. Initial crack distributions.

4. Loadings and associated occurrence rates: loadings may include internal pressure, dead weight, thermal loading, residual stress, vibratory stress, and seismic loads. Occurrence rates for the different loadings must be specified.

5. Crack growth models: $d a / d N=f(c, m, \Delta K)$ for fatigue crack growth and $d a / d t=f(C, m, K)$ for stress corrosion cracking where $C$ and $m$ are material constants; $K$ and $\Delta K$ are the applied stress intensity factor and its range respectively; $N$ is the number of cycles; and $t$ is the time variable.

6. Detection probability models for cracks.

7. Possible ISI schedules.

Distribution functions for all of the varying parameters in a PFM analysis must be specified. Selection of appropriate distribution functions is probably the most difficult aspect of applying PFM. The following distributions for various factors have been proposed in the literature; each may or may not be applicable to the 6061-T6 CPBT of the ANS reactor, but they provide a starting point based on the experience of other researchers.

The single largest uncertainty in the overall probabilistic vessel analysis conducted by Cheverton and Ball ${ }^{81}$ was the number of surface flaws assumed per vessel. Probabilistic fracture mechanics models are generally based on the assumption that failure occurs because of the subcritical and 
catastrophic growth of flaws introduced during fabrication. Such defects are initially present with some probability and their preservice detection is directly related to their size. Bloom, ${ }^{75}$ based on work by Becher and Pederson, ${ }^{82}$ presents a one-parameter exponential distribution for flaw size as

$$
f(a)=\frac{1}{\bar{a}} \exp \left(-\frac{a}{\bar{a}}\right)
$$

where $\bar{a}$ is the mean half crack length. Cheverton and Ball ${ }^{81}$ assumed that the number of flaws in a specific region with a depth in a specific range of crack depths $\Delta a_{i}$ could be expressed as

$$
N_{j}\left(\Delta a_{i}\right)=N_{j} A_{j} \int_{\Delta i} f(a) B(a) d a
$$

where

$\mathbf{N}_{\mathrm{j}}=$ number of flaws of all depths per unit surface area of the region,

$A_{j}=$ surface area of the $j^{\text {th }}$ region,

$f(a)=$ flaw-depth density function,

$B(a)=$ probability of nondetection.

The parameters $N_{j}$ and $f(a)$ pertain to vessel conditions prior to preservice inspection and repair, and $B(a)$ is derived on the basis of repairing, or otherwise disposing of, all detected flaws. The value of $N_{j}$ and the functions $f(a)$ and $B(a)$ are not well defined. The following values were suggested by Marshall ${ }^{83}$

$$
f(a)=0.16 e^{-0.162}
$$

and

$$
B(a)=0.005+0.995 e^{-0.113 a}
$$

Marshall also suggested an exponential flaw distribution where

$$
p_{0}(a)=\frac{e^{-a / \mu}}{\mu\left(1-e^{-h / \mu}\right)}
$$

where $m$ is the mean crack depth and $h$ is the wall thickness.

Becher and Hansen ${ }^{84}$ proposed the lognormal flaw distribution with

$$
P_{0}(a)=\frac{1}{\mu \mathrm{aH}(2 \pi)^{1 / 2}} \exp \left[-\frac{1}{2 \mu^{2}}(\ln a / \lambda)^{2}\right] \text {, }
$$


where $\mathrm{H}=1-1 / 2 \operatorname{erfc}\left(\frac{1}{\mu 2^{1 / 2}} \ln \frac{\mathrm{a}}{\lambda}\right)$ with $\mu=0.82$ and $\lambda=1.3 \mathrm{~mm}$.

Even the aspect ratio, which is used to define crack geometry and is defined as $\beta=c / a$, is assumed to be a distributed variable with a modified probability density function ${ }^{74}$

$$
P \beta(\beta)=\frac{C_{\beta}}{\lambda_{\beta}(2 \pi)^{1 / 2}} \exp \frac{-\ln \frac{B^{2}}{B_{m}}}{2 \lambda^{2}},
$$

where $C_{\beta}, \beta_{m}$, and $\gamma$ are constants.

Before any probabilistic model can be applied to the CPBT, knowledgeable assumptions will have to be made concerning the initial crack size distribution. The results of preservice inspections should aid in the selection of an appropriate distribution.

Harris and $\mathrm{Lim}^{85}$ addressed the effects of NDE on structural reliability in a quantitative manner. They combined the size distribution of defects introduced during fabrication with the detection probability of the inspection techniques to provide preservice crack size distributions. The ratio of failure rates with and without inspection was found to be independent of the crack size distribution, and thus it appears that an assessment of the relative benefit of ISI does not require accurate knowledge of the initial crack distribution. Several distributions for nondetection probability have been suggested. Hong and Yeater ${ }^{86}$ suggest the use of a lognormal relation to characterize the probability of nondetection:

$$
P_{N D}(a)=\frac{1}{2} \operatorname{erfc}\left[v \ln \frac{a}{a^{*}}\right]
$$

where

erfc $=$ the complementary error function,

$\mathrm{a}=$ crack depth,

$\mathrm{n}=$ slope of the $\mathrm{P}_{\mathrm{ND}}$ curve,

$\mathrm{a}^{*}=$ the crack depth that has a $50 \%$ chance of being detected.

Equation (57) indicates that the probability of not detecting a very small flaw is nearly one, whereas the probability of not detecting a very large one is nearly zero.

$\mathrm{K}_{\mathrm{Ic}}$ can be treated as a statistical variable that is generally dependent on the fluence. Cheverton and $\mathrm{Ball}^{81}$ used the following expression for the attenuation of the fluence through the wall of the vessel:

$$
F=F_{0} e^{-0.0094 a},
$$

where $F_{o}$ is the fluence at the inner surface of the vessel and $a$ is the crack depth in millimeters. The standard deviation for the error in $\mathrm{K}_{\mathrm{tc}}$ can be taken as a constant, $\gamma$, times the mean value of $\mathrm{K}_{\mathrm{tc}}$ assuming that $\mathrm{K}_{\mathrm{Ic}}$ follows a normal distribution. Jouris ${ }^{87}$ suggests the use of the normal distribution for both $K_{\mathrm{I}}$ and $K_{\mathrm{Ic}}$. 
As with overload fracture, the deterministic expressions for crack growth are applied in probabilistic models, but the growth law must be treated as a distributed variable. In order to account for the variability in the crack growth characteristics, Harris and Lim $^{85}$ suggest utilization of the crack growth expression

$$
\frac{\mathrm{da}}{\mathrm{dN}}=\mathrm{C}\left[\frac{\Delta \mathrm{K}}{(1-\mathrm{R})^{1 / 2}}\right]^{4}
$$

with the parameter $\mathrm{C}$ taken to be lognormally distributed.

If PFM is to be applied to the analysis of the CPBT, appropriate variable distributions will have to be selected. The code OCA-P developed at ORNL ${ }^{81}$ could be used to conduct the analysis, but engineering judgment will have to be applied to the distribution selections.

Importance sampling, which is a modification of the Monte Carlo simulation technique that is biased for greater efficiency, could be utilized in the PFM analysis of the CPBT. When determining conditional probabilities that are quite small (on the order of $10^{-4}$ or less), a large number of trials $(>50,000)$ is required to have even a single occurrence of failure. ${ }^{82}$ In importance sampling, the sampling is done only in the tail of the distribution to ensure that simulated failures occur. The lower the probability of failure, the farther out in the tail the sampling must be done. Because the sampling carried out this way is blatantly biased, a correction factor is used in determining the actual probability of failure. This technique results in greatly reduced computer costs when compared to those from the use of the straight Monte Carlo technique for low probability situations. ${ }^{28}$ The minimum number of simulated vessels required to satisfy a specified accuracy can be estimated by applying the central limit theorem. ${ }^{89}$

A closing warning based on comments by Marriot, ${ }^{\infty}$ who found that two important factors are invariably neglected in most PFM analyses: (1) rogue events or outliers and (2) dependencies among parameters. In most practical applications of PFM, earthquakes and/or hurricanes have finite probabilities, and the probability distribution for flaws is very likely to be dependent on fracture toughness. These effects should be considered if probabilistic methods are applied to the CPBT. Witt ${ }^{73}$ states that subjective engineering judgments must be made as to the governing statistical parameters; caution is advised.

\section{PROOF-TEST APPROACH}

The proof-test may be used to infer that the worst flaw that exists in the CPBT at the time of the proof-test does not exceed the size that would cause failure at the test load. If the proof-test loads the vessel in the same manner as the service loading, it is a reliable method of bounding the flaw size in a component. Estimates of the growth of that bounding flaw during service due to corrosion or fatigue crack growth will then provide an estimate of the bounding crack size at some future time.

The CPBT is primarily loaded by internal pressure. Therefore, a hydrostatic test would be the pertinent proof-test. The relation between the size of the worst flaw, $a_{p}$, the applied stress, $\sigma_{p}$ and the fracture toughness of the material, $\mathrm{K}_{\mathrm{Ip}}$, at the time of the proof-test is given by

$$
K_{\mathrm{lp}}>A \sigma_{p} \sqrt{\mathrm{a}_{\mathrm{p}}}
$$


If we assume that at the end of life the flaw is twice the size when the proof-test was performed, the minimum required toughness of the component $K_{\mathrm{ff}}$ is

$$
\mathrm{K}_{\mathrm{If}}=\mathrm{A} \sigma_{\mathrm{f}} \sqrt{2 \mathrm{a}_{\mathrm{p}}},
$$

where $\sigma_{f}$ is the maximum allowable stress in the component during service. The allowable stress for 6061-T6 aluminum is $40 \%$ of the yield strength. Proof-test would be to $90 \%$ of the yield strength. Thus,

$$
\sigma_{f}=\frac{0.4}{0.9} \sigma_{p}=0.444 \sigma_{p}
$$

and

$$
\begin{gathered}
\frac{\mathrm{K}_{\mathrm{ff}}}{\mathrm{K}_{\mathrm{fp}}}>\frac{\mathrm{A}\left(0.444 \sigma_{\mathrm{p}}\right) \sqrt{2 \mathrm{a}_{\mathrm{p}}}}{\mathrm{A} \sigma_{\mathrm{p}} \sqrt{\mathrm{a}_{\mathrm{p}}}}, \\
\mathrm{K}_{\mathrm{If}}>(0.444) \sqrt{2} \mathrm{~K}_{\mathrm{lp}}, \\
\mathrm{K}_{\mathrm{If}}>0.628 \mathrm{~K}_{\mathrm{lp}} .
\end{gathered}
$$

Therefore, the CPBT would be safe from nonductile rupture as long as irradiation does not reduce the fracture toughness by more than $62.8 \%$. Assuming that the unirradiated toughness is $28 \mathrm{MPa} V \mathrm{~m}$, the CPBT would have to be removed from service if the toughness fell to $17.6 \mathrm{MPa} V \mathrm{~m}$.

\section{CONCLUSIONS}

LEFM can be used to evaluate the susceptibility of the ANS CPBT to nonductile fracture. Stress intensity factors due to internal pressure stresses and thermal stresses were determined for various crack geometries in an 8.5-mm-thick CPBT. The critical flaw depth was found to be about $5.5 \mathrm{~mm}$ for unirradiated 6061-T6 aluminum. Nondestructive test methods are capable of providing assurance that no flaws exist in the CPBT which are deeper than $0.5 \mathrm{~mm}$.

Fatigue crack growth data for irradiated 6061-T6 aluminum are needed so that the crack growth can be estimated once an expected loading histogram is developed for the ANS.

Probabilistic fracture mechanics can be applied to estimate the probability of a catastrophic brittle fracture of the CPBT.

Proof-testing is an alternative approach to NDE that can be used to assure that preexisting flaws are not large enough to cause catastrophic brittle fracture of the CPBT. 


\section{REFERENCES}

1. ASME Boiler and Pressure Vessel Committee, "ASME Boiler and Pressure Vessel Code, Section III: Division I-Appendices, Article G-2000, Vessels," The American Society of Mechanical Engineers, New York, N.Y., 1992.

2. J. Dixon, CPBT Wall Temperatures Resulting from a Numerical Thermal Model of the CPBT Using the Software Package TK Solver Plus, Oak Ridge Natl. Lab., 1992.

3. P. Cento, ANS Preliminary Design Analysis of the CPBT, Martin Marietta Energy Systems Design Analysis and Calculations, Report No. DAC-XRT-017063-A002:ESO A8019AB1, December 1992.

4. T. L. Anderson, Fracture Mechanics: Fundamentals and Applications, CRC Press, Boca Raton, Fla., 1991.

5. D. J. Alexander, "The Effect of Irradiation on the Mechanical Properties of 6061-T6 Aluminum," Effects of Radiation on Materials: 16th International Symposium, ASTM STP 1175, American Society for Testing and Materials, Philadelphia, 1993.

6. C. J. Czajkowski, Brookhaven National Laboratory, test data results, December 1991.

7. V. Kumar, M. D. German, and C. F. Shih, An Engineering Approach for Elastic Plastic Fracture Analysis, EPRI Report NP 1931, Electric Power Research Institute, Palo Alto, Calif., July 1981.

8. G. T. Yahr, "Fatigue Design Curves for 6061-T6 Aluminum," Codes and Standards in a Global Environment, James E. Staffiera (ed.), PVP-Vol. 259, ASME, pp. 43-49, 1993.

9. ASME Boiler and Pressure Vessel Committee, "ASME Boiler and Pressure Vessel Code, Section XI: Rules for Inservice Inspection of Nuclear Power Plant Components-Section G-2000," The American Society of Mechanical Engineers, New York, N.Y., 1992.

10. P. C. Riccardella, and S. Yukawa, "Twenty Years of Fracture Mechanics and Flaw Evaluation Applications in the ASME Nuclear Code," J. Pressure Vessel Technol. 113, 145-153 (May 1991).

11. ASME Section XI Task Group on Reactor Vessel Integrity Requirements, "White Paper on Reactor Vessel Integrity Requirements for Level A and B Conditions,” prepared for ASME Section XI Working Group on Operating Plant Criteria, January 1991.

12. ALFRAC, Aluminum Fracture Toughness Database, U.S. Department of Commerce, National Institute of Science and Technology, Gaithersburg, Md.

13. Military Standardization Handbook, Metallic Materials and Elements for Aerospace Vehicle Structures, Vol. 1, MIL-HDBK-5D, Jan. 1, 1984. 
14. G. T. Yahr, "Fracture Toughness of Irradiated 6061-T6 Aluminum," Advanced Neutron Source Progress Report for December 1991, ORNL/ANS/INT-S/V45, Oak Ridge Natl. Lab., 1991.

15. B. W. Leitch, "Critical Depth of an Internal or External Flaw in an Internally Pressurized Tube," Nonlinear Fracture Mechanics: Volume II-Elastic Plastic Fracture, ASTM STP 995, American Society for Testing and Materials, Philadelphia, 1989, pp. 390-403.

16. D. Shum, private communication, Oak Ridge Natl. Lab., June 1993.

17. G. R. Irwin, "The Crack Extension Force for a Part Through Crack in a Plate," Trans., ASME, J. Appl. Mech. 29(4) (1962).

18. D. Broek, Elementary Engineering Fracture Mechanics, Kluwer Academic Publishers, Dordrecht, The Netherlands, 1986.

19. M. Prodan, and J. C. Radon, "Some Special Computations and Experiments on Surface Crack Growth," Surface-Crack Growth: Models, Experiments and Structures, ASTM STP 1060, American Society for Testing and Materials, Philadelphia, 1990, pp. 287-302.

20. J. M. Barsom, and S. T. Rolfe, Fracture and Fatigue Control in Structures: Applications in Fracture Mechanics, Prentice-Hall, Inc., Englewood Cliffs, N.J., 1987.

21. PVRC Ad Hoc Task Group on Toughness Requirements, PVRC Recommendations on Toughness Requirements for Ferritic Materials, Welding Research Council WRC Bulletin 175, August 1972.

22. W. H. Tuppeny, Jr., W. F. Siddall, Jr., and L. C. Hsu, Thermal Shock Analysis on Reactor Vessels Due to Emergency Core Cooling System Operation, Combustion Engineering, Inc., Report A-68-9-1, Mar. 15, 1968.

23. R. C. Hutto, C. D. Morgan, and W. A. Van Der Sluys, Analysis of the Structural Integrity of a Reactor Vessel Subjected to Thermal Shock, Babcock and Wilcox Power Generation Division, Topical Report BAW10018, May 1969.

24. T. K. Solver, Universal Technical Systems, Inc., Rockford, Ill., 1991.

25. R. J. Roark and W. C. Young, Formulas for Stress and Strain, McGraw-Hill Book Company, Fifth Ed., New York, 1975.

26. S. S. Manson, Thermal Stress and Low-Cycle Fatigue, McGraw-Hill Book Company, New York, 1966.

27. B. A. Boley and J. H. Weiner, Theory of Thermal Stresses, John Wiley and Sons, Inc., New York, 1962, p. 188.

28. D. P. Rooke and D. J. Cartwright, Compendium of Stress Intensity Factors, Her Majesty's Stationery Office, London, 1976, pp. 297-299. 
29. J. C. Newman, Jr., and I. S. Raju, "Stress Intensity Factor Equations for Cracks in ThreeDimensional Finite Bodies Subjected to Tension and Bending Loads," pp. 311-334 in Computational Methods in the Mechanics of Fracture, S. N. Atluri, Ed., Elsevier, 1986.

30. Z. Zudans, T. C. Yen, and W. H. Steigelmann, Thermal Stress Techniques in the Nuclear Industry, American Elsevier Publishing Company, Inc., New York, N.Y., 1965.

31. J. R. Weeks, C. K. Czajkowski, and K. Farrell, "Effects of High Thermal Neutron Fluences on Type 6061 Aluminum," Effects of Radiation on Materials: 16th International Symposium, ASTM STP 1175, American Society for Testing and Materials, Philadelphia, 1993.

32. V. Dimitrijevic et al., "White Paper on Use of Nondestructive Examination Data for Improved Reactor Pressure Vessel Integrity," presented at the ASME Task Group on NDE for Plant Operating Criteria, Nov. 30, 1992.

33. D. A. Bruce, "Inspection Reliability," AGARD conference proceedings No. 462, Impact of Emerging NDE-NDI Methods on Aircraft Design, Manufacture and Maintenance, AGARD-CP-462, October 1989.

34. E. L. Kennedy and J. R. Foulds, Nuclear Reactor Vessel Flaw Distribution Development Phase I-NDE Capability and Sensitivity Analyses, SAND 89-7148, Sandia National Laboratories, May 1990.

35. Evaluation of UDRPS, EPRI NP4870-LD, Electric Power Research Institute, Palo Alto, Calif., October 1986.

36. W. D. Rummel, “Assessment and Demonstration of the Capabilities of NDI Processes, Equipment and Personnel," AGARD conference proceedings No. 462, Impact of Emerging NDE-NDI Methods on Aircraft Design, Manufacture and Maintenance, AGARD-CP-462, October 1989.

37. J. J. Lance, Chairman, Recommended Changes to Regulatory Guide 1.150, Final Report by Ad Hoc Committee of the Electric Utility Industry, August 1982.

38. B. K. Christner, D. L. Long, and W. D. Rummel, NDE Detectability of Fatigue-Type Cracks in High-Strength Alloys: NDI Reliability Assessments, Final Report, NASA MCR-88-1044, September 1988.

39. W. D. Rummel, L. H. Grover, and T. D. Cooper, "Applications of NDE Reliability to Systems," Metals Handbook on Nondestructive Testing and Quality Control, Vol. 17, American Society of Metals, 1989.

40. W. D. Cowie, "Fracture Control Philosophy," Metals Handbook on Nondestructive Testing and Quality Control, Vol. 17, American Society of Metals, 1989. 
41. R. L. Jones et al., "Applications of Fatigue and Fracture Tolerant Design Concepts in the Nuclear Power Industry," pp. 28-46 in Design of Fatigue and Fracture Resistant Structures, ASTM STP 761, American Society for Testing and Materials, 1982.

42. Structural Alloys Handbook, 6061 Aluminum, Vol. 3, Battelle, Columbus, Ohio, 1989.

43. ALCOA Structural Handbook, Aluminum Company of America, Pittsburgh, 1960.

44. Military Standardization Handbook, "Metallic Materials and Elements for Aerospace Vehicle Structures," Vol. 1, MIL-HDBK-5D, Jan. 1, 1984.

45. Cryogenic Materials Data Handbook, Vol. 1, AFML-TDR-64-280, Air Force Materials Laboratory, Wright-Patterson Air Force Base, Ohio, 1970.

46. R. F. Brodrick and G. A. Spiering, "Low-Cycle Fatigue of Aluminum Alloys," J. Mater. 7(4), 515-526 (December 1972).

47. H. O. Fuchs and R. I. Stephens, Metal Fatigue in Engineering, John Wiley and Sons, Inc., 1980.

48. M. A. Miner, "Cumulative Damage in Fatigue," Trans. ASME, J. Appl. Mech. 67, A159 (September 1945).

49. J. A. Collins, Failure of Materials in Mechanical Design, John Wiley and Sons, Inc., New York, 1981.

50. J. Marin, Mechanical Behavior of Materials, Prentice-Hall, Englewood Cliffs, N.J., 1962.

51. S. M. Marco and W. L. Starkey, "A Concept of Fatigue Damage," ASME Trans. 76, 627 (1954).

52. R. R. Gatts, “Application of a Cumulative Damage Concept to Fatigue," ASME Trans. 83, Series D(4), 529 (1961).

53. H. T. Corten and T. J. Dolan, "Cumulative Fatigue Damage," p. 235 in Proceedings of the International Conference on Fatigue of Metals, ASME and IME, 1956.

54. D. L. Henry, "Theory of Fatigue Damage Accumulation in Steel," ASME Trans. 77, 913 (1955).

55. Panontin and Dittman, unpublished data, NASA Ames Research Center, 1988.

56. R. G. Forman, V. E. Kearney, and R. M. Engle, "Numerical Analysis of Crack Propagation in Cyclic-Loaded Structures," Trans. ASME, J. Basic Eng. 89(3), 459 (1967).

57. E. K. Walker, “An Effective Strain Concept for Crack Propagation and Fatigue Life with Specific Applications to Biaxial Stress Fatigue," Proceedings of the Air Force Conference on 
Fatigue and Fracture of Aircraft Structures and Materials, Miami Beach, Florida, December 15-18, 1969.

58. O. E. Wheeler, "Spectrum Loading and Crack Growth," Trans. ASME, J. Basic Eng. 94, 181 (1972).

59. J. Willenborg, R. M. Engle, and H. A. Wood, A Crack Growth Retardation Model Using an Effective Stress Concept, Wright Patterson Air Force Base, TM-71-1-FBR, 1971.

60. R. H. Heyer and D. E. McCabe, "Crack Growth Resistance in Plane-Stress Fracture Testing," Eng. Fract. Mech. 4, 413 (1972).

61. A. A. Wells, "Unstable Crack Propagation in Metals-Cleavage and Fast Fracture," p. 210 in Cranfield Crack Propagation Symposium, 1, September 1961.

62. D. S. Dugdale, "Yielding of Steel Sheets Containing Slits," J. Mech. Phys. Solids 8, 100 (1960).

63. A. R. Dowling and C. H. A. Townley, "The Effects of Defects on Structural Failure: A TwoCriteria Approach," Int. J. Pressure Vessels Piping 3, 77 (1975).

64. R. P. Harrison, K. Loosemore, and I. Milne, Assessment of the Integrity of Structures Containing Defects, CEGB Report R/H/R6, Central Electricity Generating Board, United Kingdom, 1976.

65. R. P. Harrison et al., Assessment of the Integrity of Structures Containing Defects, CEGB Report R/H/R6-Rev. 2, Central Electricity Generating Board, United Kingdom, 1980.

66. J. R. Rice, "A Path Independent Integral and Approximate Analysis of Strain Concentration by Notches and Cracks," J. Appl. Mech., Trans. ASME 35 (June 1968).

67. J. A. Begley and J. D. Landes, The Effect of Specimen Geometry on $J_{k}$, ASTM STP 514, American Society for Testing and Materials, Philadelphia, 1972, pp. 40-69.

68. V. Kumar, M. D. German, and C. F. Shih, An Engineering Approach for Elastic Plastic Fracture Analysis, EPRI NP 1931, Electric Power Research Institute, Palo Alto, Calif., July 1981.

69. A. Zahoor, Ductile Fracture Handbook, EPRI Research Project 1757-69, January 1991.

70. P. C. Riccardella, $p c-C R A C K$ : Fracture Mechanics Software Version 2.0, Structural Integrity Associates, Inc., San Jose, Calif., 1989.

71. A. G. Atkins and Y. W. Mai, Elastic and Plastic Fracture: Metals, Polymers, Ceramics, Composites, Biological Materials, Ellis Horwood, Ltd., Chichester, UK, 1988.

72. D. O. Harris, E. Y. Lim, and D. D. Dedhia, "Probability of Pipe Fracture in the Primary Coolant Loop of a PWR Plant," Probabilistic Fracture Mechanics Analysis, NUREG/CR-2189, Vol. 5, August 1981. 
73. F. J. Witt, "Development and Applications of Probabilistic Fracture Mechanics for Critical Nuclear Reactor Components," Advances in Probabilistic Fracture Mechanics, American Society of Mechanical Engineers, PVP-Volume 92, 1984 Pressure Vessel and Piping Conference and Exhibition, San Antonio, Tex., June 17-21, 1984.

74. H. H. Woo, Piping Reliability Model Development, Validations, and Its Applications to Light Water Reactor Piping, ASME 83-PVP-85, American Society of Mechanical Engineers.

75. J. M. Bloom, "Probabilistic Fracture Mechanics-A State-of-the-Art Review," Advances in Probabilistic Fracture Mechanics, American Society of Mechanical Engineers, PVP-Volume 92, 1984 Pressure Vessel and Piping Conference and Exhibition, San Antonio, Tex., June 17-21, 1984.

76. W. E. Veseley, E. K. Lynn, and F. F. Goldberg, The OCTAVIA Computer Code: PWR Reactor Pressure Vessel Failure Probabilities Due to Operationally Caused Pressure Transients, USNRC, NUREG-0258, March 1978.

77. R. M. Gamble and J. Strosnider, Jr., An Assessment of the Failure Rate for the Beltline Region of PWR Pressure Vessels During Normal Operation and Certain Transient Conditions, USNRC, NUREG-0778, June 1981.

78. A. C. Lucia, J. Elbay, and R. Brunnhuber, "COVASTOL: A Computer Code for the Estimation of Pressure Vessel Failure Probability," SMIRT Conference, Paper M8/5, Berlin, Germany, 1978.

79. R. D. Cheverton and D. G. Ball, OCA-P, A Deterministic and Probabilistic Fracture-Mechanics Code for Application to Pressure Vessels, NUREG/CR-3618 (ORNL-5991), Oak Ridge Natl. Lab., May 1984.

80. H. H. Woo and F. A. Simonen, "The Impact of Inservice Inspection on the Reliability of Nuclear Piping," Advances in Probabilistic Fracture Mechanics, American Society of Mechanical Engineers, PVP-Volume 92, 1984 Pressure Vessel and Piping Conference and Exhibition, San Antonio, Tex., June 17-21, 1984.

81. R. D. Cheverton and D. G. Ball, "Application of Probabilistic Fracture Mechanics to the Pressurized-Thermal-Shock Issue," pp. 35-50 in Fracture Mechanics: Eighteenth Symposium, ASTM STP 945, American Society for Testing and Materials, Philadelphia, 1988.

82. P. E. Becher and A. Pedersen, "Application of Statistical Linear Elastic Fracture Mechanics to Pressure Vessel Reliability Analysis," Nucl. Eng. Design, 17, 1974.

83. W. Marshall, An Assessment of the Integrity of PWR Pressure Vessels, United Kingdom Atomic Energy Authority, Second Report, March 1982.

84. P. E. Becher and B. Hansen, Statistical Evaluation of Defects in Welds and Design Implications, Danish Welding Institute, Danish Atomic Energy Commission Research Establishment. 
85. D. O. Harris and E. Y. Lim, "Applications of a Probabilistic Fracture Mechanics Model to the Influence of In-Service Inspection on Structural Reliability," pp. 19-41 in Probabilistic Fracture Mechanics and Fatigue Methods: Applications for Structural Design and Maintenance, ASTM STP 798, American Society for Testing and Materials, 1983.

86. S. Y. Hong and M. L. Yeater, "A Sensitivity Study of PWR Primary Coolant Piping Leak Failures Using Probabilistic Fracture Mechanics," Advances in Probabilistic Fracture Mechanics, American Society of Mechanical Engineers, PVP-Volume 92, 1984 Pressure Vessel and Piping Conference and Exhibition, San Antonio, Tex., June 17-21, 1984.

87. G. M. Jouris, "Probabilistic Evaluation of Conservatisms Used in Section III, Appendix G, of the ASME Code," pp. 7-18 in Probabilistic Fracture Mechanics and Fatigue Methods: Applications for Structural Design and Maintenance, ASTM STP 798, American Society for Testing and Materials, 1983.

88. K. R. Balkey and E. L. Furchi, "Probabilistic Fracture Mechanics Sensitivity Study for Plant Specific Evaluations of Reactor Vessel Pressurized Thermal Shock," Advances in Probabilistic Fracture Mechanics, American Society of Mechanical Engineers, PVP-Volume 92, 1984 Pressure Vessel and Piping Conference and Exhibition, San Antonio, Tex., June 17-21, 1984.

89. R. Y. Rubinstein, Simulation and the Monte Carlo Method, Israel Institute of Technology, Wiley, New York, 1981.

90. D. L. Marriott, "Evaluation of the Limitations of Probabilistic Fracture Mechanics in Risk Assessment," Advances in Probabilistic Fracture Mechanics, American Society of Mechanical Engineers, PVP-Volume 92, 1984 Pressure Vessel and Piping Conference and Exhibition, San Antonio, Tex., June 17-21, 1984. 
,

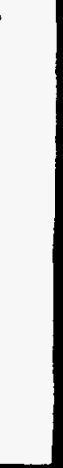


APPENDIX A

TEMPERATURE PROFILES WITHIN THE ANS CORE PRESSURE BOUNDARY TUBE 
Title: $\quad$ CPBT Temperatures with $45 \mathrm{C}$ inlet, $330 \mathrm{MW}$, and $7 \mathrm{~m} / \mathrm{s}$ flow in $3 \mathrm{~mm}$ annul Element Axial Dist (m) $T$ coolant (C) $T$ inside (C) $T$ mar (C) $T$ outside (C)

\begin{tabular}{|c|c|c|c|c|c|}
\hline 1 & -1.1420 & $4 \overline{5} .00$ & $4 \overline{8} .28$ & $5 \overline{0} .07$ & $5 \overline{0} .07$ \\
\hline 2 & -1.1247 & 45.04 & 48.50 & 50.38 & 50.38 \\
\hline 3 & -1.1074 & 45.07 & 48.71 & 50.69 & 50.69 \\
\hline 4 & -1.0902 & 45.11 & 48.93 & 51.00 & 51.00 \\
\hline 5 & -1.0729 & 45.16 & 49.15 & 51.32 & 51.32 \\
\hline 6 & -1.0556 & 45.20 & 49.38 & 51.63 & 51.63 \\
\hline 7 & -1.0383 & 45.25 & 49.60 & 51.95 & 51.95 \\
\hline 8 & -1.0210 & 45.30 & 49.83 & 52.27 & 52.27 \\
\hline 9 & -1.0038 & 45.35 & 50.06 & 52.59 & 52.59 \\
\hline 10 & -.9865 & 45.40 & 50.29 & 52.92 & 52.92 \\
\hline 11 & -.9692 & 45.45 & 50.52 & 53.24 & 53.24 \\
\hline 12 & -.9519 & 45.51 & 50.75 & 53.57 & 53.57 \\
\hline 13 & -.9346 & 45.57 & 50.99 & 53.90 & 53.90 \\
\hline 14 & -.9174 & 45.63 & 51.23 & 54.23 & 54.23 \\
\hline 15 & -.9001 & 45.69 & 51.47 & 54.56 & 54.56 \\
\hline 16 & -.8828 & 45.76 & 51.82 & 55.07 & 55.07 \\
\hline 17 & -.8655 & 45.83 & 52.68 & 56.34 & 56.34 \\
\hline 18 & -.8482 & 45.91 & 53.55 & 57.64 & 57.64 \\
\hline 19 & -.8310 & 46.00 & 54.44 & 58.95 & 58.95 \\
\hline 20 & -.8137 & 46.09 & 55.33 & 60.26 & 60.26 \\
\hline 21 & -.7964 & 46.20 & 56.21 & 61.56 & 61.56 \\
\hline 22 & -.7791 & 46.32 & 57.10 & 62.86 & 62.86 \\
\hline 23 & -.7618 & 46.45 & 57.99 & 64.15 & 64.15 \\
\hline 24 & -.7446 & 46.58 & 58.88 & 65.45 & 65.45 \\
\hline 25 & -.7273 & 46.73 & 59.78 & 66.74 & 66.74 \\
\hline 26 & -.7100 & 46.89 & 60.67 & 68.03 & 68.03 \\
\hline 27 & -.6927 & 47.05 & 61.57 & 69.33 & 69.32 \\
\hline 28 & -.6754 & 47.23 & 62.48 & 70.62 & 70.62 \\
\hline 29 & -.6582 & 47.42 & 63.39 & 71.91 & 71.91 \\
\hline 30 & -.6409 & 47.61 & 64.30 & 73.21 & 73.21 \\
\hline 31 & -.6236 & 47.82 & 65.21 & 74.51 & 74.50 \\
\hline 32 & -.6063 & 48.03 & 66.13 & 75.81 & 75.80 \\
\hline 33 & -.5890 & 48.25 & 67.05 & 77.11 & 77.10 \\
\hline 34 & -.5718 & 48.49 & 67.98 & 78.41 & 78.40 \\
\hline 35 & -.5545 & 48.73 & 72.37 & 85.00 & 84.98 \\
\hline 36 & -.5372 & 49.00 & 72.60 & 85.23 & 85.21 \\
\hline 37 & -.5199 & 49.27 & 72.84 & 85.46 & 85.44 \\
\hline 38 & -.5026 & 49.54 & 73.07 & 85.70 & 85.67 \\
\hline 39 & -.4854 & 49.82 & 75.36 & 89.06 & 89.03 \\
\hline 40 & -.4681 & 50.12 & 75.61 & 89.31 & 89.28 \\
\hline 41 & -.4508 & 50.41 & 75.87 & 89.56 & 89.53 \\
\hline 42 & -.4335 & 50.72 & 80.80 & 96.98 & 96.93 \\
\hline 43 & -.4162 & 51.04 & 81.07 & 97.25 & 97.19 \\
\hline 44 & -.3990 & 51.38 & 81.35 & 97.51 & 97.46 \\
\hline 45 & -.3817 & 51.71 & 81.63 & 97.79 & 97.73 \\
\hline 46 & -.3644 & 52.06 & 83.88 & 101.08 & 101.02 \\
\hline 47 & -.3471 & 52.41 & 84.17 & 101.36 & 101.30 \\
\hline 48 & -.3298 & 52.77 & 84.46 & 101.65 & 101.59 \\
\hline 49 & -.3126 & 53.14 & 84.77 & 101.94 & 101.88 \\
\hline 50 & -.2953 & 53.51 & 85.07 & 102.24 & 102.17 \\
\hline
\end{tabular}




\begin{tabular}{|c|c|c|c|c|c|}
\hline Element & Axial Dist (m) & I coolant (C) & $I$ inside $(C)$ & $I \max (C)$ & I outsides \\
\hline 51 & -.2780 & 53.88 & 85.38 & 102.54 & 102.47 \\
\hline 52 & -.2607 & 54.26 & 86.24 & 103.69 & 103.62 \\
\hline 53 & -.2434 & 54.64 & 86.56 & 104.00 & 103.93 \\
\hline 54 & -.2262 & 55.04 & 86.88 & 104.31 & 104.24 \\
\hline 55 & -.2089 & 55.43 & 87.21 & 104.63 & 104.55 \\
\hline 56 & -.1916 & 55.83 & 87.54 & 104.95 & 104.87 \\
\hline 57 & -.1743 & 56.23 & 87.88 & 105.27 & 105.19 \\
\hline 58 & -.1570 & 56.64 & 86.11 & 102.34 & 102.28 \\
\hline 59 & -.1398 & 57.04 & 86.44 & 102.66 & 102.60 \\
\hline 60 & -.1225 & 57.43 & 86.76 & 102.97 & 102.90 \\
\hline 61 & -.1052 & 57.80 & 87.34 & 103.69 & 103.62 \\
\hline 62 & -.0879 & 58.16 & 87.64 & 103.98 & 103.91 \\
\hline 63 & -.0706 & 58.50 & 87.93 & 104.26 & 104.19 \\
\hline 64 & -.0534 & 58.84 & 88.20 & 104.53 & 104.46 \\
\hline 65 & -.0361 & 59.16 & 86.29 & 101.40 & 101.34 \\
\hline 66 & -.0188 & 59.46 & 86.23 & 101.16 & 101.11 \\
\hline 67 & -.0015 & 59.74 & 86.84 & 101.98 & 101.92 \\
\hline 68 & .0158 & 60.01 & 88.97 & 105.16 & 105.09 \\
\hline 69 & .0330 & 60.30 & 91.39 & 108.76 & 108.68 \\
\hline 70 & .0503 & 60.63 & 92.14 & 109.76 & 109.68 \\
\hline 71 & .0676 & 60.97 & 93.42 & 111.59 & 111.50 \\
\hline 72 & .0849 & 61.32 & 94.74 & 113.48 & 113.38 \\
\hline 73 & .1022 & 61.67 & 95.40 & 114.32 & 114.22 \\
\hline 74 & .1194 & 62.02 & 95.87 & 114.89 & 114.78 \\
\hline 75 & .1367 & 62.37 & 96.34 & 115.45 & 115.34 \\
\hline 76 & .1540 & 62.73 & 96.54 & 115.59 & 115.48 \\
\hline 77 & .1713 & 63.08 & 96.67 & 115.62 & 115.51 \\
\hline 78 & .1886 & 63.40 & 96.78 & 115.63 & 115.53 \\
\hline 79 & .2058 & 63.72 & 96.90 & 115.65 & 115.54 \\
\hline 80 & .2231 & 64.05 & 97.01 & 115.67 & 115.56 \\
\hline 81 & .2404 & 64.37 & 96.79 & 115.15 & 115.05 \\
\hline 82 & .2577 & 64.69 & 96.50 & 114.55 & 114.45 \\
\hline 83 & .2750 & 65.00 & 96.21 & 113.94 & 113.84 \\
\hline 84 & .2922 & 65.32 & 95.92 & 113.33 & 113.23 \\
\hline 85 & .3095 & 65.63 & 95.63 & 112.71 & 112.62 \\
\hline 86 & .3268 & 65.93 & 95.34 & 112.10 & 112.01 \\
\hline 87 & .3441 & 66.24 & 94.98 & 111.38 & 111.30 \\
\hline 88 & .3614 & 66.54 & 94.57 & 110.58 & 110.50 \\
\hline 89 & .3786 & 66.84 & 94.15 & 109.77 & 109.70 \\
\hline 90 & .3959 & 67.14 & 93.74 & 108.97 & 108.90 \\
\hline 91 & .4132 & 67.43 & 93.32 & 108.16 & 108.09 \\
\hline 92 & .4305 & 67.72 & 92.64 & 106.94 & 106.88 \\
\hline 93 & .4478 & 68.00 & 91.79 & 105.46 & 105.40 \\
\hline 94 & .4650 & 68.28 & 90.90 & 103.93 & 103.88 \\
\hline 95 & .4823 & 68.48 & 89.90 & 102.26 & 102.21 \\
\hline 96 & .4996 & 68.67 & 88.80 & 100.44 & 100.40 \\
\hline 97 & .5169 & 68.86 & 87.08 & 97.64 & 97.61 \\
\hline 98 & .5342 & 69.04 & 84.03 & 92.74 & 92.72 \\
\hline 99 & .5514 & 69.20 & 81.50 & 88.68 & 88.67 \\
\hline 100 & .5687 & 69.35 & 81.50 & 88.59 & 88.58 \\
\hline
\end{tabular}


Title: CPBT intermediate temperatures at $45 \mathrm{C}$ inlet and $7 \mathrm{~m} / \mathrm{s}$ coolant flow Element $z(\mathrm{~m}) / \mathrm{R}(\mathrm{mml}) .247 \quad 2478,2487.2495 \quad 2504.2512 \quad 2521.2529 .2538 .2546$ $\begin{array}{llllllllllllll}1 & -1.142 & 48.28 & 48.61 & 48.91 & 49.17 & 49.4 & 49.59 & 49.75 & 49.88 & 49.98 & 50.04\end{array}$ $\begin{array}{lllllllllllll}2 & -1.125 & 48.5 & 48.84 & 49.16 & 49.43 & 49.67 & 49.88 & 50.05 & 50.18 & 50.28 & 50.35\end{array}$ $\begin{array}{llllllllllll}3 & -1.107 & 48.71 & 49.08 & 49.41 & 49.7 & 49.95 & 50.17 & 50.35 & 50.49 & 50.59 & 50.66\end{array}$ $\begin{array}{llllllllllll}4 & -1.09 & 48.93 & 49.32 & 49.66 & 49.97 & 50.23 & 50.46 & 50.65 & 50.79 & 50.9 & 50.97\end{array}$ $\begin{array}{llllllllllll}5 & -1.073 & 49.15 & 49.56 & 49.92 & 50.24 & 50.52 & 50.75 & 50.95 & 51.1 & 51.21 & 51.29\end{array}$

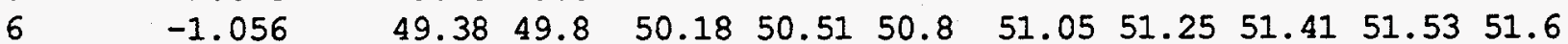
$\begin{array}{llllllllllll}7 & -1.038 & 49.6 & 50.04 & 50.44 & 50.78 & 51.09 & 51.34 & 51.55 & 51.72 & 51.84 & 51.92\end{array}$

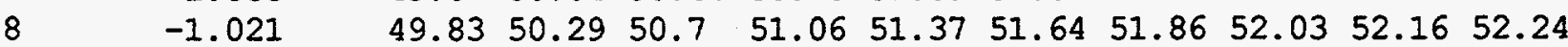
$9 \quad-1.004$ $10--.986$ $11-\quad-.969$

$-.952$

$-.935$

$-.917$

$-.9$

$-.883$

$-.866$

$-.848$

$-.831$

$-.814$

$-.796$

$-.779$

$-.762$

$-.745$

$-.727$

$-.71$

$-.693$

$-.675$

$-.658$

$-.641$

$-.624$

$-.606$

$-.589$

$-.572$

$-.554$

$-.537$

$-.52$

$-.503$

$-.485$

$-.468$

$-.451$

$-.434$

$-.416$

$-.399$

$-.382$

$-.364$

$-.347$

$-.33$

$-.313$

$-.295$

$\begin{array}{llllllllll}50.06 & 50.53 & 50.96 & 51.34 & 51.66 & 51.94 & 52.17 & 52.35 & 52.48 & 52.56\end{array}$

$\begin{array}{llllllllll}50.29 & 50.78 & 51.22 & 51.62 & 51.95 & 52.24 & 52.48 & 52.66 & 52.8 & 52.88\end{array}$

$\begin{array}{llllllllll}50.52 & 51.03 & 51.49 & 51.9 & 52.25 & 52.55 & 52.79 & 52.98 & 53.12 & 53.21\end{array}$

$\begin{array}{llllllllll}50.75 & 51.28 & 51.76 & 52.18 & 52.54 & 52.85 & 53.1 & 53.3 & 53.45 & 53.54\end{array}$

$\begin{array}{llllllllll}50.99 & 51.54 & 52.03 & 52.46 & 52.84 & 53.16 & 53.42 & 53.62 & 53.77 & 53.86\end{array}$

$\begin{array}{lllllllllll}51.23 & 51.79 & 52.3 & 52.75 & 53.14 & 53.47 & 53.74 & 53.95 & 54.1 & 54.2\end{array}$

$\begin{array}{llllllllll}51.47 & 52.05 & 52.57 & 53.04 & 53.44 & 53.78 & 54.06 & 54.27 & 54.43 & 54.53\end{array}$

$\begin{array}{llllllllll}51.82 & 52.44 & 52.99 & 53.47 & 53.89 & 54.25 & 54.54 & 54.77 & 54.93 & 55.03\end{array}$

$\begin{array}{lllllllllll}52.68 & 53.38 & 54 & 54.55 & 55.02 & 55.43 & 55.75 & 56.01 & 56.19 & 56.31\end{array}$

$\begin{array}{lllllllllll}53.55 & 54.33 & 55.03 & 55.64 & 56.17 & 56.62 & 56.98 & 57.27 & 57.47 & 57.59\end{array}$

$\begin{array}{lllllllllll}54.44 & 55.3 & 56.07 & 56.75 & 57.33 & 57.83 & 58.23 & 58.55 & 58.77 & 58.91\end{array}$

$\begin{array}{lllllllllll}55.33 & 56.27 & 57.11 & 57.85 & 58.5 & 59.04 & 59.48 & 59.82 & 60.07 & 60.21\end{array}$

$\begin{array}{lllllllllll}56.21 & 57.24 & 58.15 & 58.96 & 59.66 & 60.24 & 60.72 & 61.09 & 61.36 & 61.51\end{array}$

$\begin{array}{lllllllllll}57.1 & 58.21 & 59.19 & 60.06 & 60.81 & 61.45 & 61.96 & 62.36 & 62.64 & 62.81\end{array}$

$\begin{array}{llllllllll}57.99 & 59.18 & 60.23 & 61.17 & 61.97 & 62.65 & 63.2 & 63.63 & 63.93 & 64.1\end{array}$

$\begin{array}{llllllllll}58.88 & 60.15 & 61.28 & 62.27 & 63.13 & 63.85 & 64.44 & 64.89 & 65.21 & 65.39\end{array}$

$\begin{array}{llllllllll}59.78 & 61.12 & 62.32 & 63.38 & 64.29 & 65.06 & 65.68 & 66.16 & 66.49 & 66.69\end{array}$

$\begin{array}{llllllllll}60.67 & 62.1 & 63.37 & 64.49 & 65.45 & 66.26 & 66.92 & 67.42 & 67.78 & 67.98\end{array}$

$\begin{array}{llllllllll}61.57 & 63.08 & 64.42 & 65.6 & 66.62 & 67.47 & 68.16 & 68.69 & 69.06 & 69.27\end{array}$

$\begin{array}{llllllllll}62.48 & 64.06 & 65.48 & 66.71 & 67.78 & 68.68 & 69.41 & 69.96 & 70.35 & 70.57\end{array}$

$\begin{array}{llllllllll}63.39 & 65.05 & 66.53 & 67.83 & 68.95 & 69.89 & 70.65 & 71.23 & 71.64 & 71.86\end{array}$

$\begin{array}{llllllllll}64.3 & 66.04 & 67.59 & 68.95 & 70.12 & 71.1 & 71.9 & 72.51 & 72.93 & 73.16\end{array}$

$\begin{array}{llllllllll}65.21 & 67.03 & 68.65 & 70.07 & 71.3 & 72.32 & 73.15 & 73.78 & 74.22 & 74.46\end{array}$

$\begin{array}{llllllllll}66.13 & 68.03 & 69.72 & 71.2 & 72.47 & 73.54 & 74.4 & 75.06 & 75.51 & 75.75\end{array}$

$\begin{array}{llllllllll}67.05 & 69.03 & 70.79 & 72.33 & 73.65 & 74.76 & 75.65 & 76.33 & 76.8 & 77.06\end{array}$

$\begin{array}{llllllllll}67.98 & 70.03 & 71.86 & 73.46 & 74.83 & 75.98 & 76.91 & 77.61 & 78.1 & 78.36\end{array}$

$\begin{array}{llllllllll}72.37 & 74.88 & 77.11 & 79.06 & 80.73 & 82.13 & 83.25 & 84.09 & 84.66 & 84.96\end{array}$

$\begin{array}{llllllllll}72.6 & 75.11 & 77.34 & 79.29 & 80.96 & 82.36 & 83.47 & 84.32 & 84.89 & 85.18\end{array}$

$\begin{array}{llllllllll}72.84 & 75.34 & 77.57 & 79.52 & 81.19 & 82.59 & 83.71 & 84.55 & 85.12 & 85.42\end{array}$

$\begin{array}{lllllllllll}73.07 & 75.58 & 77.81 & 79.76 & 81.43 & 82.82 & 83.94 & 84.79 & 85.35 & 85.65\end{array}$

$\begin{array}{lllllllllll}75.36 & 78.09 & 80.52 & 82.64 & 84.46 & 85.97 & 87.19 & 88.1 & 88.71 & 89.02\end{array}$

$\begin{array}{llllllllllll}75.61 & 78.34 & 80.77 & 82.89 & 84.71 & 86.22 & 87.43 & 88.34 & 88.95 & 89.27\end{array}$

$\begin{array}{llllllllll}75.87 & 78.6 & 81.02 & 83.14 & 84.96 & 86.47 & 87.69 & 88.6 & 89.2 & 89.52\end{array}$

$\begin{array}{llllllllll}80.8 & 84.06 & 86.94 & 89.46 & 91.62 & 93.41 & 94.83 & 95.9 & 96.6 & 96.94\end{array}$

$\begin{array}{llllllllll}81.07 & 84.33 & 87.21 & 89.73 & 91.89 & 93.67 & 95.1 & 96.16 & 96.87 & 97.21\end{array}$

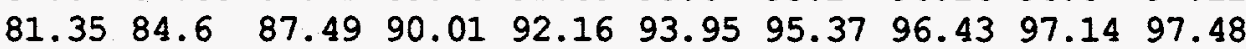

$\begin{array}{llllllllll}81.63 & 84.88 & 87.77 & 90.28 & 92.44 & 94.22 & 95.65 & 96.71 & 97.41 & 97.75\end{array}$

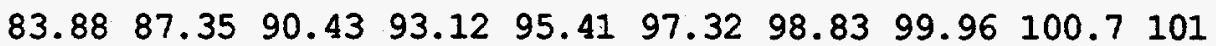

$\begin{array}{llllllllll}84.17 & 87.64 & 90.72 & 93.41 & 95.7 & 97.6 & 99.12 & 100.2 & 101 & 101.3\end{array}$

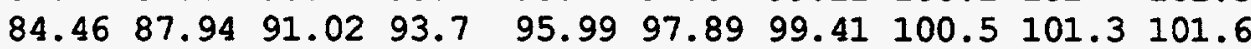
$\begin{array}{llllllllll}84.77 & 88.24 & 91.31 & 94 & 96.29 & 98.19 & 99.7 & 100.8 & 101.6 & 101.9\end{array}$

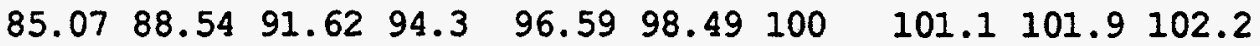




\begin{tabular}{|c|c|c|c|c|c|c|c|c|c|c|c|}
\hline ement & $2(\mathrm{~m}) / \mathrm{R}(\mathrm{mm})$ & 247 & .2478 & .2487 & 2495 & .2504 & .2512 & 2521 & .2529 & .2538 & .2546 \\
\hline 51 & -.278 & 85.38 & 88.85 & 91.92 & 94.6 & 96.89 & 98.79 & 100.3 & 101.4 & 02.2 & 102 \\
\hline 52 & -.261 & 86.24 & & 91 & 95.63 & & 9.89 & 101.4 & 102.6 & 103.3 & 03 \\
\hline 53 & -.243 & 86.56 & 90.09 & 93.22 & 5.95 & 98.28 & 100.2 & 101.7 & 102.9 & 103 & 104 \\
\hline 54 & -.226 & 86.88 & 90.41 & 93.54 & 96.27 & 98.59 & 100.5 & 102.1 & 103 & 103 & 104 \\
\hline 55 & -.209 & 87.21 & 90.74 & 93.87 & 96.59 & 98.92 & 100.8 & 102.4 & 103.5 & 10 & 104 \\
\hline 56 & -.192 & 87.54 & 91.07 & 94.19 & 96.92 & 99.24 & 101.2 & 102.7 & 103.8 & 104 & 104 \\
\hline 57 & -.174 & 87.88 & 91.4 & 9.53 & 97.25 & 99.57 & 101.5 & 103 & 104.2 & 104.9 & 105 \\
\hline 58 & -.157 & 86.11 & 89.39 & 92.3 & 94.84 & 97 & 98.8 & 100.2 & 101.3 & 102 & 102 \\
\hline 59 & -.14 & 86.44 & 89.72 & 92.63 & 95.16 & 97.33 & 99.12 & 100.5 & 101.6 & 102.3 & 10 \\
\hline 60 & -.122 & 86.76 & 90.04 & 92.94 & .48 & 97.64 & 99.43 & 100.9 & 101.9 & 102.6 & \\
\hline 61 & -.105 & 87.34 & 90.65 & 93.58 & 96.14 & 32 & 100.1 & 101.6 & 102.6 & 103.3 & 103. \\
\hline 62 & -.088 & 87.64 & 90.95 & 93.88 & 96.44 & 98.62 & 100.4 & 101.9 & 102.9 & 103.6 & 104 \\
\hline 63 & -.071 & 87.93 & 91.23 & 94.17 & 96.72 & 98.9 & 100.7 & 102.1 & 103.2 & 103.9 & 104 \\
\hline 64 & -.053 & 88.2 & 91.51 & 94.44 & 97 & 99.18 & 101 & 102.4 & 103.5 & 104.2 & 10 \\
\hline 65 & -.036 & 86.29 & 89.34 & 92.04 & 94.4 & 96.42 & 98.09 & 99.42 & 100.4 & 101.1 & 101 \\
\hline 66 & -.019 & 86.23 & 89.24 & 91.91 & 94.25 & 96.24 & 97.89 & 99.2 & 100.2 & 100.8 & 101 \\
\hline 67 & -.002 & 6.84 & 89.9 & 92.61 & 94.97 & 96.99 & 98.66 & 100 & 101 & 101.6 & 101 \\
\hline 68 & .016 & 8.97 & 92.25 & 95.16 & 97.69 & 99.85 & 101.6 & 103.1 & 104.1 & 104.8 & 105 \\
\hline 69 & .033 & 1.39 & 94.92 & 8.05 & 100.8 & 103.1 & 105 & 106.5 & 107.7 & 108.4 & 108 \\
\hline 70 & .05 & 2.14 & 95.72 & 98.9 & 101.7 & 104 & 106 & 107.5 & 108.7 & 109.4 & 109. \\
\hline 71 & .068 & 3.42 & 97.13 & 100.4 & 103.3 & 105.7 & 107.7 & 109.3 & 110.5 & 111.2 & 111. \\
\hline 72 & .085 & 4.74 & 98.57 & 01.9 & 104.9 & 107.4 & 109.5 & 111.1 & 112.3 & 113.1 & 113 \\
\hline 73 & .102 & 5.4 & 9.26 & 102.7 & 105.7 & 108.2 & 110.3 & 111.9 & 113.2 & 114 & 114 \\
\hline 74 & 9.119 & 5.87 & 99.75 & 103.2 & 106.2 & 108.7 & 110.8 & 112.5 & 113.7 & 114.5 & 114 \\
\hline 75 & .137 & 5.34 & 100.2 & 103.7 & 106.7 & 109.3 & 111.4 & 113.1 & 114.3 & 115.1 & 115 \\
\hline 76 & .154 & 5.54 & 100.4 & 103.9 & 106.9 & 109.4 & 111.5 & 113.2 & 114.4 & 115.2 & 115. \\
\hline 77 & .171 & 5.67 & 100.5 & 104 & 107 & 109.5 & 111.6 & 3.2 & 114.5 & 115.2 & 115. \\
\hline 78 & .189 & 5.78 & 100.6 & 104 & 107 & 105 & 111.6 & 3.3 & 114.5 & 115.3 & 115. \\
\hline 79 & .206 & 6.9 & 100.7 & 104.1 & 107.1 & $10 S$ & 111.7 & 3.3 & 114.5 & 115.3 & 11 : \\
\hline 80 & .223 & 7.01 & 100.8 & 104.2 & 107.1 & .6 & 111.7 & 113.3 & 114.5 & 115.3 & 11 ! \\
\hline 81 & .24 & 96.79 & 100.5 & 103.9 & 106.8 & 109.2 & 111.2 & 112.9 & 114 & 114.8 & \\
\hline 82 & .258 & 96.5 & 100.2 & 103.4 & 106.3 & 108.7 & 110.7 & 112.3 & 113.4 & 114.2 & \\
\hline 83 & .275 & 96.21 & 99.83 & 103 & 105.8 & 108.2 & 110.2 & 111.7 & 112.9 & 113.6 & 11 \\
\hline 84 & .292 & 95.92 & 99.47 & 102.6 & 105.4 & 107.7 & 109.6 & 111.1 & 112.3 & 113 & 113. \\
\hline 85 & .31 & 95.63 & 99.11 & 102.2 & 104.9 & 107.2 & 109.1 & 110.6 & 111.7 & 112.4 & 6. \\
\hline 86 & .327 & 95.34 & 98.75 & 101.8 & 104.4 & 106.7 & 108.5 & 110 & 111.1 & 111.8 & 112. \\
\hline 87 & .344 & 94.98 & 98.32 & 101.3 & 103.8 & 106 & 107.9 & 109.3 & 110.4 & 111 & 111. \\
\hline 88 & .361 & 94.57 & 97.83 & 100.7 & 103.2 & 105.4 & 107.1 & 108.5 & 109.6 & 110.2 & 110.6 \\
\hline 89 & .379 & 94.15 & 97.33 & 100.1 & 102.6 & 104.7 & 106.4 & 107.8 & 108.8 & 109.5 & 109. \\
\hline 90 & . 396 & 93.74 & 96.83 & 99.57 & 102 & 104 & 105.7 & 107 & 108 & 108.6 & 108. \\
\hline 91 & .413 & 93.32 & 96.33 & 99 & 101.3 & 103.3 & 104.9 & 106.3 & 107.2 & 107.8 & 108. \\
\hline 92 & .43 & 92.64 & 95.54 & 98.11 & 100.3 & 102.3 & 103.8 & 105.1 & 106 & 106.6 & 106. \\
\hline 93 & .448 & 91.79 & 94.55 & 97.01 & 99.14 & 101 & 102.5 & 103.7 & 104.6 & 105.2 & 105. \\
\hline 94 & .465 & 90.9 & 93.53 & 95.87 & 97.9 & 99.64 & 101.1 & 102.2 & 103.1 & 103.6 & 103. \\
\hline 95 & .482 & 89.9 & 92.39 & 94.6 & 96.53 & 98.17 & 99.54 & 100.6 & 101.4 & 102 & 102. \\
\hline 96 & .5 & 88.8 & 91.15 & 93.22 & 95.03 & 96.58 & 97.87 & 98.9 & 99.66 & 100.2 & 100. \\
\hline 97 & .517 & 87.08 & 89.2 & 91.08 & 92.72 & 94.12 & 95.29 & 96.22 & 96.92 & 97.38 & \\
\hline 98 & .534 & 34.03 & 85.76 & 87.3 & 88.65 & 89.8 & 90.77 & 91.54 & 92.12 & 92.51 & 92. \\
\hline 99 & 51 & 1.5 & 82.92 & 84.19 & 85.29 & 86.24 & 87.03 & 87.67 & 88.15 & 88.48 & \\
\hline 100 & .569 & 81.5 & 82.9 & 84.15 & 85.24 & 86.18 & & & & 88.39 & 00.2 \\
\hline
\end{tabular}


Internal Distribution

1. B. R. Appleton

2. R. L. Battiste

3. W. G. Craddick

4. D. K. Felde

5. R. G. Gilliland

6. R. C. Gwaltney

7. W. R. Hendrich

8. R. L. Johnson

9. C. R. Luttrell

10. D. L. Selby
11-15. W. F. Swinson

16. C. D. West

17-19. G. T. Yahr

20. ORNL Patent Office

21-22. Central Research Library Document Reference Sect.

23. Y-12 Technical Library

24-25. Laboratory Records Dept.

26. Laboratory Records, RC

\section{External Distribution}

27-29. K. C. Schulz, Assistant Professor, University of Turabo, College of Engineering, Box 3030, Gurabo, Puerto Rico 00778.

30. U.S. Department of Energy, ANS Project Office, Oak Ridge Operations Office, FEDC, MS-8218, P.O. Box 2009, Oak Ridge, TN 37831-8218.

31-32. Office of Scientific and Technical Information, P.O. Box 62, Oak Ridge, Tennessee 37831. 
